\title{
STRUCTURAL EVOLUTION IN NICKEL DURING ANNEALING SUBSEQUENT TO HOT DEFORMATION
}

\author{
By \\ CHARLES ROBERT SMEAL \\ A DISSERTATION PRESENTED TO THE GRADUATE COUNCIL OF \\ THE UNIVERSITY OF FLORIDA \\ IN PARTIAL FULFILLMENT OF. THE REQUIREMENTS FOR THE \\ DEGREE OF DOCTOR OF PHILOSOPHY
}

UNIVERSITY OF FIORIDA

April, 1965 


\section{ACKNOWLEDGMENTS}

The author would like to express his gratitude to the chairman of his supervisory committee, Dr. F. N. Rhines, not only for many discussions and suggestions pertaining to the problem but also for his constant encouragement. Research which eventually evolved into this thes is was performed under the supervision of Dr. R. E. Reed-Hill and the author would like to acknowledge his debt to many aspects of that work. The author is also indebted to Dr. R. T. Dehoff for his suggestions concerning the quantative metallographic: measurements.

The author would like thank Dr. H. H. Sisler and Dr. R.

Stoufer for serving on his supervisory committee.

The electron photomicrograph in Chapter 11 is the work of Mr. E. J. Jenkins. 
TABLE OF CONTENTS

Page

ACKNOWLEDGMENTS ....................... . . . . . i i

LIST OF TABLES. . . . . . . . . . . . . . . . . . . . $v$

LIST OF FIGURES . . . . . . . . . . . . . . . . . . . . vi $\mathbf{i}$

KEY TO SYMBOLS. . . . . . . . . . . . . . . . . . . xiv

ABSTRACT. ............................... xvi

Chapter

I INTRODUCTION .................. I

Purpose of the Study and Definition of

Hot Working. . . . . . . . . . . . . . . .

Previous Studies. . . . . . . . . . . . . .

Hot working. . . . . . . . . . . . . . . .

Annealing after hot working. . . . . . . .

II EXPERIMENTAL MATERIAL, APPARATUS AND

PROCEDURES.......................... 11

Experimental Material .............. . . 11

Experimental Apparatus. .............. . . 11

Experimental Procedures............. 13

Preparation of tensile bars. . . . . . . 13

Extension of tensile bars. . . . . . . . 15

Metal lography. ............. 17

Quanti tative metal lography......... 21

III EXPERIMENTAL RESULTS ................. . . . 29

Metallographic Observations .......... . 29

General observations ........... . 29

observations pertaining directly to

the initiation and early stages

of growth of strain-free grains. . . . . 35

Volume Fraction Strain-free Material. . . . . . 37

Number of Strain-free Grains Per Unit
Area and Per Unit Volume. . . . . . . . . 43

Growth Rates................... 52

Surface Area Measurements . . . . . . . . . 60 
TABLE OF CONTENTS--Continued

Page

IV DISCUSSION .................................... 74

Aspects of the Hot-worked St ructure . . . . . . . 75

0 istortion of the grain boundary network. . . 76

Dislocations not associated with a boundary network.......... . 81

Formation of a subgrain boundary network . . . 82

Serrated boundaries. . . . . . . . . . 86

Strain-free grains........... . 89

Summary. . . . . . . . . . . . . 99

Annealing after Hot Working ........ . . . . 102

The initiation of strain-free grains

during working and their growth

during annealing............ 102

The growth of strain-free grains and

the effects of temperature upon

growth.................. . 107

Summary. . . . . . . . . . . . . . 122

A Review of the Proposed Mechanism and a

Discussion of Its Applicability to Other

Studies of Annealing after Hot Working

and to Studies of Annealing after

Cold Working . . . . . . . . . . . . . . . .

A review of the mechanism. . . . . . . . . 123

Predictions based on the proposed mechanism compared with results

from other studies of hot working. . . . . . 125

Application of the proposed mechanism

to annealing after cold working. . . . . . 140 


\section{LIST OF TABLES}

Table

Page

I Certified analysis of Nickel 200, heat 513A. . . . . .

2 List of all specimens worked (at $750^{\circ} \mathrm{C}$ ) and annealed (at $750^{\circ} \mathrm{C}, 700^{\circ} \mathrm{C}$ and $670^{\circ} \mathrm{C}$ ) wi th measured extensions and reductions in area (sections mounted for metal lographic exami nation). .............

3 Microstructural positions occupied by strain-free grains at various annealing times for specimens worked at $750^{\circ} \mathrm{C}$ and annealed at $750^{\circ} \mathrm{C}$. . . . . . . .

4 Volume fraction strain-free material for specimens worked at $750^{\circ} \mathrm{C}$ and annealed at $750^{\circ} \mathrm{C}, 700^{\circ} \mathrm{C}$ and $670^{\circ} \mathrm{C}$. . . . . . . . . . . . . . .

5 Number of strain-free grains per unit area and per unit volume for specimens worked at $750^{\circ} \mathrm{C}$ and annealed at $750^{\circ} \mathrm{C}, 700^{\circ} \mathrm{C}$ and $670^{\circ} \mathrm{C}$.........

6 Grain boundary intercepts (excluding twin boundary

intercepts) for strain-free grains, $\left(\mathrm{N}_{\mathrm{L}}\right)_{\mathrm{NE}}$, for specimens worked at $750^{\circ} \mathrm{C}$ and annealed at $750^{\circ} \mathrm{C}$, $700^{\circ} \mathrm{C}$ and $670^{\circ} \mathrm{C}$. . . . . . . . . . . . . .

7 Growth rates for annealing temperatures of $750^{\circ} \mathrm{C}$, $700^{\circ} \mathrm{C}$ and $670^{\circ} \mathrm{C}$. . . . . . . . . . . . .

8 Maximum intercept of largest unimpinged grain for specimens worked at $750^{\circ} \mathrm{C}$ and annealed at $750^{\circ} \mathrm{C}$, $700^{\circ} \mathrm{C}$ and $670^{\circ} \mathrm{C}$.

9 Growth rates calculated from the expression $G \cdot\left(S_{V}\right)_{0-N}=d V_{V} / d t$ for specimens worked at

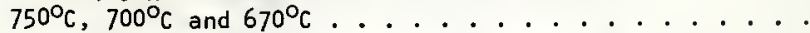

10 Experimental measurements of surface area per unit volume with strain-free material on at least one side of the boundary, $\left(S_{V}\right)_{n e w}$, with strained material on at least one side of the boundary, $\left(S_{V}\right)$ old, and the total surface area, ( $\left.S_{y}\right)$
for specimens worked at $750^{\circ} \mathrm{C}$ and annealedat

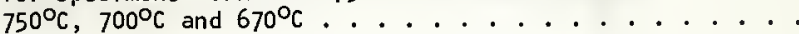




\section{LIST OF TABLES--Continued}

Table

Page

11 Calculated values of surface area per unit volume with: (1) strain-free material on both sides of the boundary, $\left(S_{V}\right)_{N-N}$; (2) strained material on both sides of the boundary, $\left(\mathrm{SV}_{\mathrm{V}_{0-0}}\right.$; and (3) strained material on one side of the boundary and strain-free material on the other side, $\left(\mathrm{S}_{V}\right)_{0-N}$ (the migrating interface area) for specimens worked at $750^{\circ} \mathrm{C}$ and annealed at $750^{\circ} \mathrm{C}, 700^{\circ} \mathrm{C}$ and $670^{\circ} \mathrm{C}$.

12 Influence of rate of extension on the apparent total strain in the grains calculated from the expression: $e_{g}=\left[\left(N_{L}\right)_{T} /\left(N_{L}\right)_{L}\right]^{2 / 3}-1$. Nicke $]$ 200. Hot-workîng temperature $=705^{\circ} \mathrm{C}$.........

13 Experimental values of $V_{V}$ compared to those calculated from the expressions $V_{V}=1$-exp$\pi L_{V} G^{2} t^{2}$ (upper $1 i m i t$ ) and $V_{V}=1$-exp$\left(\pi L_{V} G^{2} t^{2}\right) / 3$ (lower limit) for specimens worked at $705^{\circ} \mathrm{C}$ and annealed at $750^{\circ} \mathrm{C}, 700^{\circ} \mathrm{C}$ and $670^{\circ} \mathrm{C}$.

14 A listing of initial and final grain sizes, values of $n$ from the equation $V_{V}=1-\exp -k t^{n}$, and $t i m e s$ necessary for 50 per cent of the structure to become strain free $\left(t_{0.5}\right)$ for all available data on annealing after hot working of $\mathrm{Nickel} 200$......

15 0ata which illustrate the effects of initial grain size upon the type of position at which strain-free grains are formed and upon the final grain sizes....

16 Data which illustrate the effects of working temperature upon: (1) type of positions at which strain-free grains are formed, (2) growth rate and (3) final grain sizes. ................

17 0ata which illustrate the effects of rate of working upon the type of positions at which strain-free grains are formed and upon the final grain sizes....

0ata which illustrate the effects of extent of working upon the type position at which strainfree grains are formed and upon the final grain sizes. 


\section{LIST OF TABLES--Continued}

Table

Page

19 A summary of the effects of the experimental variables upon: (1) the type of position at which strain-free grains are formed, (2) growth rates and (3) final grain sizes............

20 An outline of the conditions of working and experimental materials for the various studies of hot working.

21 Measured chord lengths and calculated values for the number of grains per $\mathrm{mm}^{3}$ having a certain average diameter. 
LIST OF FIGURES

Figure

Page

1 A sketch of the high temperature deformation apparatus . . . . . . . . . . . . . . . . .

2 A sketch of the tensile bar used for the hot working and annealing experiments.......... . 14

3 A photomicrograph of the structure which resulted from the final 25 -minute anneal at $750^{\circ}$ C. $400 \mathrm{X}$

4 Electron photomicrograph illustrating the grooved surface produced on a specimen polished and etched as described in the text. 13,000x.

5 A photomicrograph which illustrates the three basic types of intercept counts performed in this study. Boundaries with strained material on at least one side are marked (2) and boundaries with strain-free material on at least one side are marked (3). Polarized light. 400x. . . . . .

6 A plot of (NA) corrected $/ N_{A}$ versus $V_{V}$ for specimens from all three annealing temperatures.

Specimen numbers are indicated beside the experimental points..................

7 Selected photomicrographs from the group of specimens worked at $750^{\circ} \mathrm{C}$ and annealed at $750^{\circ} \mathrm{C}$ (a) immediately before deformation, (b) 0 seconds anneal, (c) 45 seconds anneal, (d) 120 seconds anneal, (e) 720 seconds anneal. Polarized light. $400 x$.

8 Photomicrographs chosen to illustrate the various positions occupied by small, strain-free grains. Polarized light. $1000 \mathrm{x}$.................. 38

9 Volume fraction strain-free material versus annealing time for specimens worked at $750^{\circ} \mathrm{C}$ and annealed at $750^{\circ} \mathrm{C}$ 


\section{LIST OF FIGURES--Continued}

Figure

Page

10 Volume fraction strain-free material versus annealing time for specimens worked at $750^{\circ} \mathrm{C}$ and annealed at $700^{\circ} \mathrm{C}$

11 Volume fraction strain-free material versus annealing time for specimens worked at $750^{\circ} \mathrm{C}$ and annealed at $670^{\circ} \mathrm{C}$

12 Number of strain-free grains per unit volume versus annealing time for specimens worked at $750^{\circ} \mathrm{C}$ and annealed at $750^{\circ} \mathrm{C}, 700^{\circ} \mathrm{C}$ and $670^{\circ} \mathrm{C}$

13 Maximum intercept of largest unimpinged grain versus annealing time for specimens worked at $750^{\circ} \mathrm{C}$ and annealed at $750^{\circ} \mathrm{C}, 700^{\circ} \mathrm{C}$ and $670^{\circ} \mathrm{C}$

14 Surface area per unit volume separating strainfree from strained material (the migrating interface area) versus annealing time for specimens worked at $750^{\circ} \mathrm{C}$ and annealed at $750^{\circ} \mathrm{C} . .$.

15 Surface area per unit volume separating strainfree from strained material (the migrating interface area) versus annealing time for specimens worked at $750^{\circ} \mathrm{C}$ and annealed at $700^{\circ} \mathrm{C}$. . . .

16 Surface area per unit volume separating strainfree from strained material (the migrating interface area) versus annealing time for specimens worked at $750^{\circ} \mathrm{C}$ and annealed at $670^{\circ} \mathrm{C}$. . . .

17 Total boundary area per unit volume, $\left(s_{V}\right)_{\text {total }}$, versus annealing time for specimens worked at $750^{\circ} \mathrm{C}$ and annealed at $750^{\circ} \mathrm{C}$. . . . . . . . .

18 Total boundary area per unit volume, $\left(s_{V}\right)$ versus annealing time for the specimens worked' at $750^{\circ} \mathrm{C}$ and annealed at $700^{\circ} \mathrm{C}$..........

19 Total boundary area per unit volume, $\left(s_{V}\right)_{\text {total, }}$, versus annealing time for the specimens worked

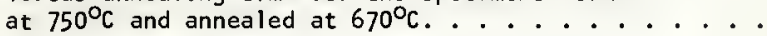

20 Boundary area per unit volume with strained material on both sides of boundary, $\left(s_{V}\right)_{0-0}$, versus annealing time for specimens worked at $750^{\circ} \mathrm{C}$ and annealed at $750^{\circ} \mathrm{C}$ 


\section{LiST OF FIGURES-- Continued}

Figure

21 Boundary area per unit volume with strained material on both sides of boundary, $(\mathrm{SV})_{0-0}$, versus annealing time for specimens worked at $750^{\circ} \mathrm{C}$ and annealed at $700^{\circ} \mathrm{C}$. . . . . . . . .

22 Boundary area per unit volume with strained material on both sides of the boundary, $\left(s_{V}\right)_{0-0}$, versus annealing time for specimens worked at $750^{\circ} \mathrm{C}$ and annealed at $670^{\circ} \mathrm{C}$.........

23 Boundary area per unit volume with strainfree material on both sides of the boundary, $\left(s_{V}\right)_{N-N}$, versus annealing time for specimens worked at $750^{\circ} \mathrm{C}$ and annealed at $750^{\circ} \mathrm{C}$. . . . . . .

24 Boundary area per unit volume with strainfree material on both sides of the boundary, $\left(s_{V}\right)_{N-N}$, versus annealing time for specimens worked at $750^{\circ} \mathrm{C}$ and annealed at $700^{\circ} \mathrm{C}$........

25 Boundary area per unit volume with strainfree material on both sides of the boundary, $\left(s_{V}\right)_{N-N}$, versus annealing time for specimens worked at $750^{\circ} \mathrm{C}$ and annealed at $670^{\circ} \mathrm{C}$.........

26 A plot of measured total extension versus calculated eg for Nickel 200. Specimens extended at $705^{\circ} \mathrm{C}$ and $0.009 /$ minute. . . . . . . . 78

27 A plot of the ratio of the calculated $e_{g}$ to the measured total extension versus hot-working temperature. Nickel 200. Rate of extension = $0.75 /$ minute. Total extension $=37$ per cent .....

28 Schematic diagram of the development of subgrain boundary networks during hot working. The extent of working increases from 1 through 3. The direction of working is indicated........

29 Average subgrain size as a function of hotworking temperature for copper worked at various rates. Method and rate of working are indicated

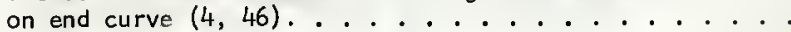




\section{LIST OF FIGURES--Conti nued}

Figure

Page

30 A plot of $\ln \left(1 / 1-V_{V}\right)$ versus annealing time for specimens worked at $750^{\circ} \mathrm{C}$ and annealed at $750^{\circ} \mathrm{C}$,

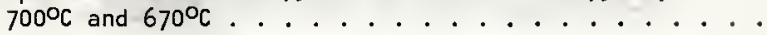

31 An electron photomicrograph of a presumably strain-free graln with a scalloped boundary growing at an old grain boundary. 10,000X...... .

32 A photomicrograph illustrating the growth of a strain-free grain from a strained grain apparently of nearly the same orientation.

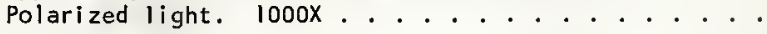

33 Schematic diagram of the partition of total dislocation content between subgrain boundaries and miscellaneous lattice distortions as a function of rate and amount of hot working. . . . . .

34 A plot of $1 / t_{c}$ versus $1 / T\left({ }^{O} K\right)$ for $V_{V}=0.05 \ldots . .$.

35 A plot of experimental growth rates (calculated from $\mathrm{G} \cdot\left(\mathrm{S}_{\mathrm{V}}\right)_{0-\mathrm{N}}=\mathrm{dV}_{\mathrm{V}} / \mathrm{dt}$ versus $\left.1 / \mathrm{T}\left(\mathrm{O}_{\mathrm{K}}\right)\right)$......

36 A plot of calculated and experimental values of $V_{V}$ versus annealing time for specimens worked at $750^{\circ} \mathrm{C}$ and annealed at $750^{\circ} \mathrm{C}$. Solid lines indicate calculated limits of circled points experimental values. . . . . . . . . . . . .

37 A plot of calculated and experimental values of $V_{V}$ versus annealing time for specimens worked at $750^{\circ} \mathrm{C}$ and annealed at $700^{\circ} \mathrm{C}$. Solid lines indicate calculated 1 imits and circled points experimental values................

38 A plot of calculated and experimental values of $V_{V}$ versus annealing time for specimens worked at $750^{\circ} \mathrm{C}$ and annealed at $670^{\circ} \mathrm{C}$. Solid lines indicate calculated $1 \mathrm{imi}$ ts and circled points experimental values. . . . . . . . . . . .

39 A plot of $\left(s_{V}\right)_{0-N}$ versus $V_{V}$ which includes all values obtained from specimens annealed at $750^{\circ} \mathrm{C}, 700^{\circ} \mathrm{C}$ and $670^{\circ} \mathrm{C}$ 


\section{LIST OF FIGURES --Continued}

Figure

Page

40 A plot of $\left(s_{V}\right)_{0-N}$ versus $V_{V}$ for hot-worked silicon iron deformed to a strain of 0.45 at $812^{\circ} \mathrm{C}$ and annealed at $812^{\circ} \mathrm{C}$. The data were taken from the study by English and Backofen. . . . . . . . . . . . . . . . . .

41 A plot of $\left(S_{V}\right)_{0-0}$ versus $V_{V}$ which includes all values obtained from specimens annealed at $750^{\circ} \mathrm{C}, 700^{\circ} \mathrm{C}$ and $670^{\circ} \mathrm{C}$............

42 A plot of diamond pyramid hardness versus annealing time for specimens extended 38 per cent at $755^{\circ} \mathrm{C}$ and annealed at $755^{\circ} \mathrm{C}$

43 A plot of $\left(s_{y}\right)_{N-N}$ versus $V_{y}$ which includes all values obtained from specimens annealed

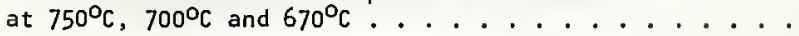

44 Photomicrographs obtained from partially annealed specimens (worked and annealed at $705^{\circ} \mathrm{C}$ ) having initial $\mathrm{N}_{L}^{\prime} \mathrm{s}$ of (a) $18 / \mathrm{mm}$, and (b) $41 / \mathrm{mm}$. Note the number of strain-free grains which have formed at old grain edges (triple points in two dimensions). 200x. . . . . . .

45 A photomicrograph obtained from a specimen of $\mathrm{Nickel} 200$ worked at $855^{\circ} \mathrm{C}$ but not annealed. Note the presence of strain-free or nearly strain-free grains at many of the old grain triple points (edge in three dimensions). 200X.

46 A photomicrograph obtained from a specimen of Nickel 200 worked at a rate of $0.009 /$ mi nute but not annealed. Note the large number of strainfree or nearly strain-free grains which have formed at old grain triple points (edges). 200x . . . .

47 A three-dimensional representation of the relationship between grain size, working temperature and degree of working for electrolytic copper fully annealed after working (from reference 2I).... .

48 Photomicrographs of specimens worked at $750^{\circ} \mathrm{C}$ and annealed at $750^{\circ} \mathrm{C}$. Annealing times are indicated. Polarized light. 400x. . . . . . . . 


\section{LIST OF FIGURES--Continued}

Figure

Page

49 Photomicrographs of specimens worked at $750^{\circ} \mathrm{C}$ and annealed at $700^{\circ} \mathrm{C}$. Annealing times are indicated. Polarized 1ight. 400x. . . . . . . .

50 Photomicrographs of specimens worked at $750^{\circ} \mathrm{C}$ and annealed at $670^{\circ} \mathrm{C}$. Annealing times are indicated. Polarized light. 400x. . . . . . . .

51 A plot of cumulative per cent of total number of grains with a certain mean diameter versus

log or the mean diameter. . . . . . . . . . . . 
KEY TO SYMBOLS
a constant
B
a constant
$e_{g}$
the average longitudinal strain in the grains calculated from the equation given by Rachinger (43)
G
the growth rate calculated from the equation $G \cdot\left(S_{V}\right)_{0-N}=$ $d V_{V} / d t$
k
a constant
k
a particular size class in Spektor's equation
$\mathrm{K}_{1}$
a geometrical constant
$\mathrm{K}_{2}$
a geometrical constant
$\mathrm{K}_{3}$
a geometrical constant
$\mathrm{L}_{\mathbf{V}}$
the length of grain edge per unit volume possessed by strain-free grains--the nucleating edge
n
a constant in the equation $V_{V}=1-\exp -k t^{n}$ indicative of the microstructural position at which new grains form
$n_{k-1}^{k}$
the number of chords per unit length of line in the kth size class
$n_{k}^{k+1}$
the number of chords per unit length of line in the size class $k+l$
$N_{A} \quad$ the number of strain-free grains per unit area of metallographic surface
$\left(N_{A}\right)_{T} \quad$ the number of triple points per unit area which are at least partially surrounded by strain-free grains
$N_{L} \quad$ the number of intercepts per unit length of random line made with a particular structural feature
$\left(N_{L}\right)_{L} \quad$ the number of boundary intercepts per unit length of line oriented parallel to the tensile axis 

$\left(N_{L}\right)_{N E}$
$\left(N_{L}\right)_{\text {new }}$
$\left(N_{L}\right)_{\text {old }}$
$\left.{ }^{\left(N_{L}\right.}\right)_{T}$
$\left(N_{L}\right)_{\text {total }}$
$N_{p}$
Nv
$\left(N_{V}\right)_{k \Delta}$
$P_{P}$
$a_{G}$
$Q_{T}$
$R$
$s_{V}$
$\left(s_{V}\right)_{\text {new }}$
$\left(s_{V}\right)_{N-N}$
$\left(s_{v}\right)_{\text {old }}$
the number of grain boundary intercepts per unit length of random line with strain-free grains on at least one side of the boundary
the number of boundary intercepts per unit length of ran- dom line with strain-free grains on at least one side of the boundary
the number of boundary intercepts per unit length of ran- dom line with strained grains on at least one side of the boundary
the number of boundary intercepts per unit length of line oriented perpendicular to the tensile axis
the total number of boundary intercepts per unit length of random line
the total number of points which fall on the microstruc- tural feature of interest
the number of strain-free grains per unit volume
the number of particles per unit volume with mean diameter $k \Delta$
the fraction of the total number of applied points which fall on a particular type of microstructural feature
The "activation energy" for grain boundary migration cal- culated from growth rates obtained from the equation $G \cdot\left(S_{V}\right)_{O-N}=d v_{V} / d t$
the "activation energy" for the evolution from a strained material to strain-free grains
the gas constant
the surface area per unit volume possessed by the feature of interest
the boundary area per unit volume wi th strain-free grains on at least one side of the boundary
the boundary area per unit volume with stain-free grains on both sides of the boundary
the boundary area per unit volume with strained material on at least one side of the boundary 

$\left(s^{V}\right)-N$
the boundary area per unit volume separating strained material and strain-free grains--the migrating interface
$\left(s_{v}\right)_{0-0}$
the boundary area per unit volume with strained material on both sides of the boundary
$\left(s_{v}\right)_{\text {total }}$
the total boundary area per unit volume
$\mathrm{t}$
time
T
temperature
$t_{c}$
the annealing time at which any specified fraction of the structure is strain-free
$t_{0.5}$
the annealing time at which 50 per cent of the structure is strain free
$v_{V}$
the volume fraction strain-free grains
$\sigma_{v_{v}}$
the interval length
the standard error of the volume fraction strain-free grains 


\section{Abstract of Dissertation Presented to the Graduate Council in Partial Fulfiliment of the Requi rements for the Degree of Doctor of Phi losophy \\ STRUCTURAL EVOLUTION IN NICKEL DURING ANNEALING SUBSEQUENT TO HOT DEFORMATION}

By

Charles Robert Smeal

Apri 1, 1965

Chai rman: F. N. Rhines

Major Department: Department of Metaliurgical and Materials Engineering

The evolution of structure during annealing after hot working was studied in Nickel 200. Attention also was directed to the structural changes which occur during hot working. Metallographic observations and quantitative metallographic measurements were used to characterize the structures formed during both processes. Quantitative metallographic procedures were used to measure: (1) the volume fraction strain-free grains, (2) the number of strain-free grains, (3) the growth rate of the strain-free grains, and (4) various types of boundary area.

Results indicated that the structure of hot-worked Nickel 200 is characterized by some or all of the following features: (1) grain elongation, (2) dislocations not associated with a boundary network, (3) subgrains, (4) serrated grain boundaries, and (5) new grains formed during working. The prominence and even the appearance of any of these features in a material of high or moderate stacking-fault energy depended upon the working conditions. 
A study of specimens annealed at 750,700 , and $670^{\circ} \mathrm{C}$ after working at $750^{\circ} \mathrm{C}$ resulted in the following characterization of the evolution from strained material to strain-free grains:

1. All grains which exist in the completely annealed structure are formed at essentially zero annealing time.

2. These grains are formed preferentially at old grain edges and to a lesser degree at old grain boundaries.

3. Many strain-free grains grow preferentially into one of the strained grains sharing the edge or boundary at which it is growing.

4. The boundary between strained material and strainfree grains migrates at a constant linear rate throughout the annealing period.

A mechanism for the initiation of new grains during hot working and the growth of these grains during annealing is proposed. This mechanism explains the close relationship between the structure formed during hot working and the structural evolution during annealing after hot working. Most of the results from other studies of annealing after hot working are explicable on the basis of this mechanism. 


\section{CHAPTER I}

\section{NTRODUCTION}

Only a few investigations of the structural evolution during and after hot working have been performed. As a result, the structural changes which occur during hot working and during annealing after hot working are poorly understood. The importance of these changes is becoming increasingly obvious. It is now apparent that some of the physical properties of metals and alloys depend to a considerable extent upon structural details which may be altered by hot working. For example, Petrova et al. (1)* noted that hot-rolled nickel $\left(800^{\circ} \mathrm{C}\right.$ followed by a water quench) exhibited a stress-rupture life 25 times that of a similar, unworked specimen quenched from $800^{\circ} \mathrm{C}$. A second example is the unique combination of room temperature strength and ductility obtained from hotworked aluminum by Whi twham and Herenguel (2). In both cases, the improvements in properties were attributed to the structures produced by hot working.

Hot working is an indispensable process in the fabrication of most metals and alloys. Only through this process is it possible to break down the form and structure of the cast material into useful shapes with desirable properties. Not only are the majority of all metals and alloys hot worked in at least the initial stages of fabrication, but also a considerable amount of metal is marketed in the hot-worked condition.

\section{References.}

* Numbers in parentheses pertain to entries in the List of 
The potential benefits from a thorough understanding of the structural evolution during and after hot working are therefore substantial.

It is, however, very difficult to study the structural evolution during and after hot working utilizing the usual industrial choices of working conditions. Temperatures and rates of working are usually so high that it is almost impossible to observe the hot-worked structure by the usual methods. Thus, it is often concluded that recovery processes operate during hot working to remove all evidence of the deformation. This viewpoint is, at best, an oversimplification. Although there is no doubt that some evolution of structure does occur during working, by far the greatest changes occur during the high-temperature dwell subsequent to working. The final structure, therefore, depends not only on the working conditions, but also on the conditions of cooling. On the other hand, at slow rates of working recovery processes may almost keep pace with the deformation so that the final structure again shows little or no evidence of working. Hence a study of the structural evolution during and after hot working requires a judicious choice of working conditions. Appropriate conditions vary with the material.

Not only do the experimentally convenient working conditions fall outside the usual range for hot working, but also they fall within a range about which very little is known. For this reason, a study utilizing the experimental conditions will yield results which may be applied in several ways. On the one hand, these results can be extrapolated into the usual hot-working region and thus add to the understanding of that process. On the other hand, it is possible to produce structures utilizing the experimental working conditions which cannot be produced by any 
other working procedure. Although the mechanical properties of these structures are largely unknown, there exist some indications that unusual combinations of strength and ductility may be obtained. There are also indications that certain working conditions may produce hot-worked structures which exhibit considerable high-temperature stability. This stability may well be combined with unusual mechanical properties. In addition, studies utilizing the experimental conditions may provide a bridge between the structural changes which occur during creep and those which occur during hot working. Eventually, it may be possible to formulate a mechanism which will account for the structural changes which occur during and after hot working over the complete range of deformation rates and temperatures.

\section{Purpose of the Study and Definition of Hot Working}

This research is a study of the evolution from a strained material to a strain-free structure which occurs during the annealing of hotworked Nickel 200. This evolution depends to a considerable extent upon the structure produced during working and hence on the working conditions. The purpose of this study is therefore to determine the influence of working conditions upon the structural evolution during annealing after hot working and to characterize this evolution by determinations of volume fraction strain-free grains, growth rates, number of strain-free grains, the effects of annealing temperature, and a microstructural history of the process.

For the purposes of this study, hot working will be defined as deformation which occurs at a high enough temperature that the usual 
crystallographic deformation mechanisms of slip and twinning are accompanied by diffusion controlled processes such as dislocation climb and boundary migration. Moreover, the rate of extension is many orders of magnitude above those experienced in creep. In addition, the working conditions must be such that the structure which obtains at any time during the working or annealing periods can be successfully "quenched-in." In this study, the possibility of structural evolution during the transfer from the heating device to the quench tank was eliminated by the novel procedure of extending the deformation very slightly into the quenching period.

\section{Previous Studies}

Hot working

The structural changes which occur during annealing after hot working depend to a considerable extent upon the structure which exists upon the completion of working, i.e., upon the working conditions. For this reason, it is necessary to inquire to what extent the structural changes which occur during hot working have been investigated. This inquiry must be tempered by the realization that hot-worked structures are usually unstable, and their stability decreases (for a particular material) with increasing temperature and rate of deformation. An extreme example, noted by Leguet, Whitwham and Herenguel (3), was the complete recrystallization of OFHC copper in as little as one-fifth of a second after a moderate reduction by rolling at $700^{\circ} \mathrm{C}$ and at a rate of $100 \mathrm{~m} / \mathrm{minute}$. For this reason, only those investigations will be considered in which the high temperature structure was preserved by a severe 
quench immediately afte/ working, or those in which observations were made at the working temperature.

Since the structural evolution during working is best characterized by the microstructural changes which occur during it, these changes will be made the basis of the discussion. Contained in the following paragraphs are outlines of and comments upon observations of slip lines, serrated boundaries, subgrains, and the formation of new grains obtained from previous studies of hot working. The interrelations amongst these characteristics will be further clarified in the discussion of the experimental results (Chapter IV).

A knowledge of the conditions of working and of the materials involved in the various studies is necessary for a complete understanding of the published observations. In order to clarify the presentation, these are included as Appendix A.

slip lines.--Slip lines are the manifestation on an external surface of dislocation movement on a definite crystallographic plane and in a specific direction. Observations made (under the optical microscope) on high temperature slip in copper $(3,4)$, nickel $(5,6)$, an austenitic stainless steel (7), and 70-30 brass are in substantial agreement. slip lines first appeared at low total deformations and became more widely spaced with increasing working temperature. Above a certain temperature they were no longer visible under the microscope. This type of observation must not be construed as indicating that deformation by slip did not occur above a certain temperature. Studies with the electron microscope have revealed high temperature slip lines too fine to be seen optically. 
These studies also showed that with increasing working temperature, the active slip planes became more closely spaced and slip on any one plane smaller in amount (8).

Grain boundary serrations.--Grain boundary serrations are the sharp offsets which are formed in grain boundaries during hot working. They have been observed in a wi de variety of hot-worked metals and alloys. Among these are: Nickel $(1,6,9)$, nickel-alumi num alloys (6), nickelcopper alloys (6), nichrome (10), an austenitic steel (7), magnesium (11, 12), zirconium (13), and uranium (10). Observations on the character and conditions for the formation of grain boundary serrations are in general agreement. Serrations appear only within a certain range of working temperatures. Below a characteristic temperature, serrations are either absent or unresolvable. Above a considerably higher temperature they are destroyed by recrystallization along old grain boundaries (1). Within their temperature range of existence, serrations become better defined with increasing temperature and amount of working $(1,7,9)$. Serrations also vary in appearance wi th the working conditions. Low temperatures and fast rates result in more or less straight sides, while high temperatures and low rates tend to yield a more "wavey" or scalloped appearance (9). An increase in grain size results in less prominent serrations (10). Subgrains.--Subgrains are small regions slightly mi soriented with respect to each other which are formed within grains under certain conditions of working or at working and annealing. Well-defined subgrains have been observed to form quite readily during hot working in torsion $(14,15,16,17,18,19)$, by forging (4), by rolling (3), and in tension $(6,10)$. The degree of development of subgrain boundaries depends not 
only on the stacking-fault energy of the material but also on the working conditions. Materials of low stacking-fault energy such as 70-30 brass form few and poorly developed subgrain boundaries even under the most favorable conditions (3). On the other hand, aluminum, with a high stacking-fault energy, forms subgrains readily during hot working $(3,14$, 16). In fact, with sufficient deformation, subgrain boundaries in aluminum develop to the point where they can not be distinguished from grain boundaries $(14,19)$. Nickel falls between these extremes, but its behavior is much closer to that of aluminum than to that of $70-30$ brass. The ease of subgrain formation during hot working may possibly be related to an increase in stacking fault energy with temperature. Swann and Nutting (20) have observed that the stacking-fault energy of a copper-7 per cent aluminum alloy increased abruptly above a certain temperature. If this behavior is general, it would lead one to expect the formation of better defined subgrains as the temperature of working is increased.

The formation of new grains during working.--The formation of new grains during working has been a controversial subject. Hardwick and Tegart (14) noted that the structures of hot-worked nickel and copper were at least partially occupied by grains which they believed formed during working. Leguet et al. (3) challenged this conclusion on the basis of their study which showed working and annealing (formation of new grains) to be separate and successive. These authors believed that the new grains observed by Hardwick and Tegart were formed during the very short time subsequent to working but prior to quenching. This was most probably the case. Rhines et al. (9), however, have noted the presence of a large number of very small grains in the structure of hot-worked 
nickel. These grains were not present prior to working. In addition, working and quenching conditions rule out the possibility of formation between the working period and quenching to room temperature. Thus it must be concluded that under certain conditions new grains can form during hot working. This is an important point and will be considered in some detail in the discussion (Chapter IV).

\section{Annealing after hot working}

The evolution from a strained material to strain-free grains which occurs during annealing after hot working is the principal concern of this study. Thus, the few existing investigations of annealing after hot working are of considerable importance. These studies are discussed in the following paragraphs. They can be divided conveniently into two periods with respect to time and general approach to the subject. The first of these periods begins about 1920 and ends with the second World War. Most investigations in this period were performed by German workers who were concerned with establishing the relationships between amount of working, annealing temperature and the completely annealed grain size (results were plotted as a type of Czochralski diagram). The second active period begins in the late 1950's and is characterized by a more detailed study of the structural evolution during annealing.

The original investigations of annealing after hot working (by rolling and forging) appear to have been made by Hanemann and Lücke (21), by Hanemann (22), and by Tafel, Hanemann and Schneider (23). Similar investigations were performed at a later date by Kornfeld (24) and by Kornfeld and Hartleif (25). In all of these studies the emphasis was on 
the recrystallized grain size as a function of the amount and temperature of working. No attempt was made to determine the kinetics of the evolution from strained to strain-free material. Hanemann and co-workers concluded that the initial grain size has no influence on the fully annealed grain size and that the latter is determined only by the temperature and amount of working. These conclusions were disputed by Kornfeld, and by Kornfeld and Hartleif who established for an "Armco" type iron forged in the alpha region that the fully annealed grain size does depend on initial grain size. The conclusion of Tafel, Hanemann, and Schneider, however, was found to be valid for working in the gamma field.

More recent investigations have yielded some interesting information on the structural changes which occur during annealing after hot working. These are summarized in the following paragraphs.

The microstructural positions occupied by grains formed during annealing after hot working were noted by Malyshev et al. (7) in their investigation of the structural changes in an austenitic steel during hot rolling. Specimens rolled at various temperatures and then quenched were partially recrystallized by reheating to a suitable temperature. New grains in a specimen deformed at room temperature showed a very marked preference for formation on slip lines. This tendency is much less in material deformed at $450^{\circ} \mathrm{C}$ and most new grains were formed at old grain boundaries. The marked preference exhibited by strain-free grains for formation along old grain edges and at serrated grain boundaries was also noted by Rhines et al. (9) and by English and Backofen (26).

Observations of the effect of different variables on the velocity of formation of strain-free grains have been made by a number of authors. 
Leguet et al. (3) found for a 70-30 brass annealed at a constant temperature that the rate of recrystallization decreases with increasing working temperature (their specimens were quenched after working and reheated to the annealing temperature). Rossard and 81 ain (27) noted that a certain minimum amount of working was necessary before new grains formed during annealing. This "threshold" value decreases with increasing annealing time. These authors also noticed that the annealed grain size decreased with increasing velocity and degree of working and decreasing temperature of working. Growth rates were measured in only one study, namely that by English and Backofen (26). This study is also the only one in which the structural evolution during annealing after hot working was followed by measuring the amount of strain-free (recrystallized) material as a function of annealing time.

It is obvious from the above discussion that little qualitative and practically no quantitative data are available from previous studies of the structural evolution during annealing after hot working. Thus, there is not even a basis for the formulation of general principles such as have been established for annealing after cold working. The present study is a systematic attempt to partially remedy this situation. 


\section{CHAPTER II}

\section{EXPERIMENTAL MATERIAL, APPARATUS AND PROCEDURES}

\section{Experimental Material}

All tensile bars were machined from 5/8-inch diameter rod obtained from one heat of Nickel 200. A certified analysis of this heat is included as Table 1.

TABLE 1.--Certified analysis of Nickel 200, heat $513 \mathrm{~A}$

\begin{tabular}{cc}
\hline Element & Per Cent \\
\hline C & 0.07 \\
Mn & 0.26 \\
$\mathrm{Fe}$ & 0.04 \\
$\mathrm{~S}$ & 0.005 \\
$\mathrm{Si}$ & 0.07 \\
$\mathrm{Cu}$ & 0.01 \\
$\mathrm{Ni}$ & 99.52 \\
\hline
\end{tabular}

The rod was received in the cold-drawn condition.

\section{Experimental Apparatus}

High temperature deformation utilized a jig designed to extend a standard tensile bar at a controlled rate. A sketch of this jig is included as Figure 1. Rate of extension could be varied in a step-wise manner by adjusting the combination of gear reducers and gears. The jig was self-contained and designed to sit over a 12-inch diameter salt pot so that the specimen was immersed completely in the liquid salt. 


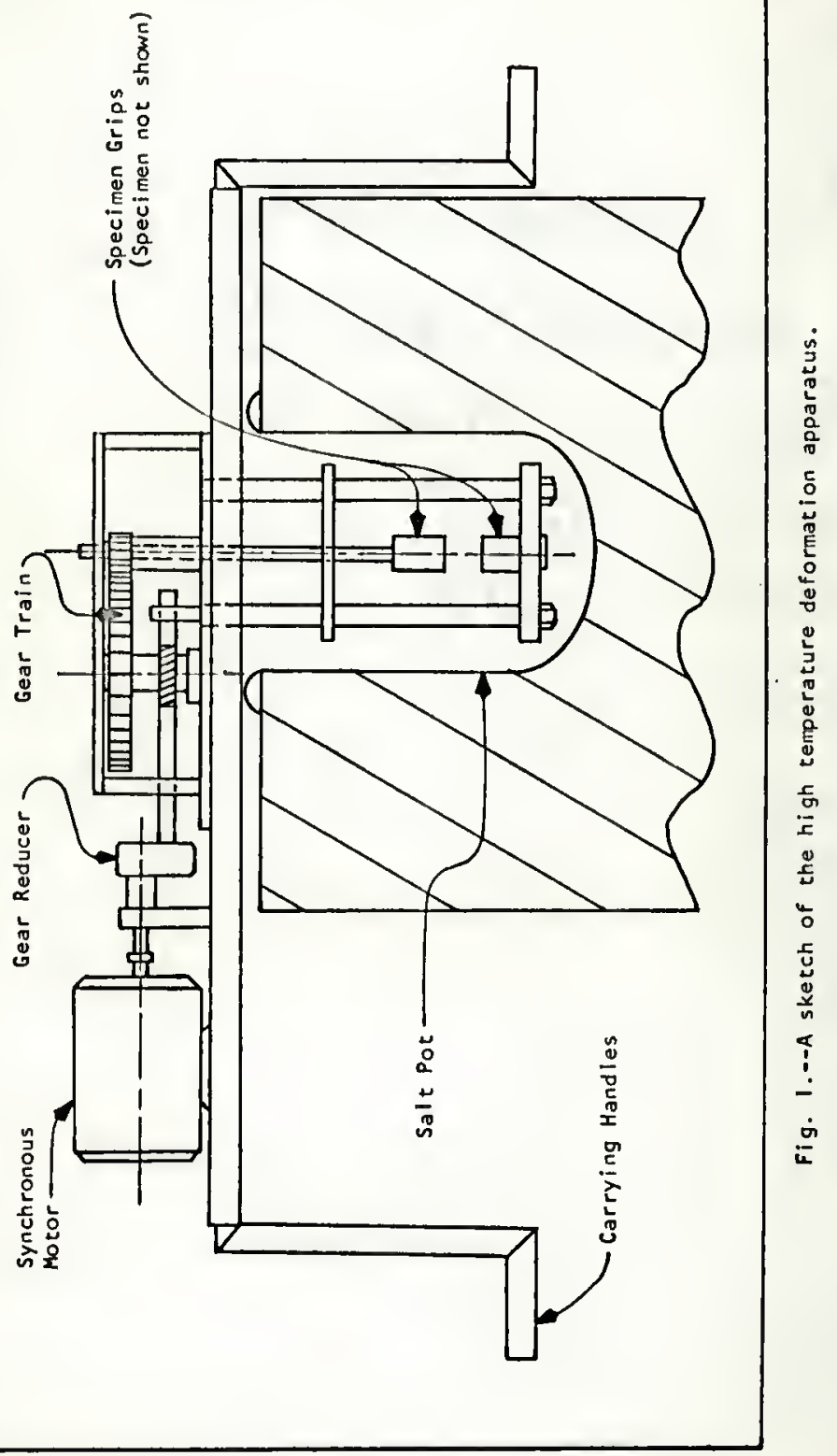


Quenching was easily and rapidly performed by two men lifting the jig out of the salt pot and dropping it into a tank of cold water. Two electrically heated pot furnaces, both equipped wi th Inconel pots, were used throughout the testing. The heating media were: (1) Houghton's Liquid Heat 1145 for the pot in which the deformation was performed, and (2) Houghton's Liquid Heat 1145 plus 5 to 10 per cent $1 \mathrm{i}$ thi um chloride for the pot in which annealing at $700^{\circ} \mathrm{C}$ and $670^{\circ} \mathrm{C}$ was performed. Both pot furnaces were equipped wi th sui table temperature controllers. Temperature fluctuations within the pots were reduced to a minimum by stirring wi th variable speed laboratory stirrers.

All measurements and photomicrographs were made on a Bausch and Lomb Research Model Metallograph.

\section{Experimental Procedures}

Preparation of tensile bars

The as-received Nickel 200 rod was cut into 11-inch lengths and annealed for 18 minutes at $750^{\circ} \mathrm{C} \pm 1{ }^{\circ} \mathrm{C}$ in Liquid Heat 1145 . This treatment resulted in a completely recrystallized structure. The annealed, 5/8-inch diameter bars were cold swaged in two stages to a nominal diameter of $1 / 2$ inch. Actual reductions in area varied from 34 to 36 per cent. Tensile bars similar to that illustrated by Figure 2 were machined from the swaged bars. Each length provided 5 tensile bars and the same number of $1 / 16-i n c h$ thick disks. These disks received the same subsequent thermal treatments as the tensile bars (one disk accompanying each bar) and were useful for control and comparative purposes. 


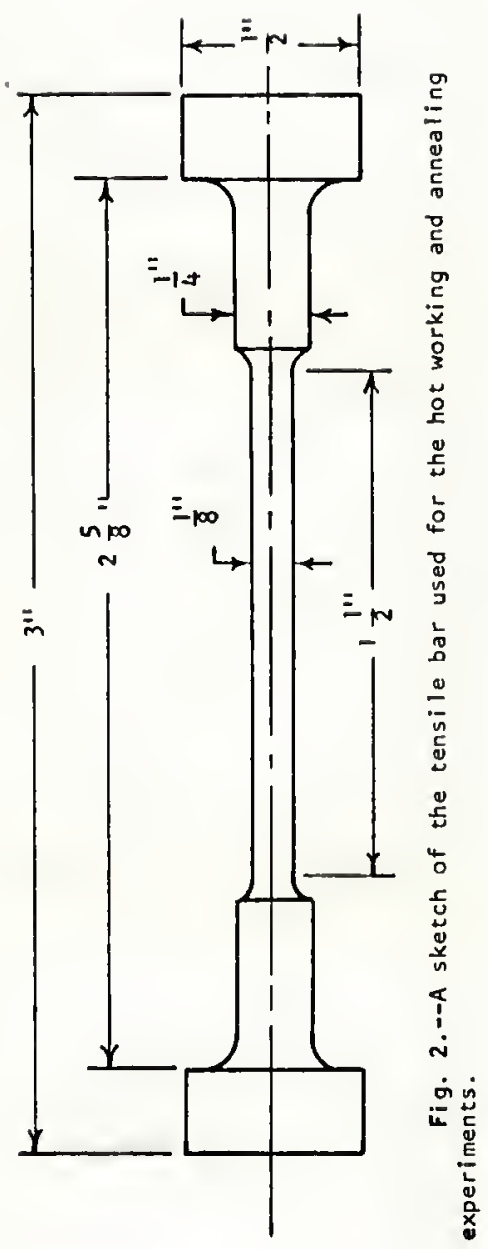


After machining, the gauge section of all tensile bars was polished in order to remove the layer of badly distorted material produced by machining. This treatment prevented the formation of a fine-grained "skin" during subsequent annealing. The complete procedure consisted of grinding through 240-, 320-, 400-, and 600-grit Silicon Carbide Metallographic Papers and electropolishing the gauge section. The $1 / 2-i$ nch diameter disks were similarly treated. Electropolishing was performed in a solution containing $144 \mathrm{ml} \mathrm{C} \mathrm{C}_{2} \mathrm{H}_{5} \mathrm{OH}, 32 \mathrm{ml} \mathrm{H}_{2} \mathrm{O}, 16 \mathrm{ml}$-butyl alcohol, $45 \mathrm{~g}$ $\mathrm{ZnCl}_{2}$, and $10 \mathrm{~g} \mathrm{AlCl}_{3} \cdot 6 \mathrm{H}_{2} 0$. Polishing was accomplished satisfactorily at voltages from 14 to 16 volts, and at temperatures from $-10^{\circ} \mathrm{C}$ to $-25^{\circ} \mathrm{C}$ utilizing a stainless steel cathode and a polishing time of approximately one hour. After electropolishing, the bars were given a final anneal in Liquid Heat 1145 at $750^{\circ} \mathrm{C} \pm 1^{\circ} \mathrm{C}$ for 25 minutes. The final anneal resulted in a fairly equiaxed structure, illustrated by Figure 3, wi th an $N_{L}$ of $45 / \mathrm{mm}$. The gauge length and gauge diameter of all bars were measured on an optical comparator.

\section{Extension of tensile bars}

The same procedure was followed in extending all tensile bars. A bar was placed in the grips of the deformation apparatus and all slack taken up manually. One of the $1 / 2$-inch diameter disks was wired on the upper grip so that it hung adjacent to the gauge section of the tensile bar. The jig was next placed in the liquid salt and the whole apparatus annealed for 20 minutes. During this time the temperature of the pot was adjusted to $749^{\circ} \mathrm{C} \pm 1^{\circ} \mathrm{C}$. At the end of the holding period, the jig was switched on for 25 seconds (a time calculated to give a total extension 


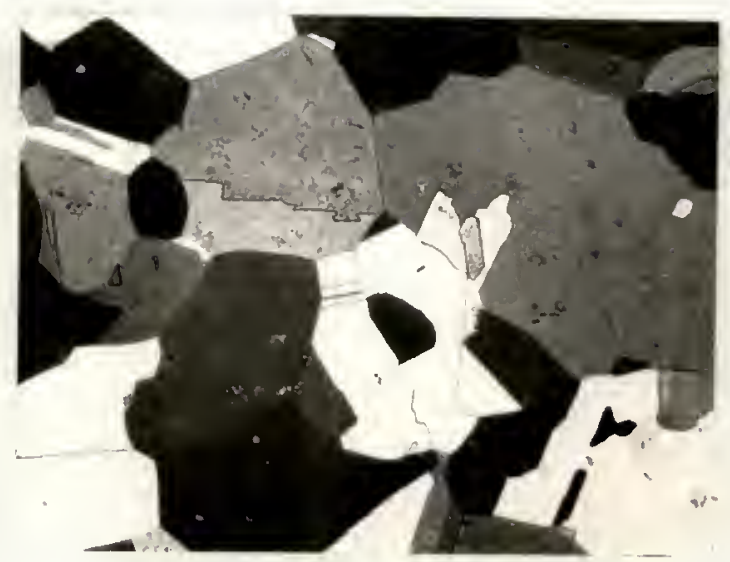

Fig. 3.--A photomicrograph of the structure which resulted from the final 25-minute anneal at $750^{\circ} \mathrm{C}$. $400 \mathrm{X}$. 
of about 31 per cent to all test bars) and then switched off if annealing was to be performed at $750^{\circ} \mathrm{C}$. If annealing was to be performed at $700^{\circ} \mathrm{C}$ or $670^{\circ} \mathrm{C}$, the $\mathrm{jig}$ motor was shut off as the $\mathrm{jig}$ was $\mathrm{lifted}$ for transfer to the second pot. Total transfer time was approximately 3 seconds. A simple experiment wi th a test bar exactly the same as those used for the actual tests showed that 6 seconds were required for the surface of the gauge section to cool from $750^{\circ} \mathrm{C}$ to $700^{\circ} \mathrm{C}$. At the end of the annealing period, the jig was water quenched. Approximately one second was necessary to transfer the $\mathrm{jig}$ from the salt pot to the quench bath. After quenching, the tensile bar and the slug were removed from the $\mathrm{jig}$ and the gauge section of the bar remeasured on the optical comparator. Total extensions were calculated from the initial and final measurements.

Temperature control for the $750^{\circ} \mathrm{C}$ anneals was fairly simple and in all cases the temperature was held between $748^{\circ} \mathrm{C}$ and $750^{\circ} \mathrm{C}$. Control was not so simple for the lower temperature anneals; however, all runs fell within the following limits: $698^{\circ} \mathrm{C}$ to $702^{\circ} \mathrm{C}$ for nominal $700^{\circ} \mathrm{C}$ anneals and $664^{\circ} \mathrm{C}$ to $671^{\circ} \mathrm{C}$ for the nominal $670^{\circ} \mathrm{C}$ anneals.

\section{Metal lography}

A portion of the gauge length which had experienced a reduction in area of approximately 24 per cent was located in each tensile bar and a 3/8-inch to $3 / 4-i n c h$ section removed wi th a jeweler's saw. This piece was mounted in Bakelite, rough ground to approximately mid-diameter, and ground through 240-, 320-, 400-, and 600-grit Silicon Carbide Metallographic Papers. Initial polishing was performed with 6-micron diamond paste on a Nylon cloth and I-micron diamond paste on Microcloth. The 
final mechanical polish utilized a Syntron vibratory polisher. The abrasive was Linde " $B$ " on Microcloth and the polishing time was 40 minutes. In order to remove all traces of distorted metal, the specimens were electropolished in the same solution used to polish the tensile bars before the final anneal. Polishing conditions, however, were much more critical. A well-aged solution wi th a deep green color was used. The temperature of the polishing bath was maintained between $-30^{\circ} \mathrm{C}$ and $-35^{\circ} \mathrm{C}$ and the specimen allowed to reach this temperature before polishing was begun. The most satisfactory open circuit vol tage was found to be 35 volts and the best polishing time 40 seconds. A stainless steel cathode was satisfactory. No agitation was necessary. At the end of the polishing periad, the specimen was removed from the bath wi th the current on, washed under warm, running water, and blown dry.

Correct etching was of extreme importance and was performed as described below. A solution containing $45 \mathrm{ml} \mathrm{H}_{2} \mathrm{O}, 47 \mathrm{ml}$ concentrated

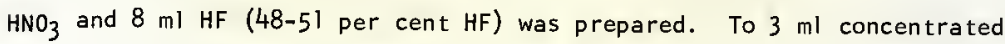
$\mathrm{HCl}$ in a polyethylene graduate was added $17 \mathrm{ml}$ of the above solution and the mixture was heated in a water bath until light yellow. The solution then was poured into a polyethylene beaker and used to saturate a cotton swab on the end of a pair of stainless steel tongs. In a few seconds, a reaction wi th the tongs began and the cotton swab gradually acqui red a dark green color. When a large portion of the cotton had become stained, the swab was swirled around in the solution remaining in the polyethylene beaker for a few seconds, squeezed as dry as possible and discarded. The green solution in the beaker was allowed to cool to $25^{\circ} \mathrm{C}$ and used as an immersion etch. Etching times were between 8 and 12 seconds. The 
specimen was held face down in the solution and agitated very slightly. At the end of the etching period, the specimen was removed from the etch and washed thoroughiy in warm, running water.

The above etching procedure was developed during the investigation and is a refinement of the procedure used by Reed-Hill et al. (28). It produced a surface highly sensitive to polarized light and one which can be easily examined at magnifications as high as or higher than $1000 x$. Many metallic surfaces prepared for examination under polarized light cannot be viewed at magnifications over a few hundred times. The success of the present procedure lies in the production by the etch of a very fine pseudo-crystallographic grooving (28). The appearance of the grooves as revealed by the electron microscope is illustrated by figure 4 taken from a chromi um shadowed formvar replica of a surface etched as described above.

Although all groove axes wi thin a particular grain are oriented in a unique direction, this direction is not truly crystallographic and hence cannot be used in precise orientation determinations. However, the grooves do reflect accurately the degree of lattice strain present in individual grains. If the grain is undistorted, then the grooves produced by the etch will all be straight and all oriented in the same manner with respect to the surface of the specimen. Examination with polarized light will result in all of the grain reaching a particular degree of extinction at the same position of the microscope stage. There will be no variation in shading within a grain unless caused by a twin or by a polishing or etching artifact. On the other hand, if the grain is distorted and the lattice planes bent, the grooves produced by etching wi 11 also be 


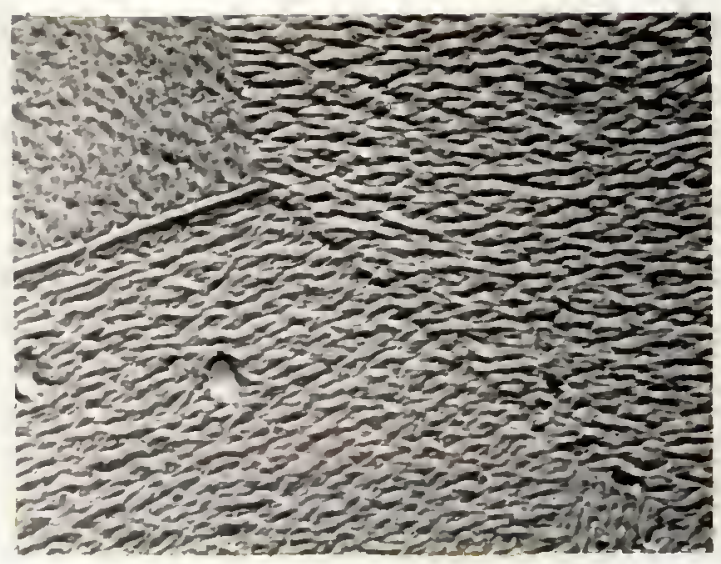

Fig. 4.--Electron photomi crograph illustrating the grooved surface produced on a specimen polished and etched as described in the text. 13,000x. 
bent and possibly will not all be oriented in the same manner with respect to the surface of the specimen. Thus, various parts of the grain, when exami ned under polarized light, will reach different degrees of extinction at a particular microscope stage position and variations in shading will appear. The type of extinction noted under polarized light is therefore a rather sensitive indication of the lattice strain present in a particular grain. Undistorted or recrystallized grains thus can be unequivocally separated from distorted or unrecrystallized grains. It is also possible to reveal all grain and twin boundaries.

The above procedure, however, has a number of disadvantages:

1. All stages of specimen preparation must be carefully performed.

2. A finite number of grains will be oriented such that no grooves will form on etching. Thus, no extinction is possible under polarized light.

3. A minimum amount of strain is necessary to produce enough lattice bending to be visible under polarized light. Specimens extended as little as 4 per cent, however, have shown lattice bending and the threshold value for the specimen as a whole must be less than this.

\section{Quantitative metallography}

Most of the quanti tative data obtained resulted from two types of measurements: (1) point counting, and (2) intercept counting. Both procedures are well established. The papers by Hilliard and Cahn (29) and by Smi th and Guttman (30) may be consulted for further details. In addition, one type of measurement involving number per unit area was performed.

All measurements, except those of caliper diameter, were performed at a magnification of $1025 X$. 
Point counting.--Point counting is most easily performed by superimposing a uniform array of points on the microstructure and counting the number of points which fall within a certain structural feature. The ratio of the number of points falling on the feature of interest to the total number of points applied is defined as $P_{P}^{*}$ and is equal to $V_{V}$, the volume fraction occupied by the feature of interest.

In the present investigation a $7 \times 7 \mathrm{grid}$ was introduced into the microscope eyepiece. This grid had the advantage that it could be used as a 25-point, 16-point, 9-point, 4-point or even a 1-point grid, depending on the structure being measured. New areas were brought into the field of view simply by moving the microscope stage a predetermined amount. An estimate of the number of points which must be counted for a predetermined precision can be made from the expression given by Hilliard and Cahn (29): $\quad\left(\sigma_{V} / V_{V}\right)^{2}=1 / N_{P}$ where $\sigma_{V}$ is the standard deviation for the volume fraction of the feature of interest, $V_{V}$ is the volume fraction of this feature present, and $N_{P}$ is the total number of points which fall on this feature. It is assumed that: (1) the feature of interest occurs as discrete particles randomly distributed in three dimension, and (2) the point grid is so coarse that the distance between points is larger than the intercept length for the feature of interest. This expression is then, strictly speaking, only valid for small and for large amounts of strain-free material. For intermediate amounts the empirical expression $\left(\sigma_{V} / V_{V}\right)^{2}=\left(1-V_{V}\right) / N_{P}$ given by Hilliard and Cahn can be used.

*All symbols have been defined in the Table of Symbols which is located in front of the text. 
Both of these equations also can be used to calculate the precision obtained from the number of classified points.

Intercept counting.--Intercept counts were used to determine the surface area per unit volume of various features through the expression $2 N_{L}=S_{V}$. In this expression $N_{L}$ is the number of intercepts per unit length made by a test line with the feature of interest and $S_{V}$ is the surface area per unit volume possessed by the feature of interest. The eyepiece grid and movement from area to area were the same as described above. The grid was rotated $9^{\circ}$ between areas in order to avoid an orientation dependence in the results due to the position of the test line with respect to the tensile axis of the specimen. A total of 20 areas were counted as a group. This is equivalent to the superposition of a uni form array of lines on the gross area examined. Enough groups of 20 areas were measured that the standard error of the average number of intercepts per unit length of test line was usually less than 10 per cent of the average and quite often in the neighborhood of 5 per cent. A section perpendicular to the tensile axis of a specimen with $V_{V}=0.94$ was also examined. A measurement of the total grain boundary area for this section yielded the same result as obtained from a section parallel to the tensile axis. This result and metallographic observations made on the same specimen proved that the new grains are equiaxed. 0ther authors have found that the volume fraction new grains is independent of the orientation of the metallographic surface $(31,32)$.

Three basic types of intercept counts were made:

1. Total number of intercepts made with all grain and twin boundaries-- $\left(\mathrm{N}_{\mathrm{L}}\right)_{\text {total }}=1 / 2\left(\mathrm{~S}_{\mathrm{V}}\right)_{\text {total }}$. 
2. The number of intercepts made with grain and twin boundaries having strained material on at least one side-- $\left(\mathrm{N}_{\mathrm{L}}\right)_{\text {old }}=1 / 2\left(\mathrm{~S}_{\mathrm{V}}\right)_{\text {old }}$.

3. The number of intercepts made wi th grain and twin boundaries having strain-free material on at least one side-- $\left(N_{L}\right)_{\text {new }}=1 / 2\left(S_{V}\right)_{\text {new }}$.

All three types are illustrated by Figure 5. The line drawn on the print intercepts boundaries wi th strained material on at least one side at points marked (2) and boundaries wi th strain-free material on at least one side at points marked (3). The total boundary area is obtained by counting all the intersections. Note that in all cases both grain and twin boundaries were counted as equivalent. The reasons for this procedure will be discussed later.

Calculation of $N_{V}$, the number of strain-free grains per unit volume, necessitated counting the number of grain boundary intercepts carefully excluding all twin boundaries. This measurement was performed exactly as were the other types of intercept measurements. Difficulty in separating grain from twin boundaries, however, resulted in it being more difficult to perform and subject to a greater inaccuracy than the other intercept measurements.

Determination of number per unit area.--The number of new grains per unit area, $\mathrm{N}_{A}$, was measured. This involved only a straightforward counting of the number of new grains in a certain area of the eyepiece grid. Again, enough areas were counted that the standard error of the mean was usually between 5 per cent and 10 per cent of the mean value. The measurement was subject to errors from two sources:

1. At very short annealing times the area of intersection on the metallographic surface wi th a particular new grain may be below the smallest size recognizable as 


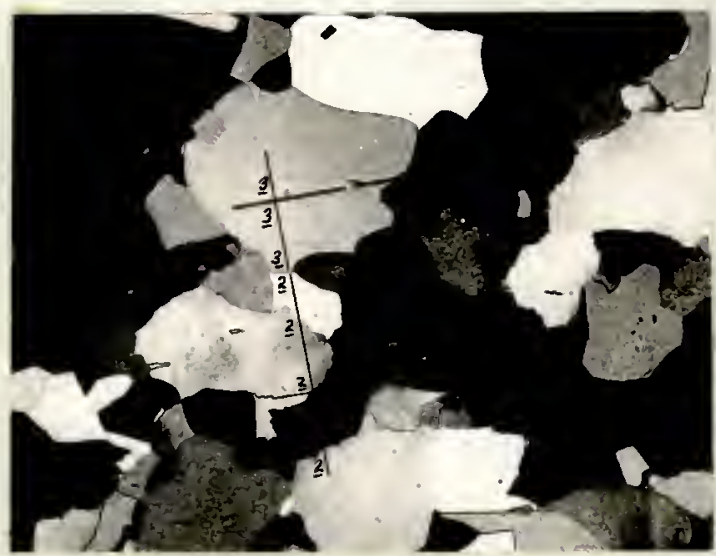

Fig. 5.--A photomicrograph which illustrates the three basic types of intercept counts performed in this study. Boundaries with strained material on at least one side are marked (2) and boundaries with strain-free material on at least one side are marked (3). Polarized light. $400 x$. 
a new grain. With the aid of an estimate of the smallest area visible (around a diameter of two microns or possibly somewhat less) and the assumption that all new grains grow initially as spheres, one can calculate the probability of intersecting a sphere of a certain size and revealing a visible section. With the aid of the experimental growth rates, and assuming a suitable minimum probability, one can then calculate the time necessary for a new grain which originated at zero annealing time to reach visible size. These times were found to be less than the shortest annealing times at all three annealing temperatures.

2. All grains which appeared inside a particular area in the eyepiece were counted, even if the largest part of the grain was outsidethe measured area. Strictly speaking, those grains which appeared both in and out of the measured area should have been weighed by a factor of one-half. Errors from this source were later realized to be considerable. Consequently, the data were adjusted with the aid of empirical correction factors. These were calculated for a number of specimens by measuring $N_{A}$ with all grains having a weighing factor of one and then remeasuring the same area with the grains which extended over the edge of the area being given a weighing factor of one-half. The ratio of the corrected $N_{A}$ to the uncorrected $N_{A}$ was then plotted versus $V_{V}$. Measurements from specimens at all three annealing temperatures (Figure 6) indicated that the ratio was a function of $V_{V}$ only and not a function of temperature. The plot of Figure 6 was used to correct all the measured values of $\mathrm{N}_{A}$.

A few determinations were made of the length of grain edge per unit volume. This involved measuring the number of triple points per unit area. The length of edge was then calculated from the expression $\left(N_{A}\right)_{T}=1 / 2 L_{V}$ where $\left(N_{A}\right)_{T}$ is the number of triple points per unit area and $L_{V}$ is the length of grain edge per unit volume. Although this measurement was the most difficult to perform, duplicate determinations agreed to within 10 per cent of the average.

Miscellaneous measurements. --The maximum intercept length of the largest unimpinged grain was measured where possible. For the purpose of 


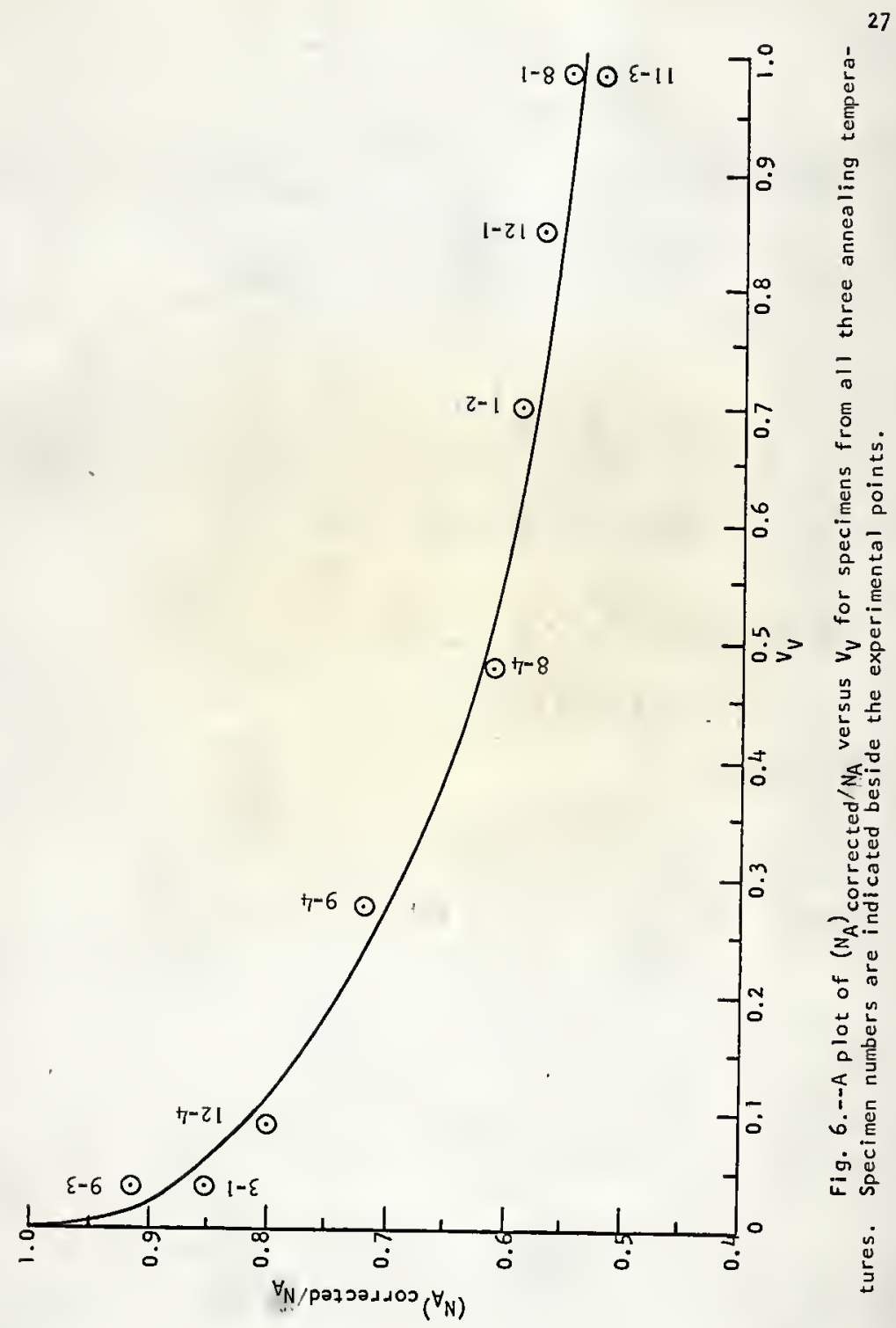


this measurement, maximum intercept was defined as the longest dimension wi thin an unimpinged strain-free grain which would be found on the metallographic surface. The measurement was performed at a somewhat lower magnification than the other measurements described above. A filar eyepiece was used and the metallographic surface scanned enough times that the author was fairly certain that the largest revealed grain was measured.

Calibration of optics.--A stage micrometer was used to calibrate the eyepiece grid for the particular magnification used. The error in the calibration was estimated as approximately \pm 0.5 per cent . 


\section{CHAPTER I||}

\section{EXPERIMENTAL RESULTS}

\section{Metal lographic Observations}

\section{General observations}

A list of all worked specimens has been included as Table 2 . In addition, this table lists for each specimen: (1) values for total extension calculated from the measured length change, and (2) the reduction in area experienced by the section of each specimen prepared for metallographic examination.

Photomicrographs of all specimens were obtained. These are included as Appendix B. In all photomicrographs the tensile axis is parallel to the long dimension of the photographic print. Four photomicrographs were abstracted from Appendix $B$ and are included in this section as Figure 7. Also included as Figure 7 (a) is a photomicrograph of the structure immediately before deformation. These five photomicrographs illustrate the most important metallographic observations. These observations are discussed in the following paragraphs.

Grain boundary serrations are very marked in the as-deformed mi crostructure, Figure 7 (b). These serrations are evidently characteristic of hot-worked structures as they also have been observed in aluminum, nichrome, an austenitic stainless steel, zi rconium, magnesium, and uran i um. 
TABLE 2.--List of all specimens worked (at $750^{\circ} \mathrm{C}$ ) and annealed (at $750^{\circ} \mathrm{C}, 700^{\circ} \mathrm{C}$ and $670^{\circ} \mathrm{C}$ ) wi th measured extensions and reductions in area (sections mounted for metallographic examination)

\begin{tabular}{|c|c|c|c|c|c|c|c|c|}
\hline \multicolumn{9}{|c|}{$\begin{array}{c}\text { Annealing Temperature } \\
700^{\circ} \mathrm{C}\end{array}$} \\
\hline $\begin{array}{l}\text { Specimen } \\
\text { Number }\end{array}$ & $\begin{array}{l}\text { Over-all } \\
\text { Extension } \\
\text { (Per Cent) }\end{array}$ & $\begin{array}{c}\text { Reduction } \\
\text { in Area } \\
\text { (Per Cent) } \\
\end{array}$ & $\begin{array}{l}\text { Specimen } \\
\text { Number }\end{array}$ & $\begin{array}{l}\text { Over-all } \\
\text { Extension } \\
\text { (Per Cent) }\end{array}$ & $\begin{array}{c}\text { Reduction } \\
\text { in Area } \\
\text { (Per Cent) }\end{array}$ & $\begin{array}{l}\text { Specimen } \\
\text { Number }\end{array}$ & $\begin{array}{l}\text { Over-all } \\
\text { Extension } \\
\text { (Per Cent) }\end{array}$ & $\begin{array}{l}\text { Reduction } \\
\text { in Area } \\
\text { (Per Cent) }\end{array}$ \\
\hline $2-1$ & 29 & 25 & $2-1$ & 29 & 25 & $2-1$ & 29 & 25 \\
\hline $2-2$ & 30 & 23 & $7-5$ & 29 & 24 & $9-3$ & 30 & 24 \\
\hline $3-1$ & 30 & 22 & $6-2$ & 28 & 26 & $12-4$ & 32 & 25 \\
\hline $11-4$ & 31 & 24 & $6-4$ & 32 & 23 & $10-2$ & 30 & 24 \\
\hline $3-4$ & 29 & 24 & $8-2$ & 30 & 23 & $9-4$ & 31 & 26 \\
\hline $11-1$ & 30 & 24 & $7-1$ & 33 & 23 & $10-4$ & 31 & 24 \\
\hline $1-3$ & 30 & 22 & $8-4$ & 30 & 25 & $10-3$ & 31 & 27 \\
\hline $2-3$ & 30 & 22 & $7-2$ & 31 & 27 & $12-1$ & 31 & 26 \\
\hline $1-2$ & 29 & 25 & $8-5$ & 30 & 25 & $12-2$ & 31 & 26 \\
\hline $2-4$ & 31 & 19 & $8-3$ & 29 & 25 & & & \\
\hline $1-1$ & 29 & 25 & $8-1$ & 31 & 27 & & & \\
\hline $11-3$ & 31 & 23 & & & & & & \\
\hline $11-5$ & 31 & 24 & & & & & & \\
\hline $7-3$ & 30 & 26 & & & & & & \\
\hline
\end{tabular}




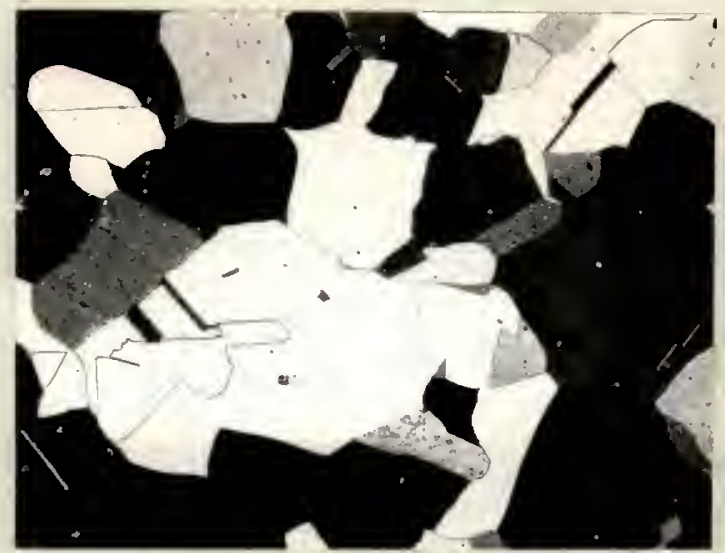

(a) Specimen number 2-1T

$$
v_{v}=100
$$

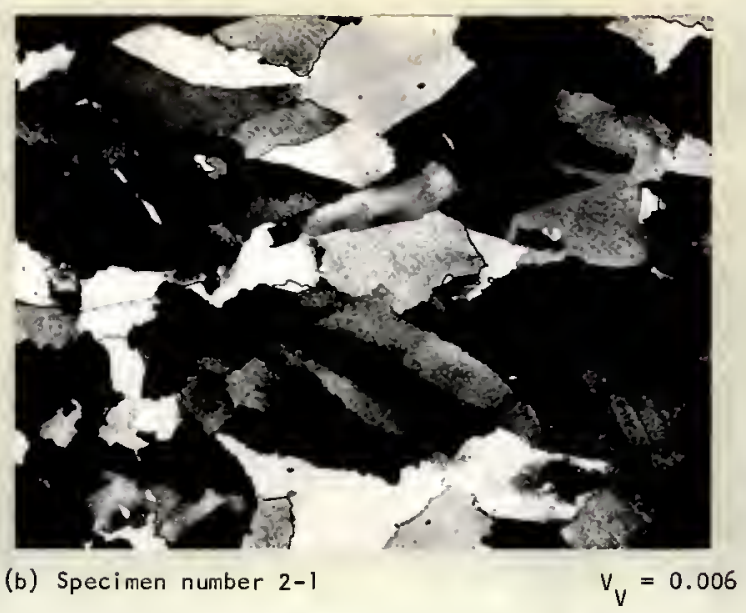

Fig. 7.--Selected photomicrographs from the group of specimens worked at $750^{\circ} \mathrm{C}$ and annealed at $750^{\circ} \mathrm{C}$ (a) immediately before deformation, (b) 0 seconds anneal, (c) 45 seconds anneal, (d) 120 seconds anneal, (e) 720 seconds anneal. Polarized light. $400 x$. 

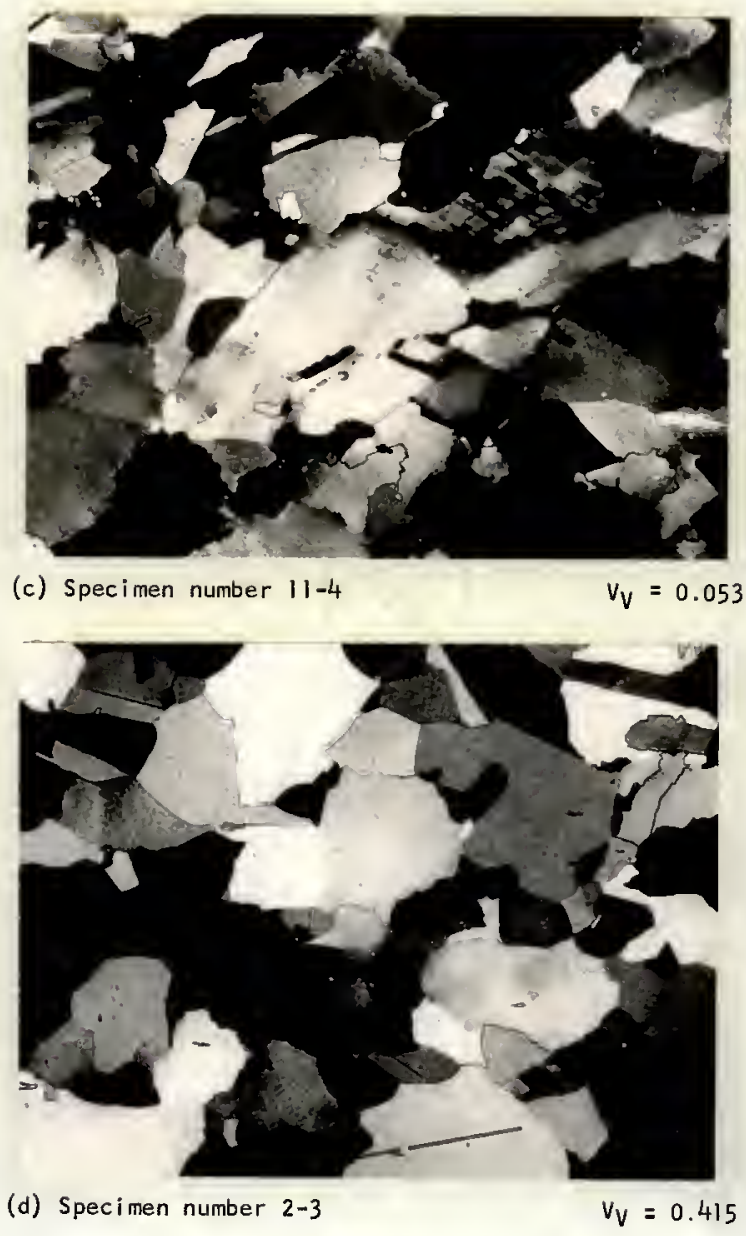

Fig. 7.- - Cont inued 


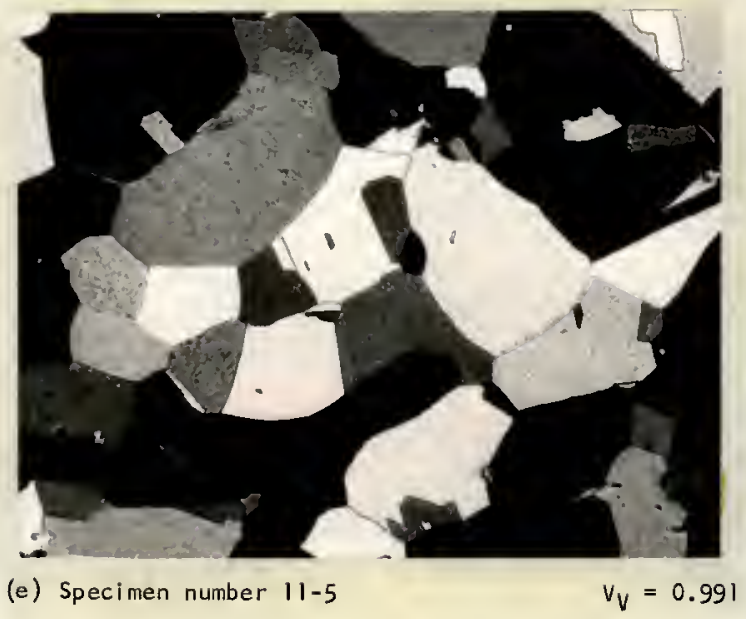

Fig. $7,-$ - Continued 
The large amount of banding and shading present in the as-deformed microstructure, Figure 7 (b), was never observed in undeformed grains and is indicative of lattice bending. Since deformation was performed at an elevated temperature, one might expect rapid dislocation climb and the formation of a well-defined subgrain network. Only a few grains, however, were observed to possess a network of subgrain boundaries similar to that often observed in aluminum. One of these grains is located to the right of center in Figure 7 (c).

A comparison of the stacking-fault energies for aluminum and nickel led to the conclusion that subgrains would probably not be as well developed in nickel as in alumi num. This conclusion follows from the fact that the presently accepted value for the stacking-fault energy of nickel, $150 \mathrm{ergs} / \mathrm{cm}^{2}$ (33) is somewhat less than that for aluminum, 225 ergs $/ \mathrm{cm}^{2}$ (34). A high stacking-fault energy is associated with a small separation between the two partial dislocations produced by the dislocation reaction $\frac{a}{2}[110] \rightarrow \frac{a}{6}[T 2 T]+\frac{a}{6}[21]$, an energetically feasible reaction. The small separation between partials in turn means that the dislocation can climb much more easily than one composed of two widely separated partials in a material of low stacking-fault energy. Since climb is necessary for the formation of a well-developed subgrain structure, the development of substructure depends greatly on the stackingfault energy. On the other hand, one should not overlook the possibility that subgrains are not observed in some grains simply because the ease of subgrain formation varies from grain to grain due mainly to orientation effects. 
Ormerod and Tegart (16) have reported that subgrains formed in nickel during hot torsion at $600^{\circ} \mathrm{C}$ are small with diffuse boundaries and contain many dislocations in their interiors. An increase in the deformation temperature to about $850^{\circ} \mathrm{C}$ resulted in a considerable increase in subgrain size, an increased sharpness of the subgrain boundaries and a decrease in the number of dislocations in the interior of the grains. Thus, one might expect that deformation at $750^{\circ} \mathrm{C}$ would result in a fairly well-defined subgrain network in almost all grains.

With increasing annealing time, more and more of the structure became strain-free by the initiation and growth of regular, equiaxed grains. The number of grains with serrated boundaries and shading decreased, finally to none, Figure 7 (d) and 7 (e).

\section{Observations pertaining directly to}

the initiation and early stages of

growth of strain-free grains

Note in Figure 7 (b) the number of very small grains which are si tuated along the grain boundaries and at triple points (along grain edges in three dimensions). Close examination showed most of these to be strain free. A somewhat more quantitative measure of the type of positions occupied by the strain-free grains was obtained by recording the number of strain-free grains which appeared in grain interiors, along grain boundaries and at triple points (grain edges in three dimensions) for a number of random areas in a series of specimens annealed at the same temperature. These data appear in Table 3 . For annealing times longer than 30 seconds, an appreciable fraction of the new grains had grown so large that classification was impossible. 


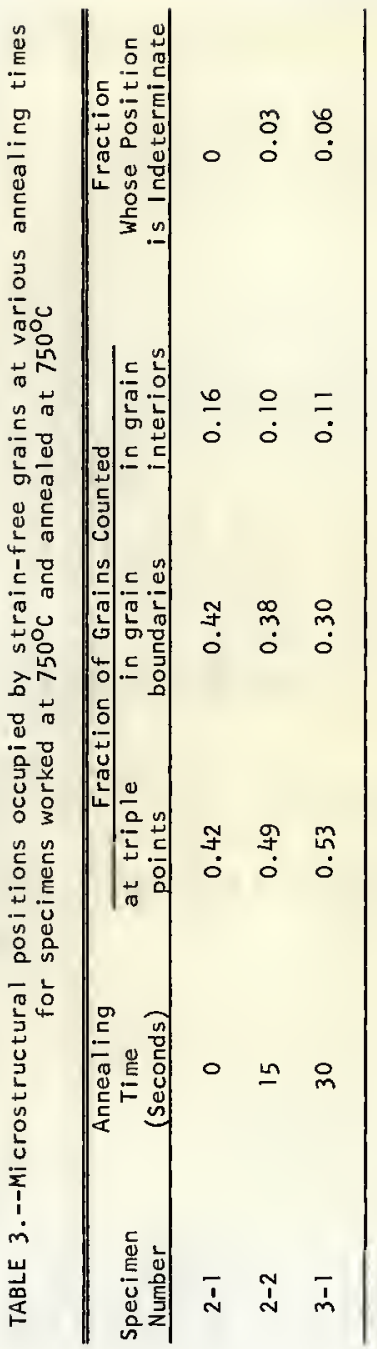


With increasing annealing time, the data apparently show a slight increase in the fraction of new grains which appeared at triple points, and slight decreases in the fractions which appeared along grain boundaries and in grain interiors. The changes were small.

The characteristic positions and appearance of the small, strainfree grains were documented by a series of photomicrographs taken at 1000X. These are included as Figure 8. Note the following features:

1. Although a number of "colonies" containing two, three or more new grains were observed, there was a larger number of grains apparently growing completely divorced from other new grains, Figure $8(a),(c)$, and (d).

2. Strain-free grains in some cases appeared to grow with equal ease into the strained grains on both sides of the boundary. Figure 8 (a), (c), and (e). In most cases, however, there appeared to be a preferential growth into one of the strained grains.

3. Small, strain-free grains initially had a rather irregular boundary, but exhibited roughly circular cross-sections. Wi th increasing annealing times, they acquired more regular boundaries, compare Figure 8 (a) and (c) with Figure 8 (e). There is one aspect of the boundaries possessed by the strain-free grains indicated in Figure 8 (a) and (b) (in particular) which should be given close attention. This aspect is the "scalloped" appearance of the boundaries, note especially the middle grain in Figure 8 (b). It is believed that this particular feature provides considerable insight into the mechanism by which strain-free grains originate and grow before impingement. This idea will be developed in a subsequent chapter.

4. A number of the strain-free grains appeared to have formed in graln boundary serrations, Figure $8(\mathrm{f})$, $(g)$, and $(h)$.

\section{Volume Fraction Strain-free Material}

Experimental values for the volume fraction of strain-free material were collected into Table 4 . These values also were plotted versus 


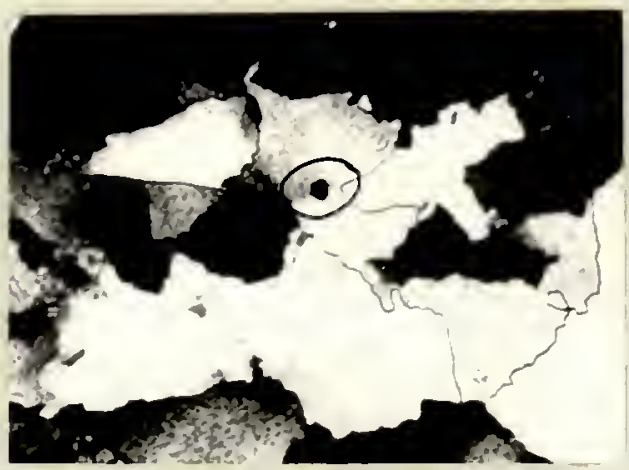

(a) Annealing temperature- $-750^{\circ} \mathrm{C}$; Annealing time--0 seconds. An approximately equiaxed, strain-free grain is growing at apparently almost equal velocities into both grains sharing the boundary in which it originated. Mean grain diameter is about 3 microns.

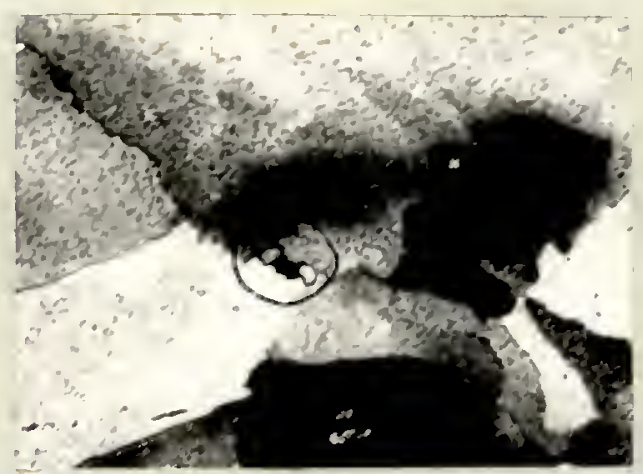

(b) Annealing temperature $--750^{\circ} \mathrm{C}$; Annealing time--0 seconds. Indicated is a group of contiguous, strain-free grains, one of which is growing along a grain edge and the other two in a grain boundary.

Fig. 8.--Photomicrographs chosen to illustrate the various positions occupied by small, strain-free grains. Polarized light. 1000X. 


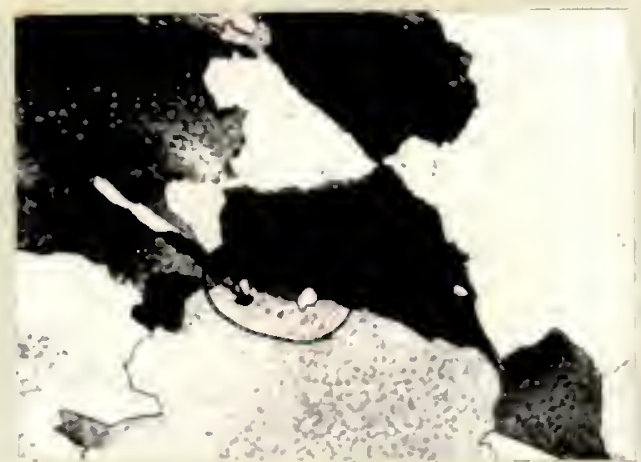

(c) Annealing temperature-- $750^{\circ} \mathrm{C}$; Annealing time--0 seconds. A group of contiguous strain-free grains is growing at or near a grain boundary. One of the group is apparently divorced from the boundary. Further along the same boundary is a single, somewhat larger strain-free grain similar to that in Figure 8 (a). Note the irregular boundary of both single grains.

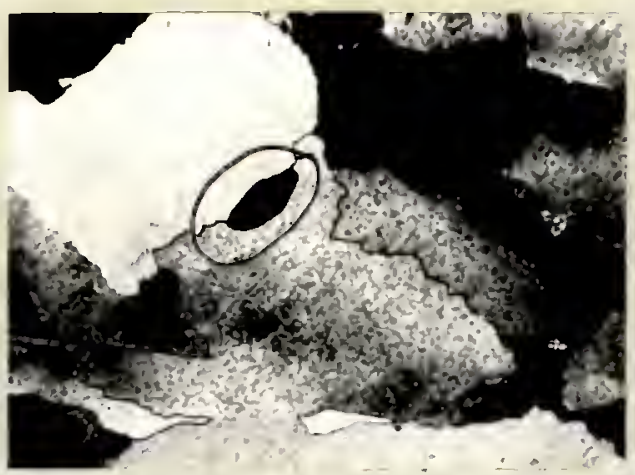

(d) Annealing temperature- $-750^{\circ} \mathrm{C}$; Annealing time--15 seconds. A rather large, elliptical strain-free grain is growing in a grain boundary. Note that this grain possesses a fairly regular boundary.

Fig. 8. -- Continued 


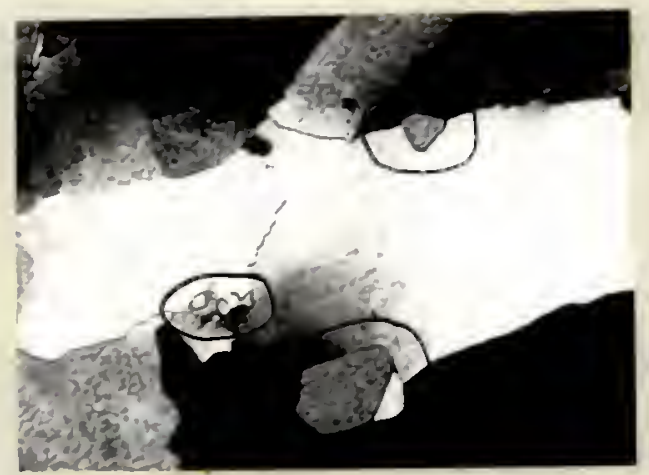

(e) Annealing temperature- $-750^{\circ} \mathrm{C}$; Annealing time--90 seconds. At lower center of the photo note the rather large, strain-free grain which has apparently grown to about an equal extent into both grains sharing the boundary. Compare this grain wi th the somewhat smaller grain in upper right of center which has grown preferentially into one of the strained grains.

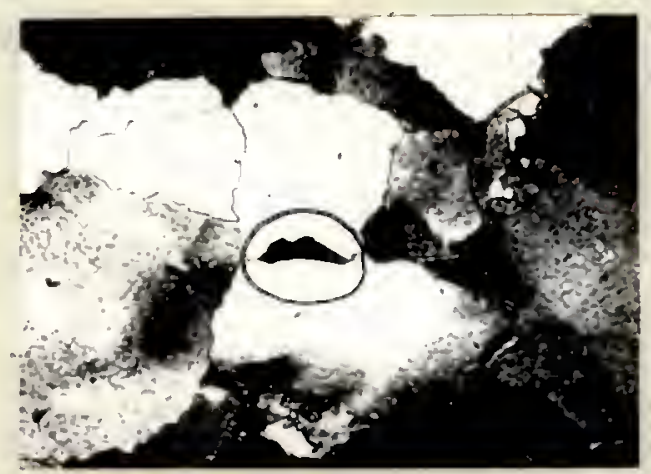

(f) Annealing temperature-- $750^{\circ} \mathrm{C}$; Annealing time-- 15 seconds. Note the rather large strain-free grain slightly to the left of center. It apparently occupies two serrations in the boundary between the strained grains. One of the strain-free grains growing in the boundary slightly to the right of center apparently has grown preferentially into the left-hand strained grain and the second new grain into the right-hand strained grain.

Fig. 8.-- Continued 


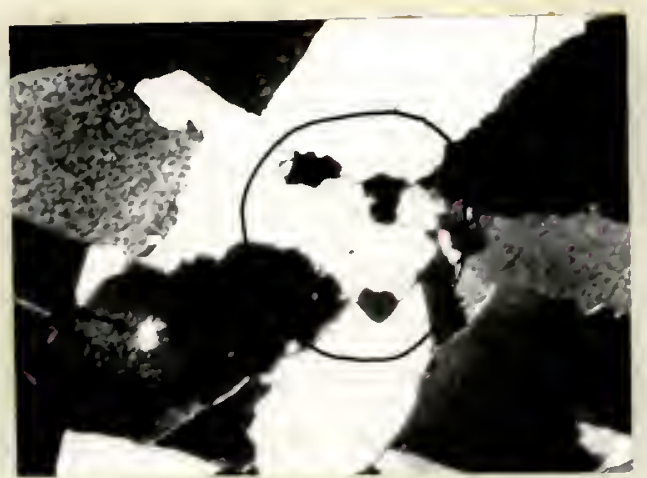

(g) Annealing temperature- $-750^{\circ} \mathrm{C}$; Annealing time--60 seconds. The two strain-free grains growing along the upper, serrated boundary apparently have experienced a preferred growth into the lower grain. The strain-free grain occupying the lower boundary has evidently grown into both strained grains.

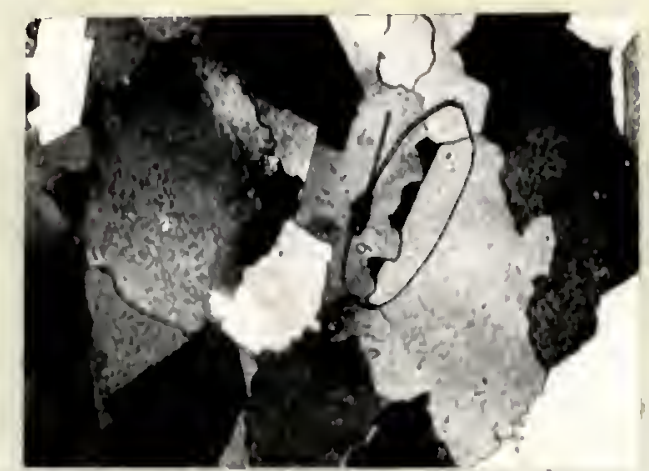

(h) Annealing temperature-- $700^{\circ} \mathrm{C}$; Annealing time--240 seconds. The group of three strain-free grains have apparently formed in serrations and are growing preferentially into the right-hand grain.

Fig. 8. - - - Continued 
TABLE 4.--Volume fraction strain-free material for specimens worked at $750^{\circ} \mathrm{C}$ and annealed at $750^{\circ} \mathrm{C}, 700^{\circ} \mathrm{C}$ and $670^{\circ} \mathrm{C}$

\begin{tabular}{|c|c|c|c|c|c|c|c|c|c|c|c|}
\hline \multicolumn{12}{|c|}{$\frac{\text { Annealing Temperature }}{700^{\circ} \mathrm{C}}$} \\
\hline $\begin{array}{l}\text { Specimen } \\
\text { Number }\end{array}$ & $\begin{array}{l}\text { Annealing } \\
\text { Time } \\
\text { (seconds) }\end{array}$ & $\begin{array}{c}\text { Volume } \\
\text { Fraction, } V_{V} \\
\end{array}$ & $\sigma_{V_{V}} *$ & $\begin{array}{l}\text { Specimen } \\
\text { Number }\end{array}$ & $\begin{array}{l}\text { Annealing } \\
\text { Time } \\
\text { (seconds) }\end{array}$ & $\begin{array}{c}\text { Volume } \\
\text { Fraction, } v_{V} \\
\end{array}$ & $\sigma_{v_{v} *}$ & $\begin{array}{l}\text { Specimen } \\
\text { Number }\end{array}$ & $\begin{array}{l}\text { Annealing } \\
\text { Time } \\
\text { (seconds) }\end{array}$ & $\begin{array}{c}\text { Volume } \\
\text { Fraction, } V_{V} \\
\end{array}$ & $\sigma_{V_{V}^{*}}^{*}$ \\
\hline $2-1$ & 0 & 0.006 & 0.002 & $2-1$ & 0 & 0.006 & 0.002 & $2-1$ & 0 & 0.006 & 0.002 \\
\hline $2-2$ & 15 & 0.015 & 0.005 & $7-5$ & 60 & 0.014 & 0.004 & $9-3$ & 480 & 0.029 & 0.003 \\
\hline $3-1$ & 30 & 0.031 & 0.005 & $6-2$ & 120 & 0.031 & 0.005 & $12-4$ & 960 & 0.089 & 0.008 \\
\hline $11-4$ & 45 & 0.053 & 0.005 & $6-4$ & 240 & 0.047 & 0.006 & $10-2$ & 1440 & 0.174 & 0.011 \\
\hline $3-4$ & 60 & 0.081 & 0.008 & $8-2$ & 360 & 0.140 & 0.008 & $9-4$ & 1920 & 0.273 & 0.012 \\
\hline $11-1$ & 75 & 0.16 & 0.01 & $7-1$ & 480 & 0.213 & 0.010 & $10-4$ & 2880 & 0.465 & 0.015 \\
\hline $1-3$ & 90 & 0.225 & 0.015 & $8-4$ & 600 & 0.48 & 0.01 & $10-3$ & 3840 & 0.745 & 0.015 \\
\hline $2-3$ & 120 & 0.415 & 0.015 & $7-2$ & 720 & 0.62 & 0.02 & $12-1$ & 4800 & 0.85 & 0.01 \\
\hline $1-2$ & 180 & 0.70 & 0.01 & $8-5$ & 960 & 0.78 & 0.01 & $12-2$ & 5760 & 0.90 & 0.01 \\
\hline $2-4$ & 240 & 0.94 & 0.01 & $8-3$ & 1440 & 0.90 & 0.01 & & & & \\
\hline $1-1$ & 300 & 0.980 & 0.004 & $8-1$ & 1920 & 0.986 & 0.004 & & & & \\
\hline $11-3$ & 360 & 0.984 & 0.001 & & & & & & & & \\
\hline $11-5$ & 720 & 0.991 & 0.003 & & & & & & & & \\
\hline $7-3$ & 1440 & 0.999 & 0.001 & & & & & & & & \\
\hline
\end{tabular}

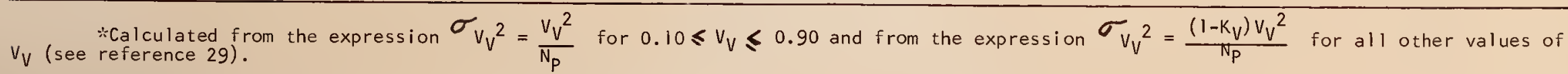


annealing time for each annealing temperature in Figures 9, 10, and 11 .

All three sets of data could be represented by sigmoidal curves. In only one or two cases were the actual data points more than $\pm \sigma_{V_{v}}$ from these curves. The curves differ from those commonly obtained in studies of recrystallization after cold deformation in two important respects:

1. A small fraction of strain-free material was present immediately after working. This material may have resulted either from small areas which experienced growth during working instead of becoming deformed, or from strain-free areas which originated and grew during the working process. This small amount of strain-free material present at the beginning of the annealing period removed all possibility of an incubation period such as is commonly observed in studies of annealing after cold working.

2. A small fraction of strained material persisted to very long annealing times. This is illustrated by Figure 9 for specimens annealed at $750^{\circ} \mathrm{C}$. This phenomenon also has been observed during a study of the recrystallization of high-purity iron (35). Other authors also have noted small islands of unrecrystallized material in a recrystallized matrix (36). The latter study showed that these areas were either very close in orientation or twin-related to the surrounding recrystallized material.

\section{Number of Strain-free Grains Per Unit Area and Per Unit Volume}

DeHoff (37) has derived an expression relating the three experimetally measurable quantities $V_{V}, N_{A}$, and $\left(N_{L}\right)_{N E}$ to the number of particles, or grains, per unit volume. The exact relationship is:

$N_{V}=\frac{V_{V}\left(N_{A}\right)^{3}}{\left(N_{L}\right)_{N E}} \cdot \frac{K_{2}^{3}}{8 K_{1}^{3} K_{3}}$ where $K_{1}, K_{2}$ and $K_{3}$ are shape factors and $\left(N_{L}\right)_{N E}$ is the number of grain boundary intersections per unit length of test line. Assuming that the strain-free grains were spheres, a rather good assumption for short annealing times, the ratio of shape factors was 


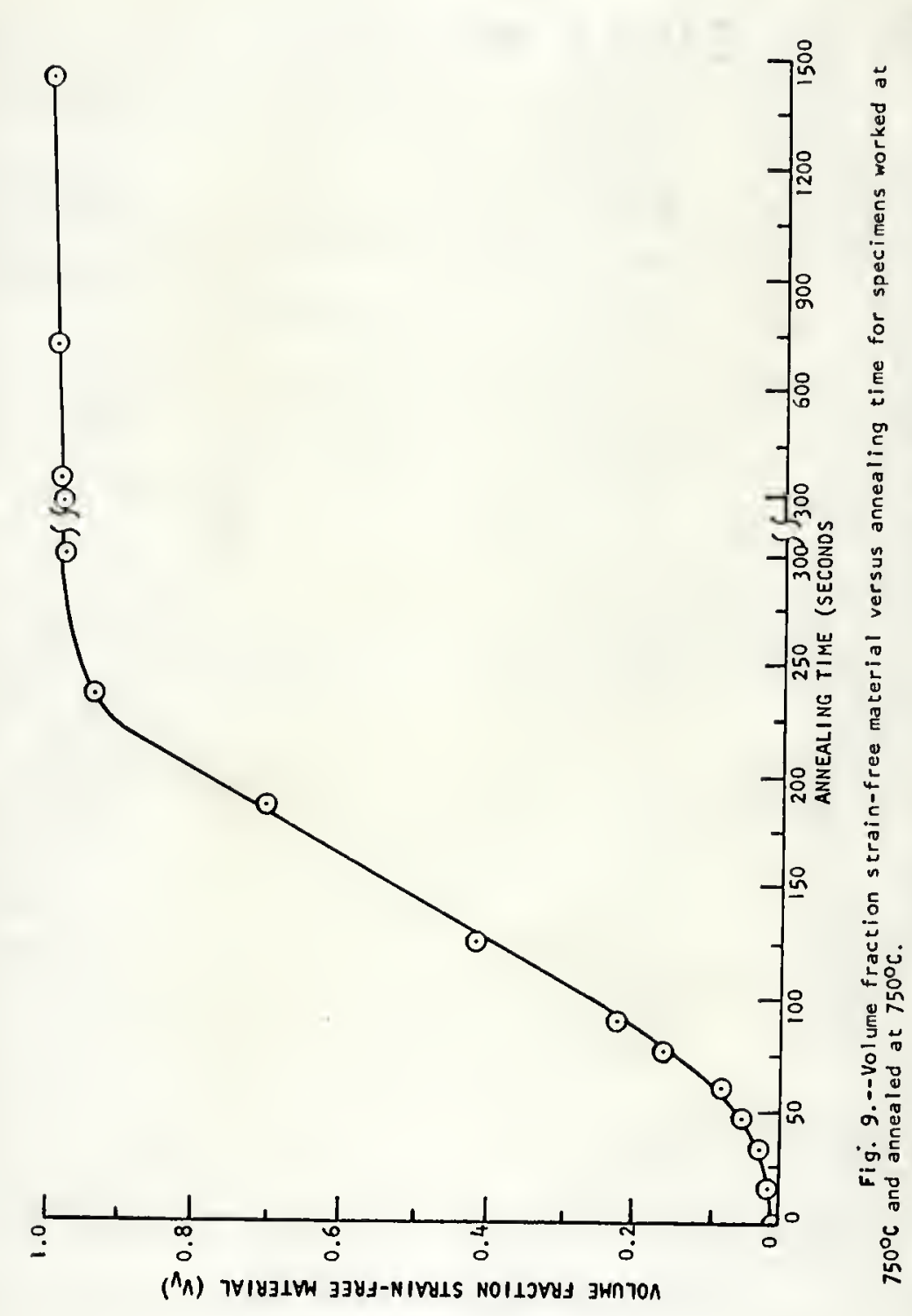




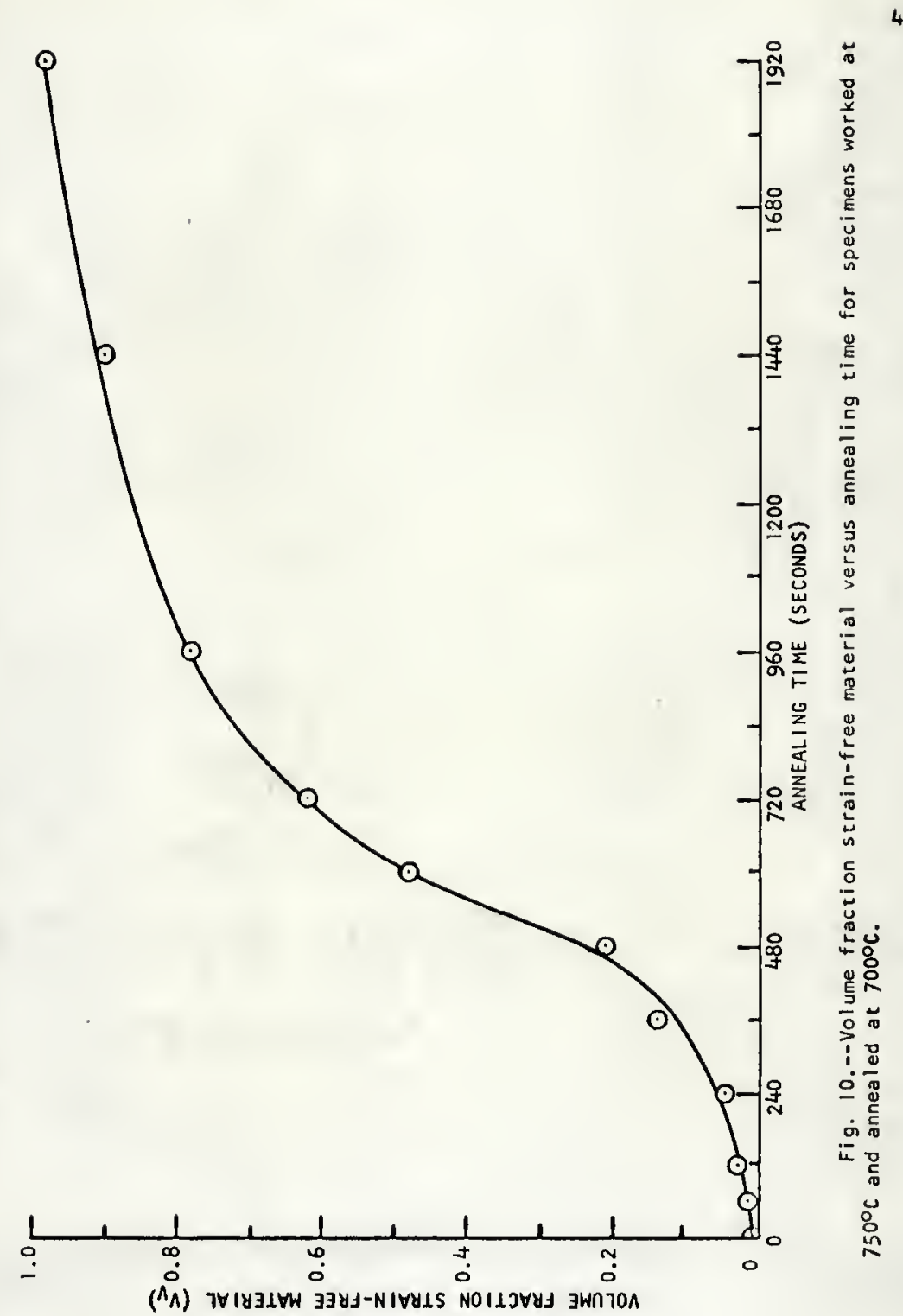




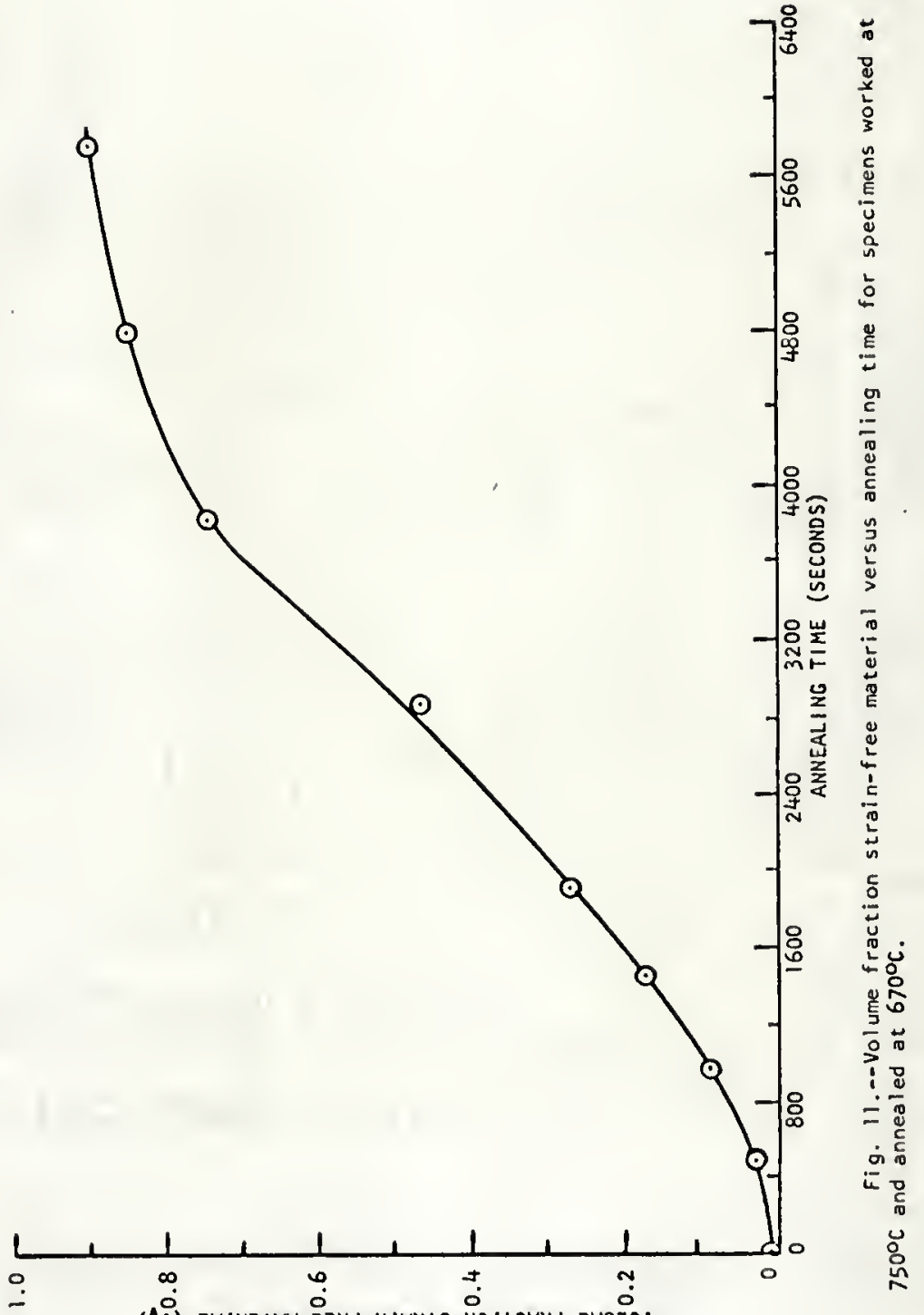

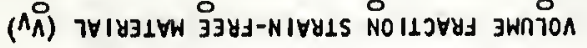


found to be 7.39. The major assumption of the derivation which resulted in the above equation was that the distribution of particle sizes is log normal. This assumption was tested by measuring over 400 chord lengths and calculating the actual particle size distribution according to the method of Spektor as described by Underwood (38). Procedure, calculations and results are described in Appendix $C$. It is sufficient to state here that the particle size distribution was close to log normal.

Corrected values for the number of strain-free grains per unit area are included in Table 5. These values, in conjunction wi th the appropriate values for $V_{V}$ and $\left(N_{L}\right)_{N E}$, were used to calculate the number of strain-free grains per unit volume. Table 6 contains the experimental values of $\left(N_{L}\right)_{N E}$.

Calculated values for the number of strain-free grains per unit volume are included in Table 5 and plotted in Figure 12. The data were subject to errors from several sources. There were not oniy the usual errors of a statistical nature but also those which stem from: (1) the assumptions used to derive the relationship between $N_{V}$ and the measurable quantities, and (2) those inherent in the approximate correction applied to the original experimental data. A rough calculation involving estimates of the errors from the above sources indicated that the calculated values of $N_{V}$ were most probably within $\pm 0.5 \times 10^{5} / \mathrm{mm}$ of the true value. These limits are indicated on the plots of Figure 12. In all but two cases the experimental points fall wi thin the probable error of the measurement.

The most important thing to note about Figure 12 is that there was no tendency at any temperature for the number of new grains per unit 
TABLE 5.--Number of strain-free grains per unit area and per unit volume for specimens worked at $750^{\circ} \mathrm{C}$ and annealed at $750^{\circ} \mathrm{C}$, $700^{\circ} \mathrm{C}$ and $670^{\circ} \mathrm{C}$

\begin{tabular}{|c|c|c|c|c|c|c|c|c|c|c|c|}
\hline & & & & & inealing Te & perature & & & & & \\
\hline & $750^{\circ} \mathrm{C}$ & & & & $700^{\circ} \mathrm{C}$ & & & & $670^{\circ} \mathrm{C}$ & & \\
\hline $\begin{array}{l}\text { Specimen } \\
\text { Number }\end{array}$ & $\begin{array}{c}\text { Annealing } \\
\text { Time } \\
\text { (seconds) }\end{array}$ & $\mathrm{N}_{\mathrm{A}} / \mathrm{mm}^{2}$ & $\begin{array}{l}N_{V}{ }_{\text {mm }}^{3} \\
\times \quad 10^{-5} \\
\end{array}$ & $\begin{array}{c}\text { Specimen } \\
\text { Number }\end{array}$ & $\begin{array}{c}\text { Annealing } \\
\text { Time } \\
\text { (seconds) }\end{array}$ & $\mathrm{N}^{\prime} / \mathrm{mm}^{2}$ & $\begin{array}{l}\mathrm{NV}_{\mathrm{V}} / \mathrm{mm}^{3} \\
\times \quad 10^{-5} \\
\end{array}$ & $\begin{array}{l}\text { Specimen } \\
\text { Number }\end{array}$ & $\begin{array}{l}\text { Annealing } \\
\text { Time } \\
\text { (seconds) }\end{array}$ & $\mathrm{N}_{\mathrm{A}} / \mathrm{mm}^{2}$ & $\begin{array}{l}\mathrm{NV}_{\mathrm{V}} \mathrm{mm}^{3} \\
\times \quad 10^{-5} \\
\end{array}$ \\
\hline $2-1$ & 0 & 425 & 1.3 & $2-1$ & 0 & 425 & 1.3 & $2-1$ & 0 & 425 & 1.3 \\
\hline $2-2$ & 15 & 490 & 1.4 & $7-5$ & 60 & 460 & 1.15 & $9-3$ & 480 & 550 & 1.1 \\
\hline $3-i$ & 30 & 480 & 1.15 & $6-2$ & 120 & 475 & 1.4 & $12-4$ & 960 & 600 & 0.8 \\
\hline $11-4$ & 45 & 485 & 1.0 & $6-4$ & 240 & 570 & 1.25 & $10-2$ & 1440 & 590 & 0.75 \\
\hline $3-4$ & 60 & 475 & 1.05 & $8-2$ & 360 & 595 & 1.0 & $9-4$ & 1920 & 580 & 0.60 \\
\hline $11-1$ & 75 & 630 & 0.8 & $7-1$ & 480 & 655 & 0.7 & $10-4$ & 2880 & 595 & 0.50 \\
\hline $1-3$ & 90 & 710 & 0.8 & $8-4$ & 600 & 790 & 0.6 & $10-3$ & 3840 & 670 & 0.60 \\
\hline $2-3$ & 120 & 800 & 0.7 & $7-2$ & 720 & 875 & 0.8 & $12-1$ & 4800 & 740 & 0.85 \\
\hline $1-2$ & 180 & 890 & 1.0 & $8-5$ & 960 & 885 & 1.0 & $12-2$ & 5760 & 690 & 1.3 \\
\hline $2-4$ & 240 & 925 & 1.2 & $8-3$ & 1440 & 900 & 1.2 & & & & \\
\hline $1-1$ & 300 & 880 & 1.9 & $8-1$ & 1920 & 920 & 1.2 & & & & \\
\hline $11-3$ & 360 & 795 & 1.9 & & & & & & & & \\
\hline $11-5$ & 720 & 740 & 1.5 & & & & & & & & \\
\hline $7-3$ & 1440 & 740 & 1.2 & & & & & & & & \\
\hline
\end{tabular}


TABLE 6.--Grain boundary intercepts (excluding twin boundary intercepts) for strain-free grains ( $\mathrm{N}_{L}$ ) $N E$, for specimens worked at $750^{\circ} \mathrm{C}$ and annealed at $750^{\circ} \mathrm{C}, 700^{\circ} \mathrm{C}$ and $670^{\circ} \mathrm{C}$

\begin{tabular}{|c|c|c|c|c|c|c|c|c|}
\hline & & & Anr & Iing Temp & ture & & 67000 & \\
\hline & $750^{\circ} \mathrm{C}$ & & & $700^{\circ} \mathrm{C}$ & & & $670^{\circ} \mathrm{C}$ & \\
\hline $\begin{array}{l}\text { Specimen } \\
\text { Number }\end{array}$ & $\begin{array}{l}\text { Annealing } \\
\text { Time } \\
\text { (seconds) }\end{array}$ & $\left(\mathrm{N}_{\mathrm{L}}\right)_{\mathrm{NE} / \mathrm{mm}}$ & $\begin{array}{c}\text { Specimen } \\
\text { Number }\end{array}$ & $\begin{array}{l}\text { Annealing } \\
\text { Time } \\
\text { (seconds) }\end{array}$ & $\left(\mathrm{N}_{\mathrm{L}}\right)_{\mathrm{NE}}{ }_{\mathrm{mm}}$ & $\begin{array}{l}\text { Speci men } \\
\text { Number }\end{array}$ & $\begin{array}{l}\text { Annealing } \\
\text { Time } \\
\text { (seconds) }\end{array}$ & $\left(\mathrm{N}_{\mathrm{L}}\right)_{\mathrm{NE}} /_{\mathrm{mm}}$ \\
\hline $2-1$ & 0 & 2.8 & $2-1$ & 0 & 2.8 & $2-1$ & 0 & 2.8 \\
\hline $2-2$ & 15 & 4.3 & $7-5$ & 50 & 4.2 & $9-3$ & 480 & 6.2 \\
\hline $3-1$ & 30 & 5.8 & $6-2$ & 120 & 5.4 & $12-4$ & 960 & 11.9 \\
\hline $11-4$ & 45 & 7.7 & $6-4$ & 240 & 7.9 & $10-2$ & 1440 & 15.3 \\
\hline $3-4$ & 60 & 8.4 & $8-2$ & 360 & 13.1 & $9-4$ & 1920 & 18.9 \\
\hline $11-1$ & 75 & 15.3 & $7-1$ & 480 & 18.6 & $10-4$ & 2880 & 25.1 \\
\hline $1-3$ & 90 & 19.6 & $8-4$ & 600 & 31.2 & $10-3$ & 3840 & 30.7 \\
\hline $2-3$ & 120 & 28.0 & $7-2$ & 720 & 33.5 & $12-1$ & 4800 & 31.5 \\
\hline $1-2$ & 180 & 33.4 & $8-5$ & 960 & 34.1 & $12-2$ & 5760 & 29.2 \\
\hline $2-4$ & 240 & 34.0 & $8-3$ & 1440 & 30.6 & & & \\
\hline $1-1$ & 300 & 29.6 & $8-1$ & 1920 & 31.7 & & & \\
\hline $11-3$ & 360 & 26.7 & & & & & & \\
\hline $11-5$ & 720 & 27.0 & & & & & & \\
\hline $7-3$ & 1440 & 27.8 & & & & & & \\
\hline
\end{tabular}



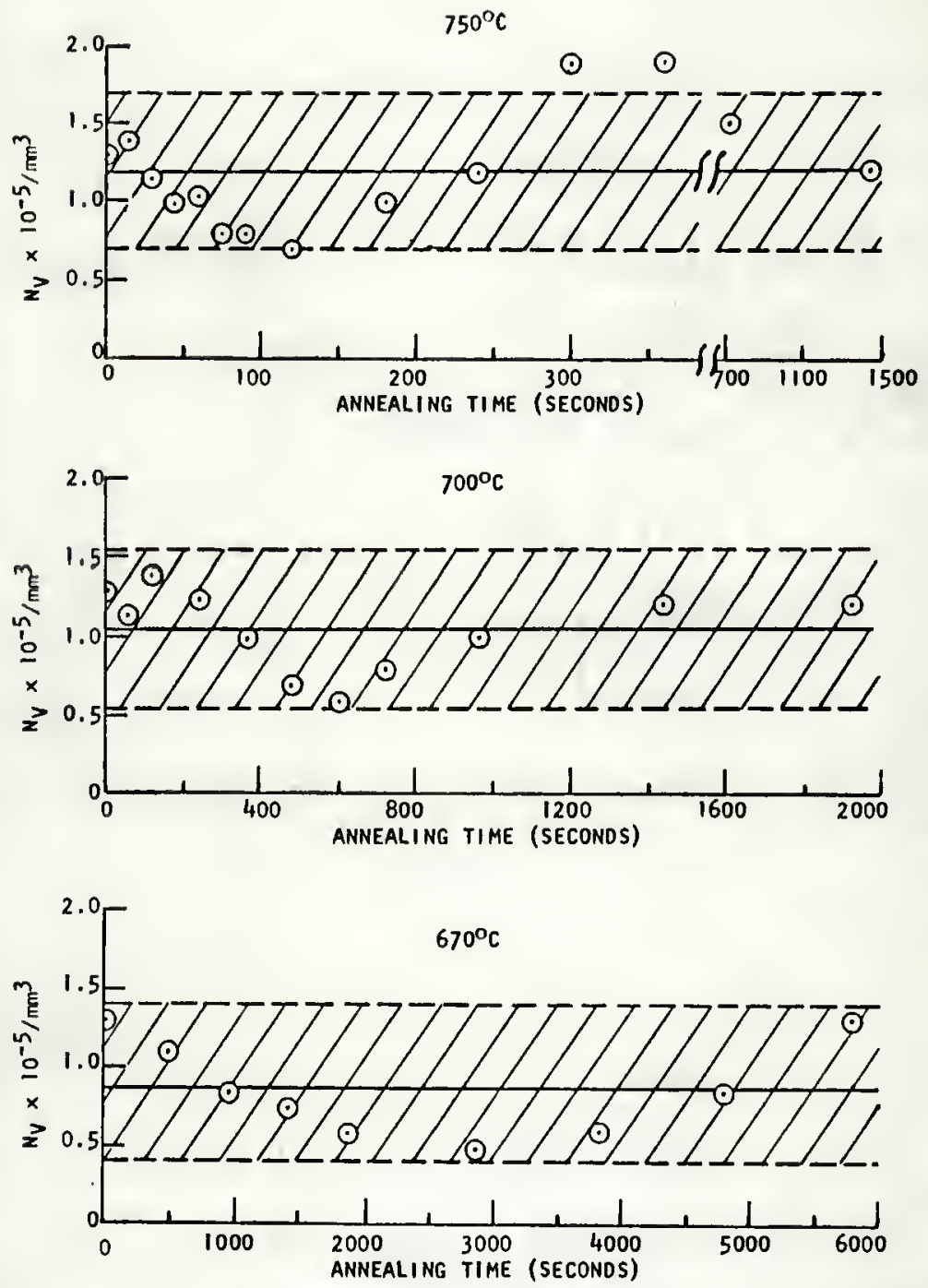

FIg. 12.--Number of strain-free grains per unlt volume versus annealing time for specimens worked at $750^{\circ} \mathrm{C}$ and annealed at $750^{\circ} \mathrm{C}$, $700^{\circ} \mathrm{C}$ and $670^{\circ} \mathrm{C}$. 
volume to increase with increasing annealing time until over 40 per cent of the structure was strain free. The decrease noted in the number of strain-free grains per unit volume for short annealing times at all temperatures is most likely due to the selective absorption of some grains by their neighbors, which neighbors possess a considerable growth advantage. For instance, it is unlikely that all three grains of the group indicated in Figure 8 (b) will survive and grow. At least one will probably disappear. Since impingement of grains growing in the same boundary occurs very early, one could expect a considerable number of the strainfree grains originally present to disappear by this mechanism. The increase in the number of strain-free grains per unit volume which begins at moderate annealing times for all temperatures is not so readily rationalized. There are two other changes which occur at the same annealing times: (1) experimental values of $\left(\mathrm{S}_{V}\right)_{0-N}$ begin to decrease, and (2) the slope of the $V_{V}$ versus annealing time plots begins to decrease. Both of these phenomena are probably associated wi th the beginning of rapid impingement of grains which originated in different boundaries or along different edges. It is at this point that the assumption of spherical, strain-free grains could be expected to result in a serious error.

A comparison of ali three plots revealed a slight tendency for the number of new grains per unit volume to decrease with decreasing annealing temperature. The average values indicated in figure 12 are as follows: $1.2 \times 10^{5} / \mathrm{mm}^{3}$ at $750^{\circ} \mathrm{C}, 1.05 \times 10^{5} / \mathrm{mm}^{3}$ at $700^{\circ} \mathrm{C}$ and $0.87 \times$ $105 / \mathrm{mm}^{3}$ at $670^{\circ} \mathrm{C}$. However, an analysis based on Student's " $t$ " test indicated that the three averages are not significantly different. 


\section{Growth Rates}

The two methods used to calculate growth rates of the strain-free grains yielded qui te different results. These are summarized in the following table.

TABLE 7.--Growth rates for annealing temperatures of $750^{\circ} \mathrm{C}$, $700^{\circ} \mathrm{C}$ and $670^{\circ} \mathrm{C}$

\begin{tabular}{|c|c|c|}
\hline \multirow[b]{2}{*}{$\begin{array}{l}\text { Anneal ing } \\
\text { Temp. }\left({ }^{\circ} \mathrm{C}\right)\end{array}$} & \multicolumn{2}{|c|}{ Growth Rates, $\mathrm{G}(\mathrm{mm} / \mathrm{sec})$} \\
\hline & $\begin{array}{c}\text { Calculated from Maximum } \\
\text { Intercept Data }\end{array}$ & $\begin{array}{l}\text { Calculated from } \\
\text { the Expression } \\
\text { G } \cdot\left(S_{V}\right)_{(-N}= \\
d V_{V} / d t(26)\end{array}$ \\
\hline 750 & $1.0 \times 10^{-3}$ & $1.4 \times 10^{-4}$ \\
\hline 700 & $2.3 \times 10^{-4}$ & $2.6 \times 10^{-5}$ \\
\hline 670 & $6.1 \times 10^{-5}$ & $6.4 \times 10^{-6}$ \\
\hline
\end{tabular}

*These values are averages of the data given in Table 9.

The actual measurements of maximum intercept appear in Table 8 and are plotted versus annealing time in Figure 13. Values listed above are the slopes of these curves.

Data necessary for the calculation of growth rates from the expression $G \cdot\left(S_{V}\right)_{0-N}=d V_{V} / d t$ are readily avai lable. Slopes measured from the curves of Figures 9,10 and 11 at the appropriate times gave directly values for $d V_{V} / d t$. Table 11 contains values for $\left(S_{V}\right)_{O-N}$ calculated from the expression $\left(s_{V}\right)_{O-N}=\left(s_{V}\right)_{O l d}+\left(s_{V}\right)_{n e w}-\left(s_{V}\right)_{\text {total }}$ as explained in a subsequent section. These values are plotted in Figures 14 , 15 and 16. Values of $\left(\mathrm{S}_{V}\right)_{\mathrm{O}-\mathrm{N}}$ for the calculation of growth rates were obtained from the smooth curve drawn through the experimental points. The growth rates thus calculated have been collected into Table 9 . 
TABLE 8. - Maximum intercept of largest unimpinged grain for specimens worked at $750^{\circ} \mathrm{C}$ and annealed at $750^{\circ} \mathrm{C}$, $700^{\circ} \mathrm{C}$ and $670^{\circ} \mathrm{C}$

\begin{tabular}{|c|c|c|c|c|c|c|c|c|}
\hline \multicolumn{9}{|c|}{ Annealing Temperature } \\
\hline \multicolumn{3}{|c|}{$\frac{750^{\circ} \mathrm{C}}{\text { Annealing }}$} & \multicolumn{3}{|c|}{$700^{\circ} \mathrm{C}$} & \multicolumn{3}{|c|}{$670^{\circ} \mathrm{C}$} \\
\hline $\begin{array}{l}\text { Specimen } \\
\text { Number }\end{array}$ & $\begin{array}{l}\text { Annealing } \\
\text { Time } \\
\text { (seconds) }\end{array}$ & $\begin{array}{c}\text { Di amę ter } \\
\left(\times 10^{2} \mathrm{~mm}\right) \\
\end{array}$ & $\begin{array}{c}\text { Specimen } \\
\text { Number }\end{array}$ & $\begin{array}{l}\text { Annealing } \\
\text { Time } \\
\text { (seconds) }\end{array}$ & $\begin{array}{c}\text { Diameter } \\
\left(\times \quad 10^{2} \mathrm{~mm}\right) \\
\end{array}$ & $\begin{array}{l}\text { Specimen } \\
\text { Number }\end{array}$ & $\begin{array}{l}\text { Annealing } \\
\text { Time } \\
\text { (seconds) }\end{array}$ & $\begin{array}{c}\text { Di ame ter } \\
\left(\times 10^{2} \mathrm{~mm}\right) \\
\end{array}$ \\
\hline $2-1$ & 0 & 1.2 & $2-1$ & 0 & 1.2 & $2-1$ & 0 & 1.2 \\
\hline $2-2$ & 15 & 2.2 & $7-5$ & 60 & 2.4 & $9-3$ & 480 & 3.9 \\
\hline $3-1$ & 30 & 4.2 & $6-2$ & 120 & 3.7 & $12-4$ & 960 & 7.2 \\
\hline $11-4$ & 45 & 6.2 & $6-4$ & 240 & 6.5 & $10-2$ & 1440 & 10.0 \\
\hline $3-4$ & 60 & 7.1 & $8-2$ & 360 & 9.4 & & & \\
\hline $11-1$ & 75 & 8.6 & & & & & & \\
\hline
\end{tabular}



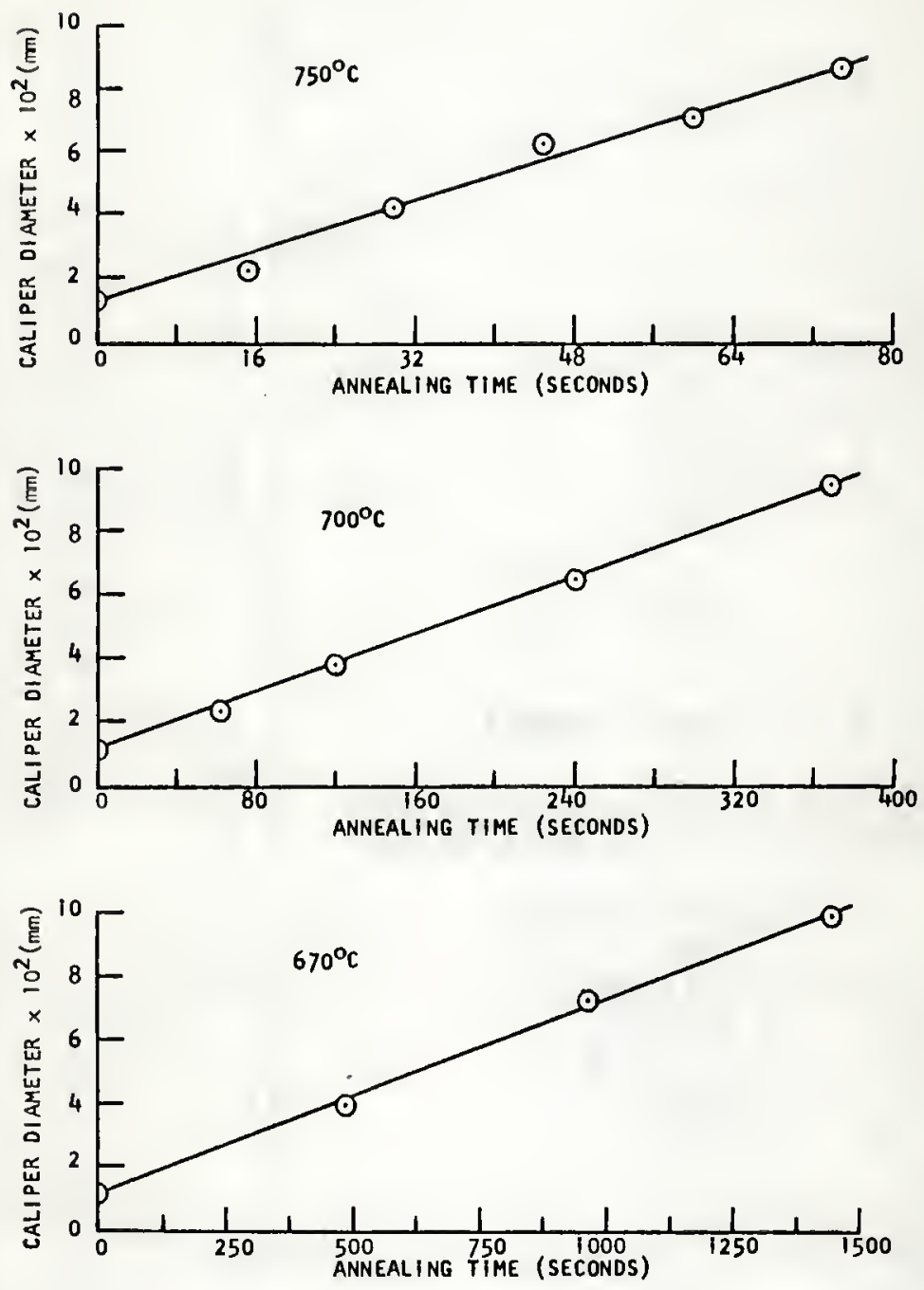

Fig. 13.--Maximum intercept of largest unimpinged grain versus annealing time for specimens worked at $750^{\circ} \mathrm{C}$ and annealed at $750^{\circ} \mathrm{C}, 700^{\circ} \mathrm{C}$ and $670^{\circ} \mathrm{C}$. 


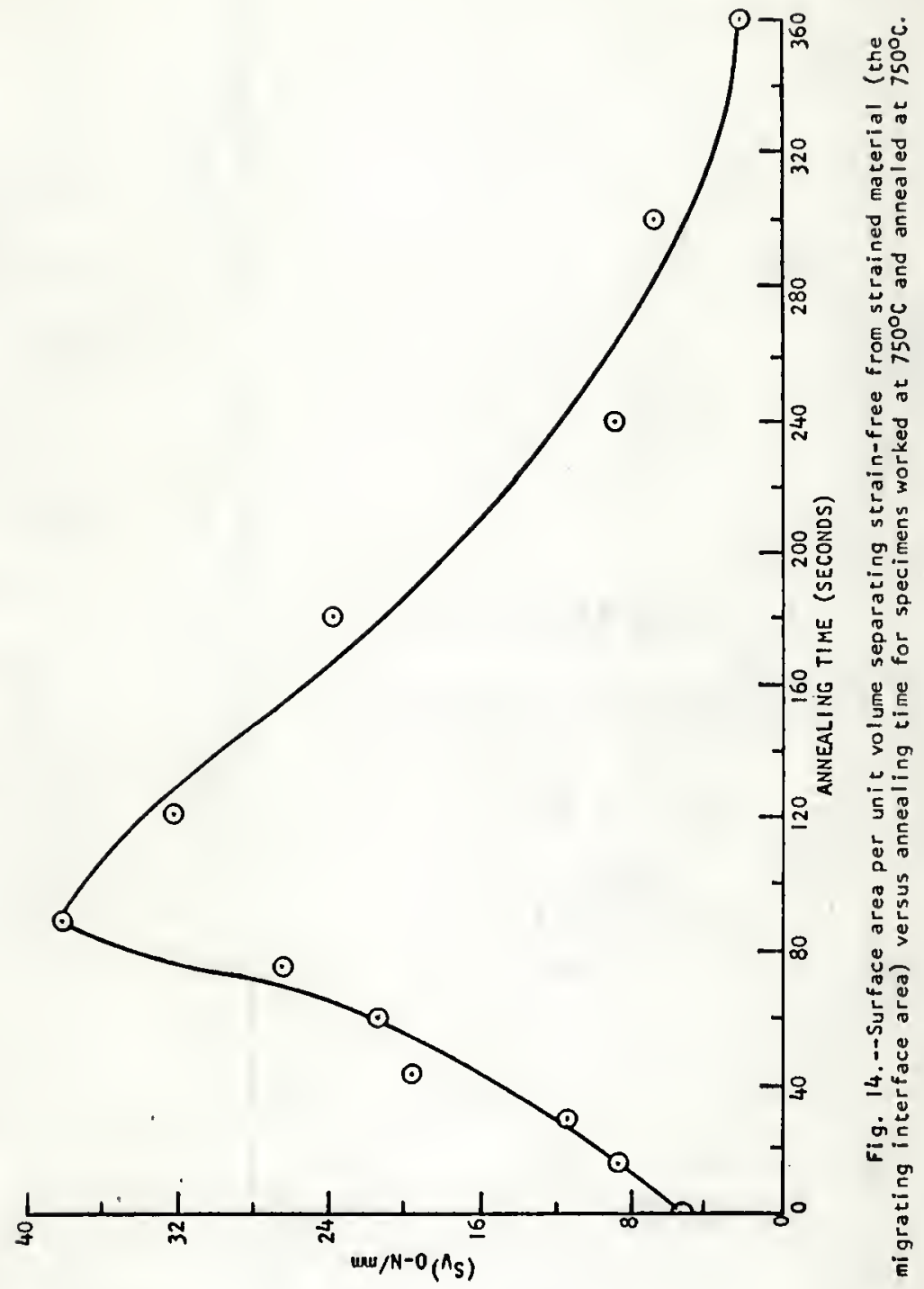




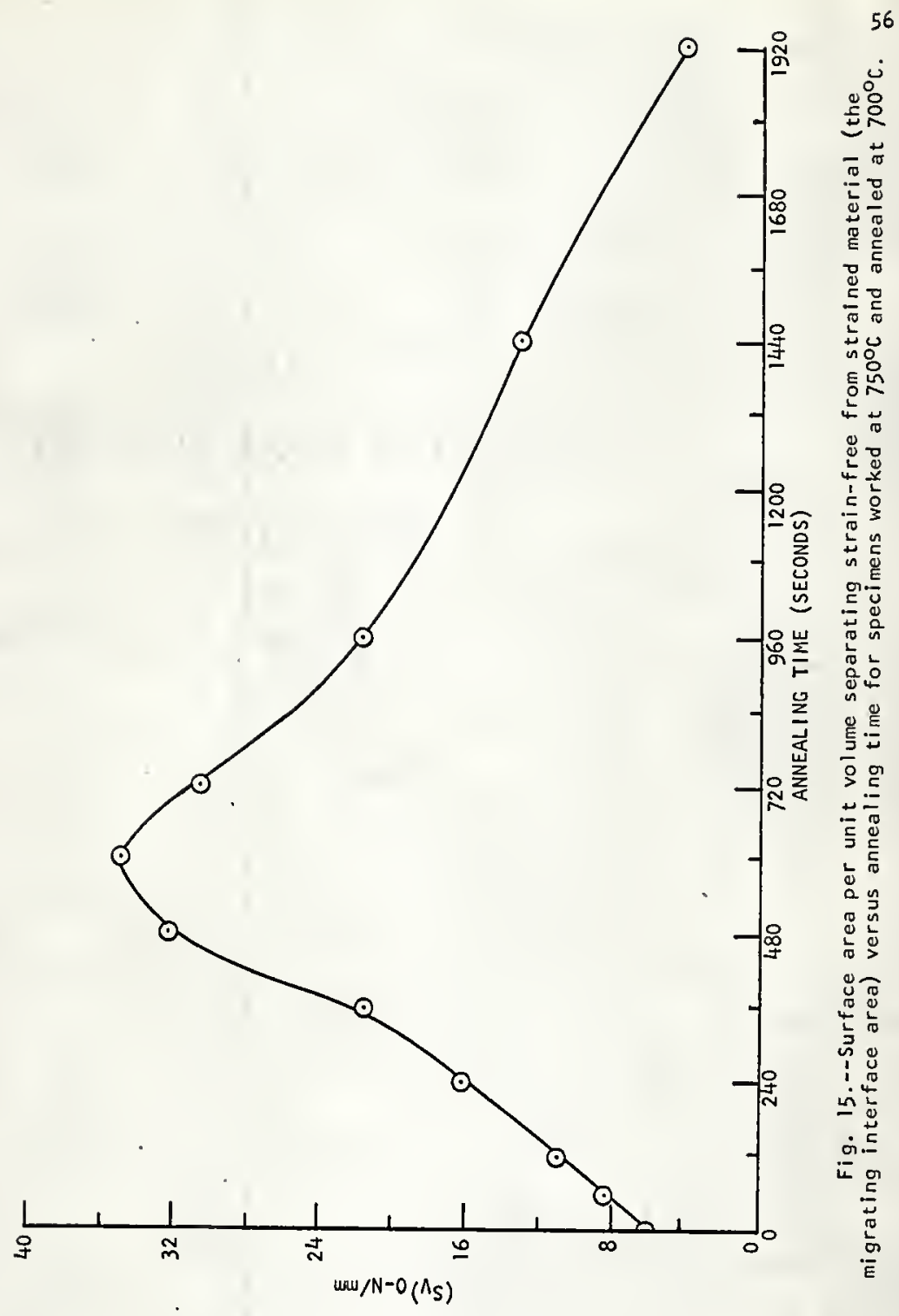



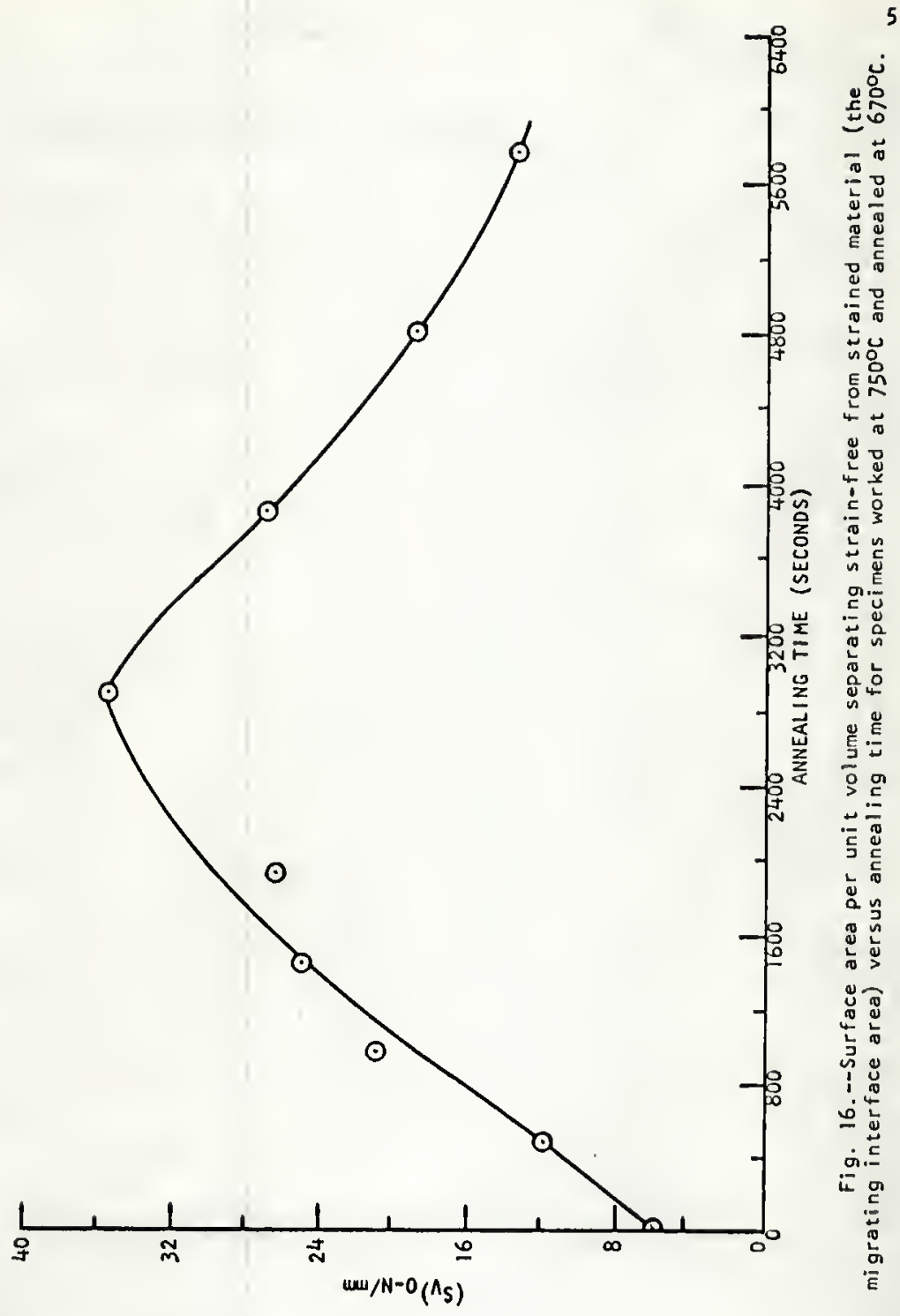
TABLE 9.--Growth rates calculated from the expression $G \cdot\left(S_{V}\right)_{0-N}=d V_{V} / d t$ for specimens worked at $750^{\circ} \mathrm{C}$ and annealed at $750^{\circ} \mathrm{C}, 700^{\circ} \mathrm{C}$ and $670^{\circ} \mathrm{C}$

\begin{tabular}{|c|c|c|c|c|c|c|c|c|}
\hline \multicolumn{9}{|c|}{ Annealing Temperature } \\
\hline \multicolumn{3}{|c|}{$750^{\circ} \mathrm{C}$} & \multicolumn{3}{|c|}{$700^{\circ} \mathrm{C}$} & \multicolumn{3}{|c|}{$670^{\circ} \mathrm{C}$} \\
\hline $\begin{array}{l}\text { Specimen } \\
\text { Number }\end{array}$ & $\begin{array}{c}\text { Annealing } \\
\text { Time } \\
\text { (seconds) }\end{array}$ & $\begin{array}{l}\mathrm{G} \times 10^{4} \\
(\mathrm{~mm} / \mathrm{sec})\end{array}$ & $\begin{array}{l}\text { Specimen } \\
\text { Number }\end{array}$ & $\begin{array}{l}\text { Annealing } \\
\text { Time } \\
\text { (seconds) }\end{array}$ & $\begin{array}{l}G \times 10^{5} \\
(\mathrm{~mm} / \mathrm{sec})\end{array}$ & $\begin{array}{l}\text { Specimen } \\
\text { Number }\end{array}$ & $\begin{array}{l}\text { Annealing } \\
\text { Time } \\
\text { (seconds) }\end{array}$ & $\begin{array}{l}G \times 10^{6} \\
(\mathrm{~mm} / \mathrm{sec})\end{array}$ \\
\hline $2-1$ & 0 & - & $2-1$ & 0 & - & $2-1$ & 0 & - \\
\hline $2-2$ & 15 & 0.9 & $7-5$ & 60 & 2.1 & $9-3$ & 480 & 5.8 \\
\hline $3-1$ & 30 & 1.2 & $6-2$ & 120 & 2.0 & $12-4$ & $96 \theta$ & 9.9 \\
\hline $11-4$ & 45 & 1.2 & $6-4$ & 240 & 2.4 & $10-2$ & 1440 & 7.8 \\
\hline $3-4$ & 60 & 1.3 & $8-2$ & 360 & 2.8 & $9-4$ & 1920 & 6.6 \\
\hline $11-1$ & 75 & 1.4 & $7-1$ & 480 & 4.0 & $10-4$ & 2880 & 7.2 \\
\hline $1-3$ & 90 & 1.5 & $8-4$ & 600 & 4.2 & $10-3$ & 3840 & 7.2 \\
\hline $2-3$ & 120 & 1.5 & $7-2$ & 720 & 2.9 & $12-1$ & 4800 & 3.5 \\
\hline $1-2$ & 180 & 2.2 & $8-5$ & 960 & 1.4 & $12-2$ & 5760 & 3.3 \\
\hline $2-4$ & 240 & 1.7 & $8-3$ & 1440 & 1.6 & & & \\
\hline $1-1$ & 300 & - & $8-1$ & 1920 & - & & & \\
\hline $11-3$ & 360 & - & & & & & & \\
\hline $11-5$ & 720 & - & & & & & & \\
\hline $7-3$ & 1440 & - & & & & & & \\
\hline
\end{tabular}


Neglecting the values calculated for zero time and those calculated for long annealing times, one notes that the calculated values for a particular temperature vary (with one exception) only by a factor of between two and three. In the absence of any systematic variation, one can assume that the data indicated a constant growth rate for each temperature. The calculation of growth rates from area or length measurements performed on a metallographic surface has a long history. Measurements of this type were made as early as 1930 (39) and as recently as 1964 (35). Although the descriptions of the actual procedures are often less than precise, it can be inferred that either a maximum revealed diameter or area was measured, usually the latter. The objections to these procedures are widely realized, but should probably be repeated.

One must first consider the probability that a random plane wi 11 intersect the largest strain-free grain to reveal a maximum area. This probability is, of course, close to zero. If this unlikely event were to occur in each of a series of specimens, one must still face the problem that growth rates have been shown to vary widely from grain to grain. The result, therefore, is the growth rate of a grain which may be nei ther the first formed nor the fastest growing. The only rational appears to be that results plotted versus annealing time yield a monotonic curve, usually li near.

In the present study initiation of new grains was complete at zero time. Growth rates calculated from maximum intercept measurements performed should therefore approach those of the fastest growing grain, subject to the probability considerations outlined above. In this respect, it should be noted that measurement of a maximum intercept will 
approach more closely the maximum growth rate than maximum area measurements. This is so since there are an infinite number of planes which contain the maximum intercept, but only one which contains the plane of maximum area.

The major reason for performing the maximum intercept measurement was to provide comparisons with the growth rates calculated from the expression $G \cdot\left(S_{V}\right)_{0-N}=d V_{V} / d t$. This'method is free of the above objections and yields an average rate for all interfaces between the strained material and strain-free grains. The results are therefore much more satisfactory and satisfying than those from the maximum intercept measurements

\section{Surface Area Measurements}

Three basic surface area measurements were made on all specimens. They were:

1. Total surface area per unit volume, $\left(S_{V}\right)_{\text {total }}$.

2. Surface area per unit volume possessed by the new, unstrained grains, $\left(S_{V}\right)_{\text {new' }} i . e$. , the grain boundary area which had undeformed material on at least one side of the boundary.

3. Surface area per unit volume possessed by the old, strained grains, $\left(s_{V}\right)_{o l d}$, i.e., the grain boundary area which had deformed material on at least one side of the boundary.

These measurements were described in greater detail in a previous section. Since subgrain boundaries were not revealed by the etching procedure used, measurements could include only grain and twin boundaries. Data obtained are included as Table 10 . Values for $\left(S_{V}\right)_{\text {total }}$ have been plotted versus annealing time for each annealing temperature, Figures 17, 18, and 19. In 


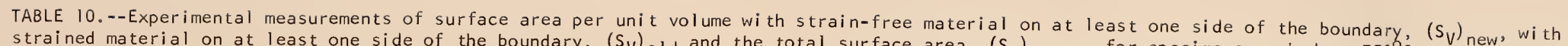

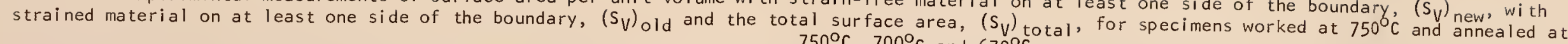
$750^{\circ} \mathrm{C}, 700^{\circ} \mathrm{C}$ and $670^{\circ} \mathrm{C}$

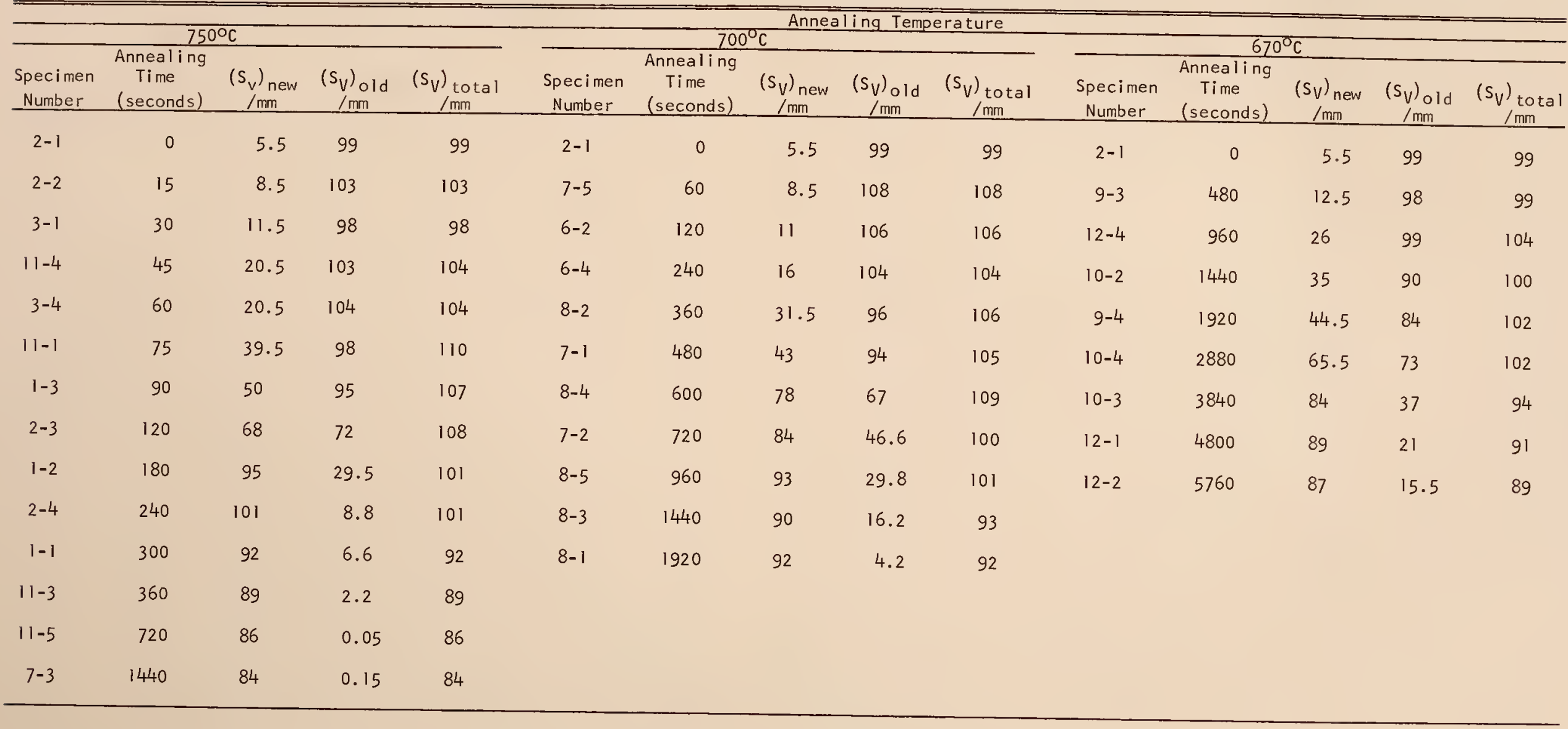




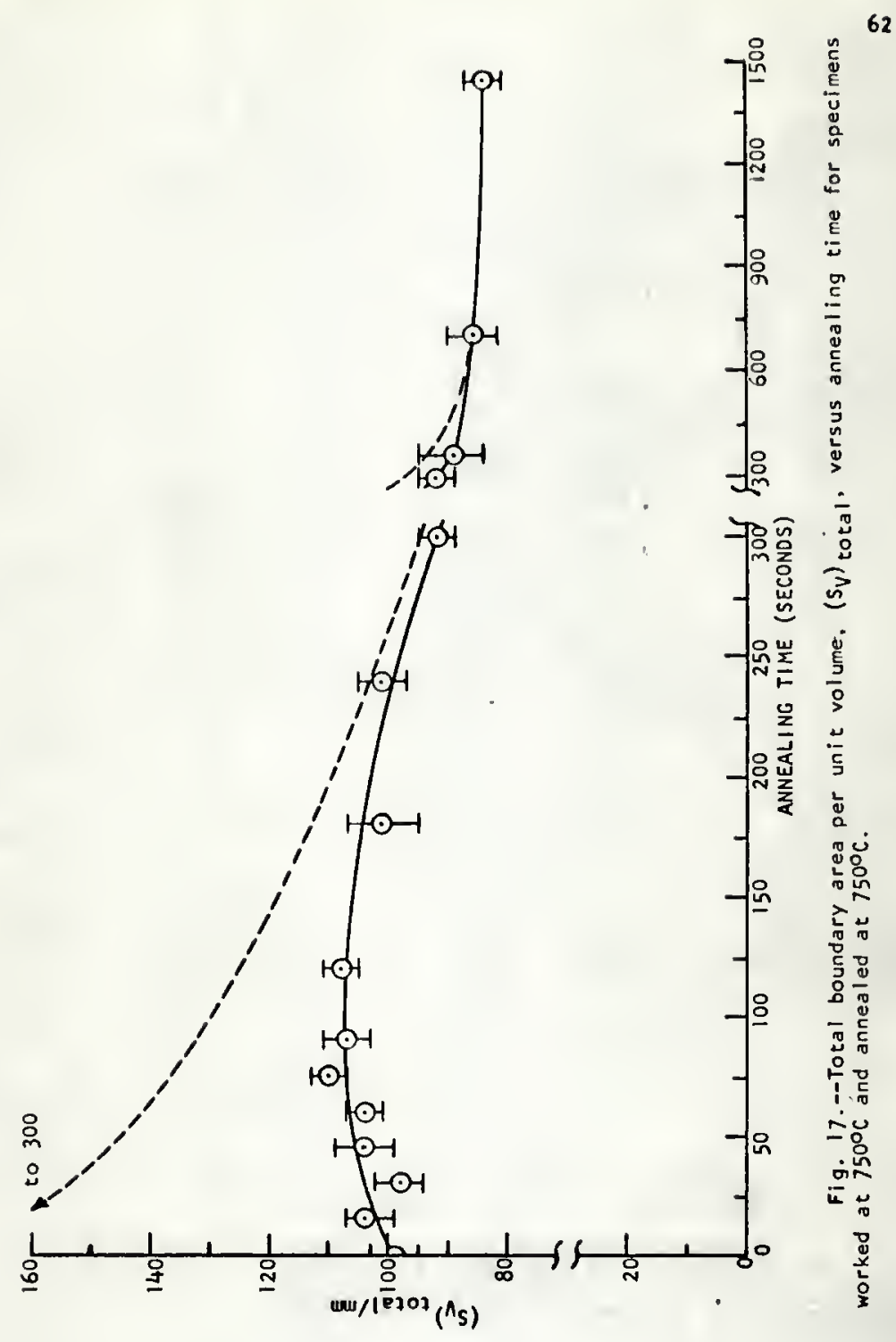




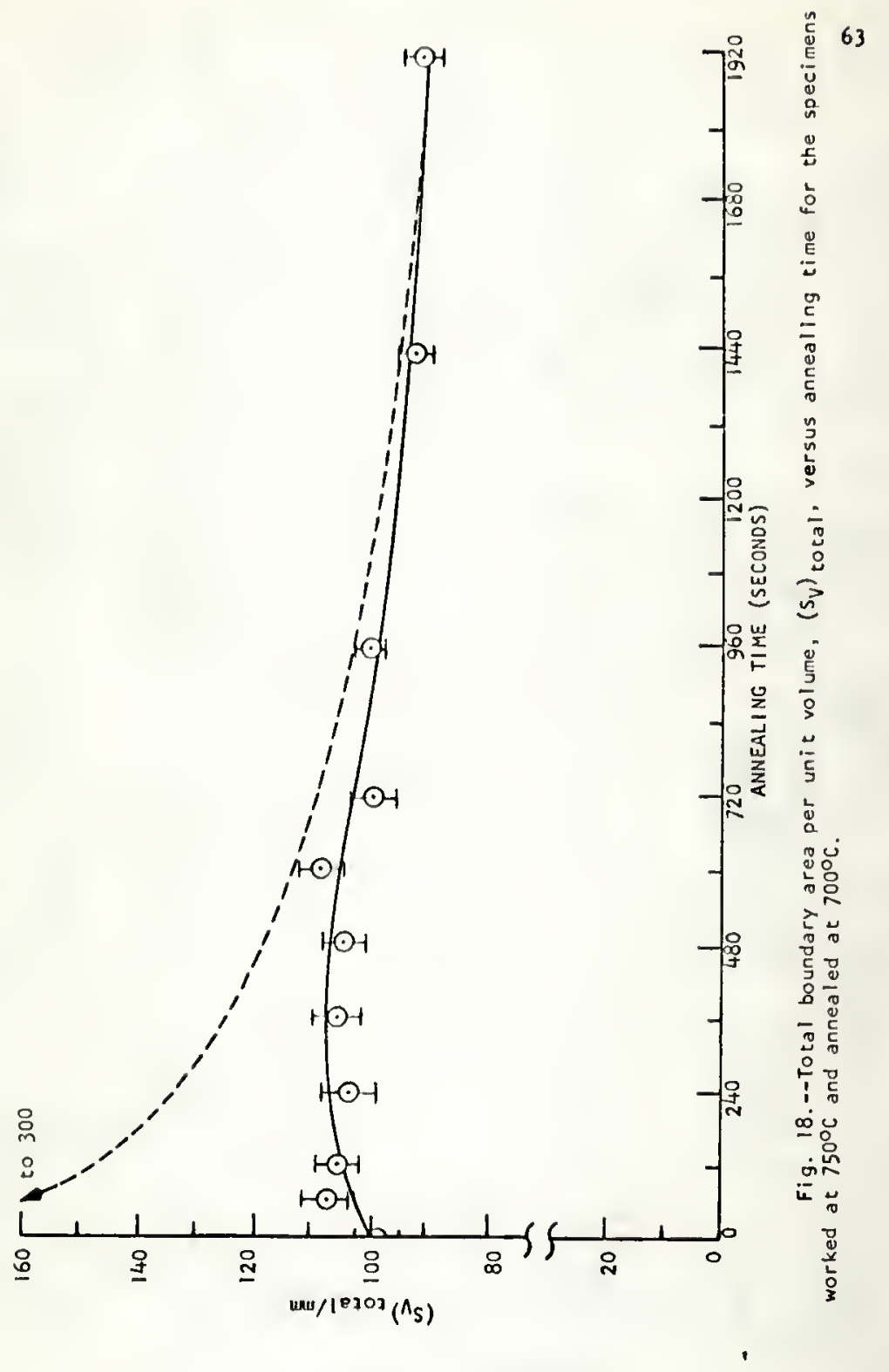




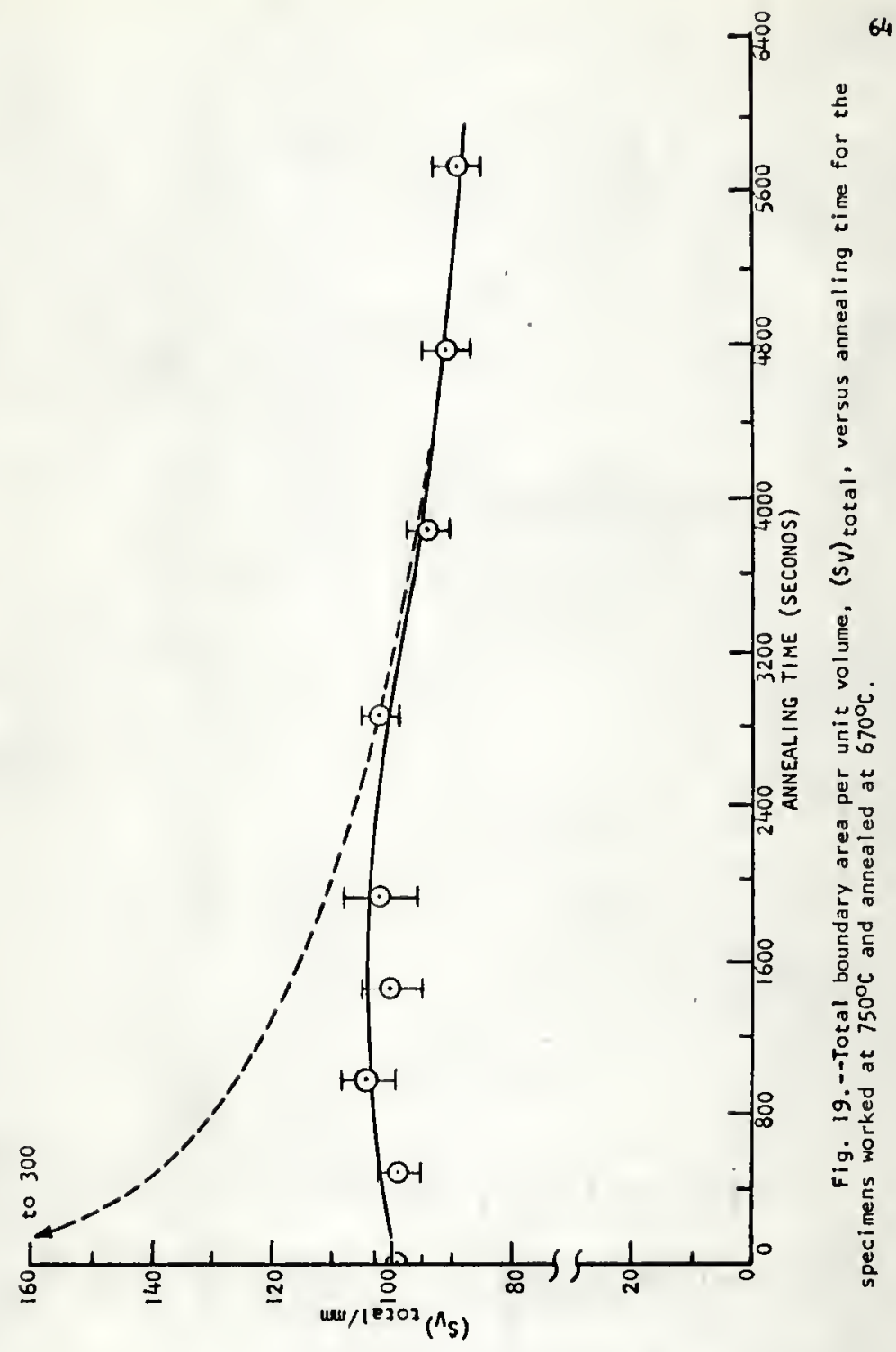


all of the above data no effort was made to separate twin boundaries from grain boundaries. Thus, all surface area values represent the sum of the grain boundary area and the twin boundary area. Twin boundaries not only form a part of the total boundary network but also one could argue that since twin boundaries evidently serrate and distort as readily as grain boundaries during working there is no real difference between them. They, thus, may be considered as high-angle boundaries.

Experimental measurements of $\left(s_{V}\right)_{o l d},\left(s_{V}\right)_{\text {new }}$ and $\left(s_{V}\right)_{\text {total }}$ permitted the calculation of three more significant types of surface area:

1. $\left(\mathrm{S}_{V}\right)_{0-0}$, the grain boundary area per unit volume separating deformed grains.

2. $\left(S_{V}\right)_{N-N}$, the grain boundary area per unit volume separating strain-free grains.

3. $\left(\mathrm{S}_{\mathrm{V}}\right)_{0-\mathrm{N}}$, the grain boundary area per unit volume wi th deformed material on only one side of the boundary.

It is obvious from the above definitions that:

$$
\begin{aligned}
& \left(s_{v}\right)_{\text {total }}=\left(s_{V}\right)_{0-O}+\left(s_{V}\right)_{N-N}+\left(s_{V}\right)_{0-N} \\
& \left(s_{v}\right)_{\text {old }}=\left(s_{v}\right)_{0-0}+\left(s_{v}\right)_{0-N} \\
& \left(s_{v}\right)_{\text {new }}=\left(s_{v}\right)_{N-N}+\left(s_{V}\right)_{0-N}
\end{aligned}
$$

From these three expressions, one finds that:

$$
\begin{aligned}
& \left(s_{V}\right)_{N-N}=\left(s_{V}\right)_{\text {total }}-\left(s_{V}\right)_{\text {old }} \\
& \left(s_{V}\right)_{0-0}=\left(s_{V}\right)_{\text {total }}-\left(s_{V}\right)_{\text {new }} \\
& \left(s_{V}\right)_{0-N}=\left(s_{v}\right)_{\text {old }}+\left(s_{v}\right)_{\text {new }}-\left(s_{V}\right)_{\text {total }}
\end{aligned}
$$

Values of $\left(S_{V}\right)_{0-0},\left(S_{V}\right)_{N-N}$, and $\left(S_{V}\right)_{0-N}$ calculated from the above equations are included in Table 11. Values obtained for all three types of 


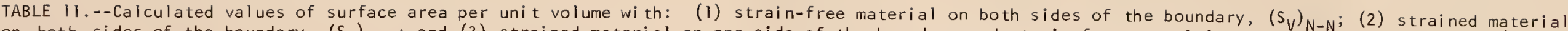

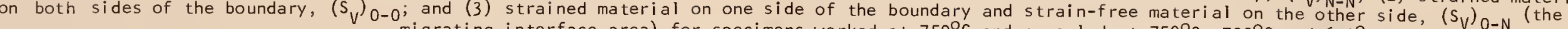
migrating interface area) for specimens worked at $750^{\circ} \mathrm{C}$ and annealed at $750^{\circ} \mathrm{C}, 700^{\circ} \mathrm{C}$ and $670^{\circ} \mathrm{C}$

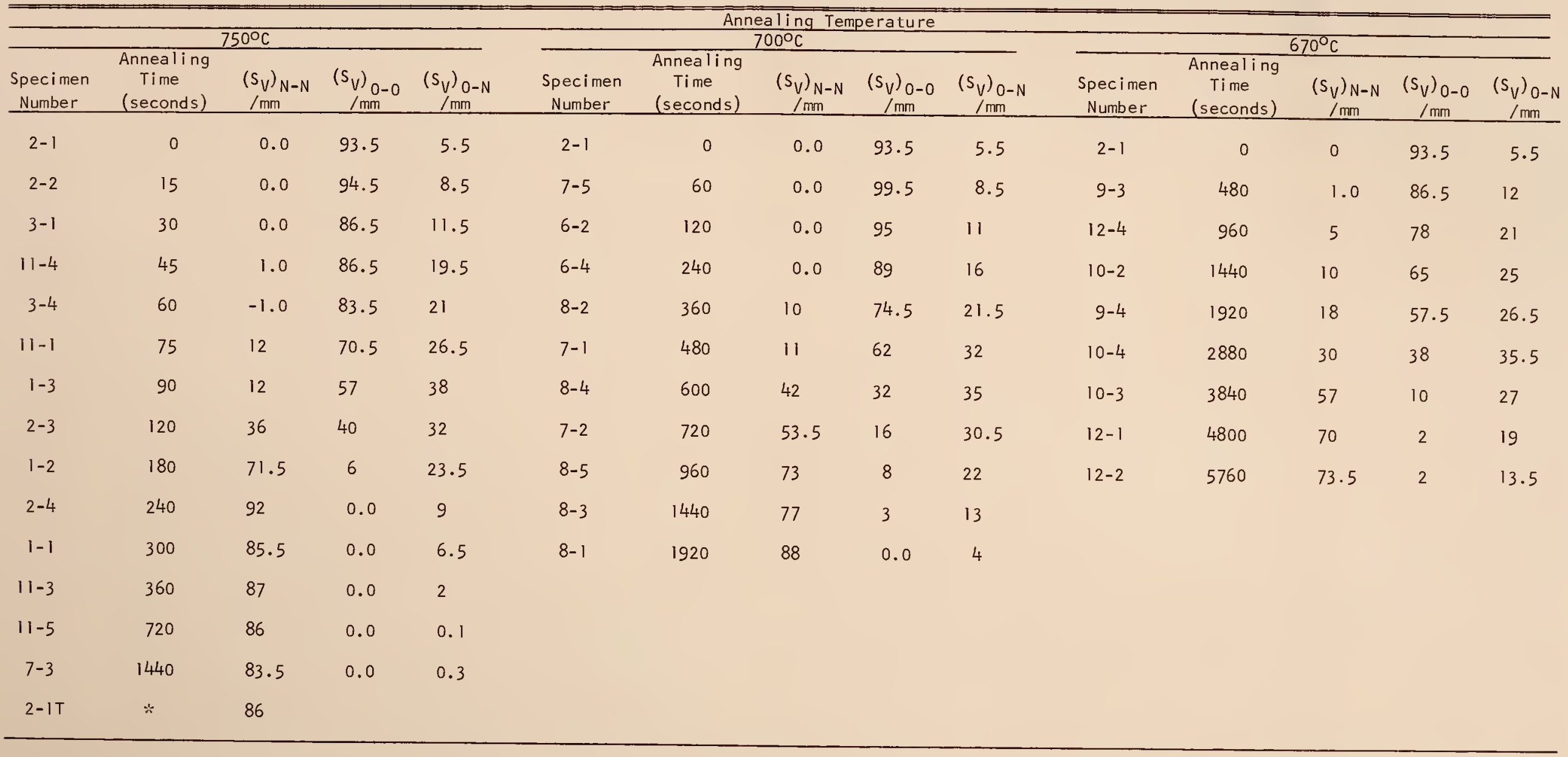

*This specimen had the same thermal history as specimen $2-1$, but was not worked. 
boundary area have been plotted versus annealing time: $\left(\mathrm{S}_{\mathrm{V}}\right)_{0-\mathrm{N}}$ in

Figures 14, 15 and 16; $\left(S_{V}\right)_{0-0}$ in Figures 20,21 and 22 ; and $\left(S_{V}\right)_{N-N}$ in

Fi gures 23,24 and 25 . 


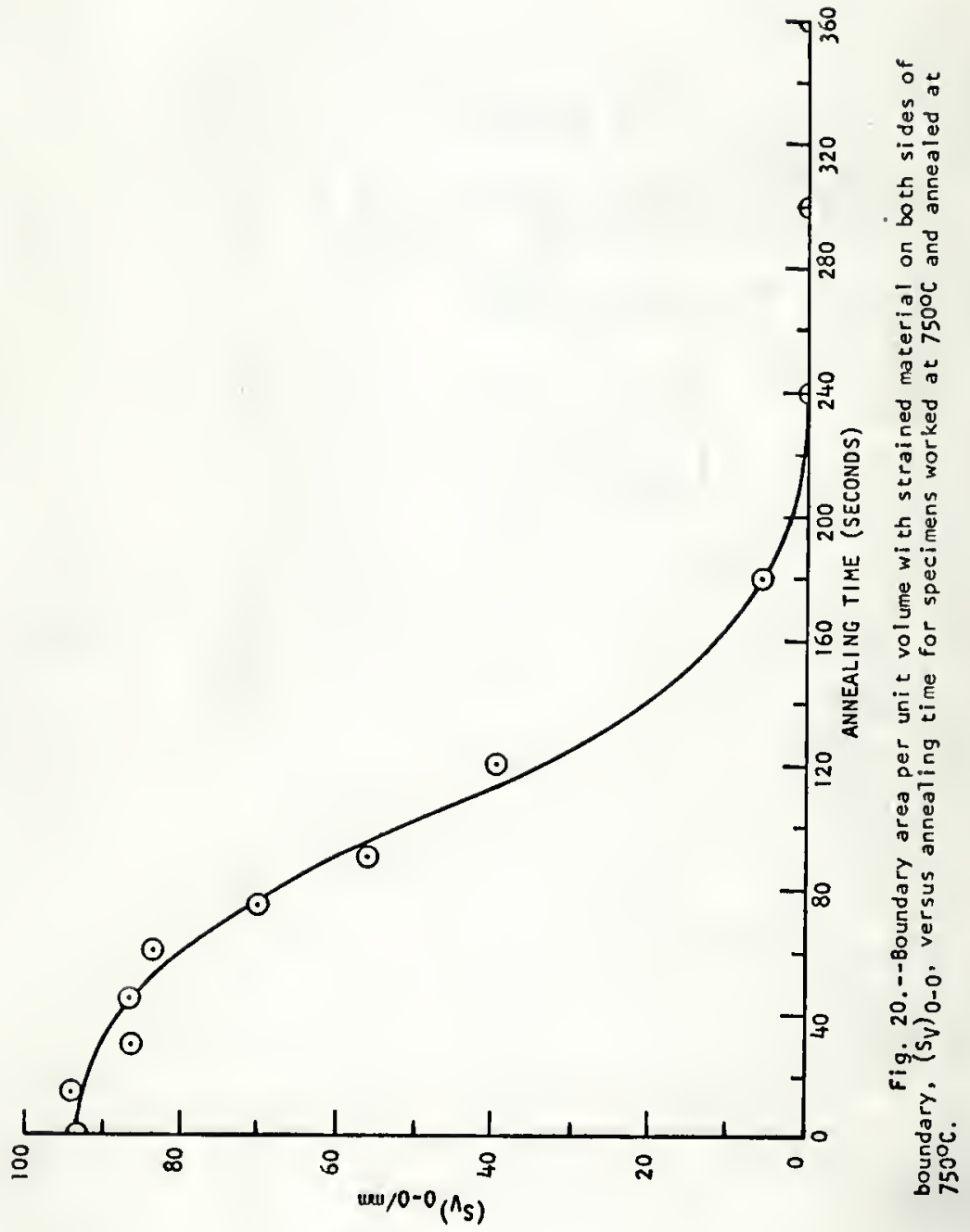




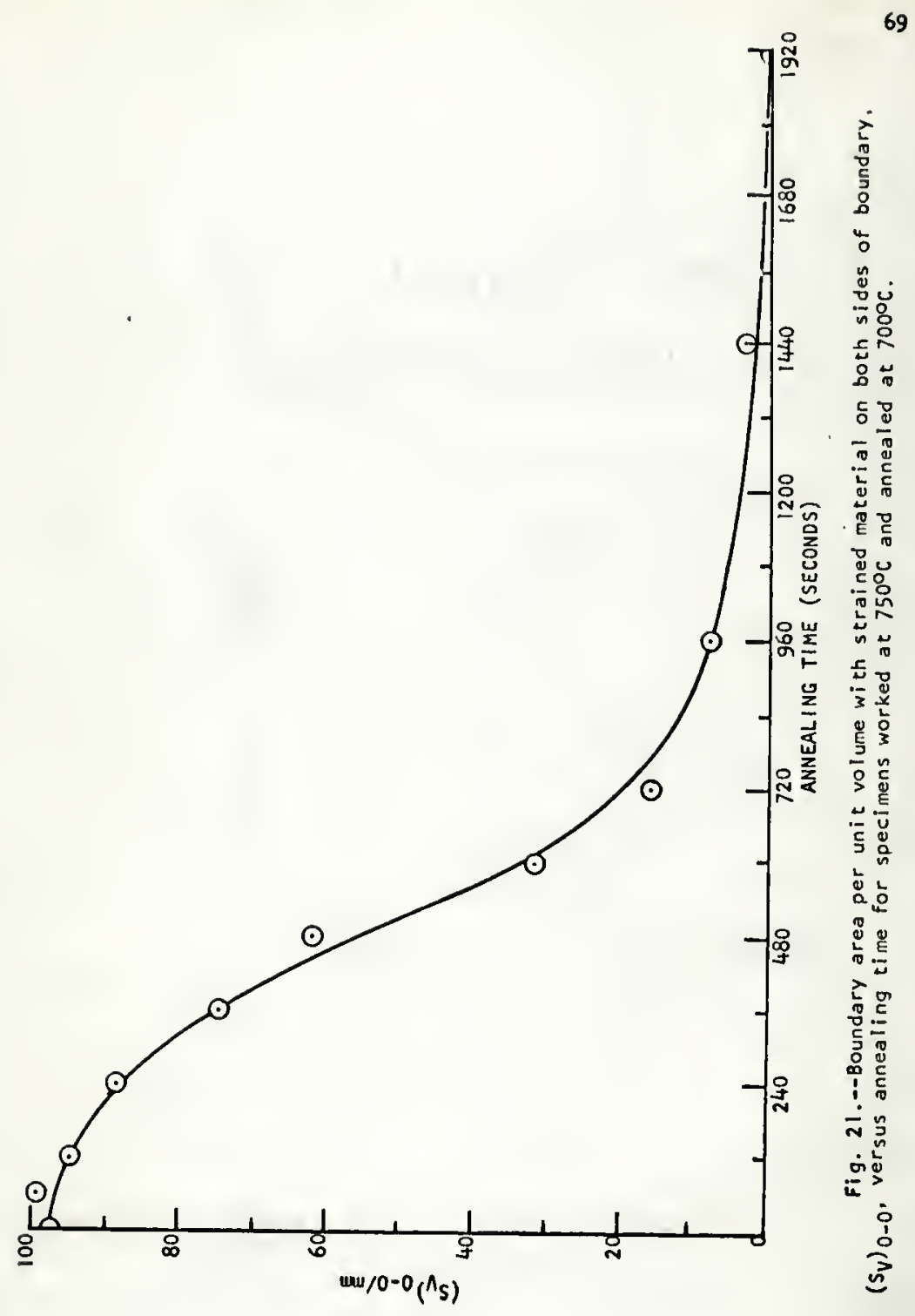




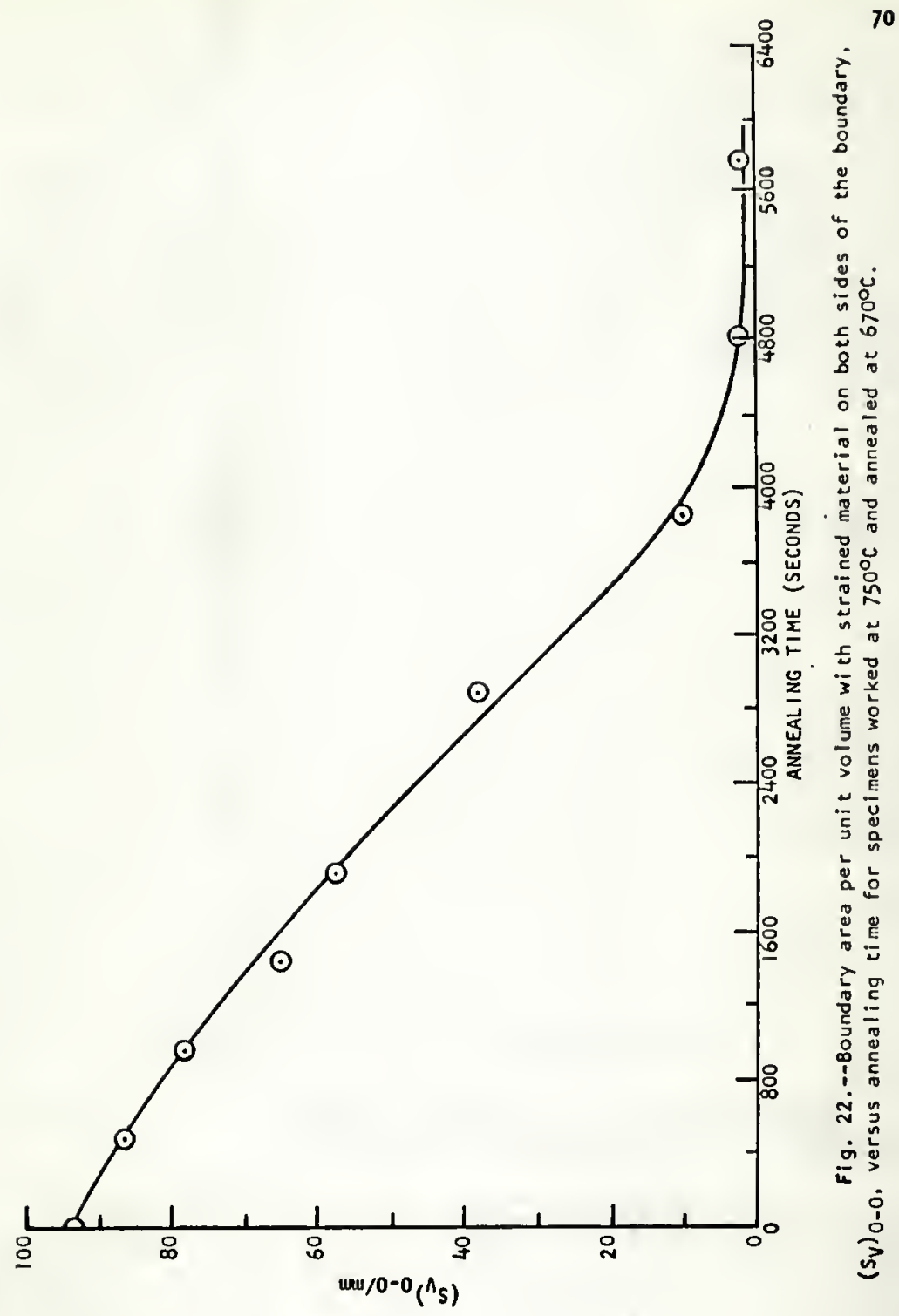




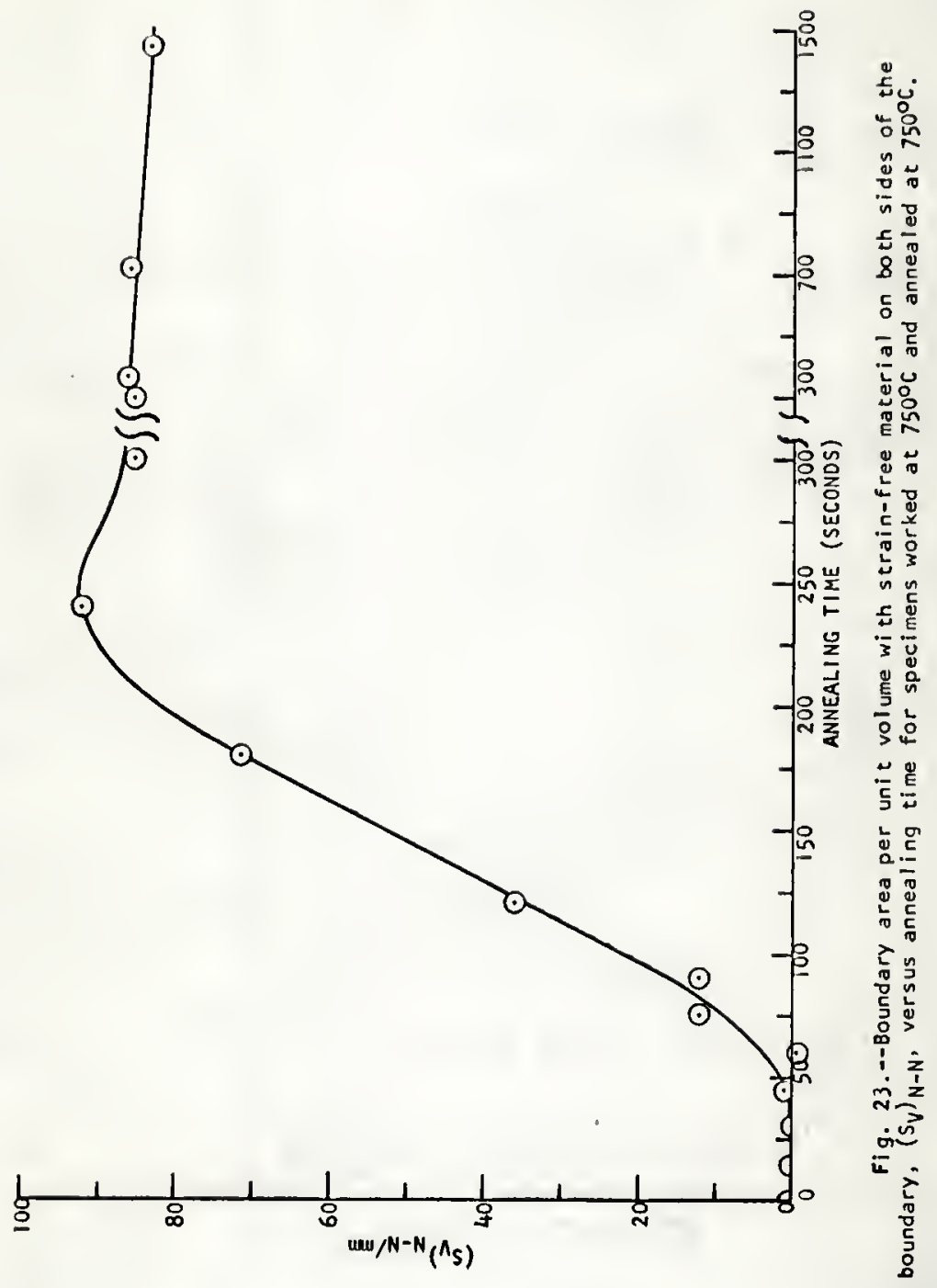




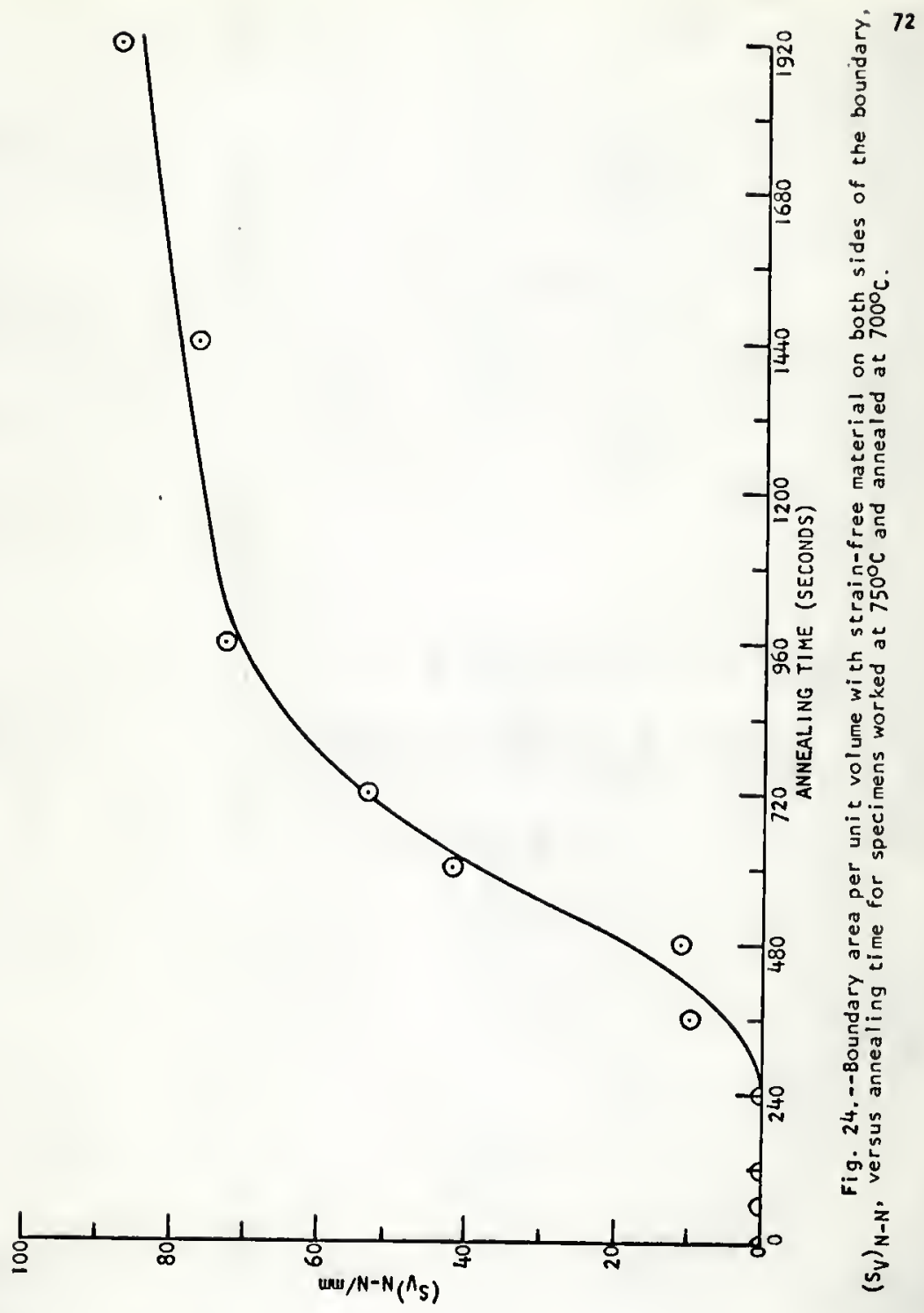




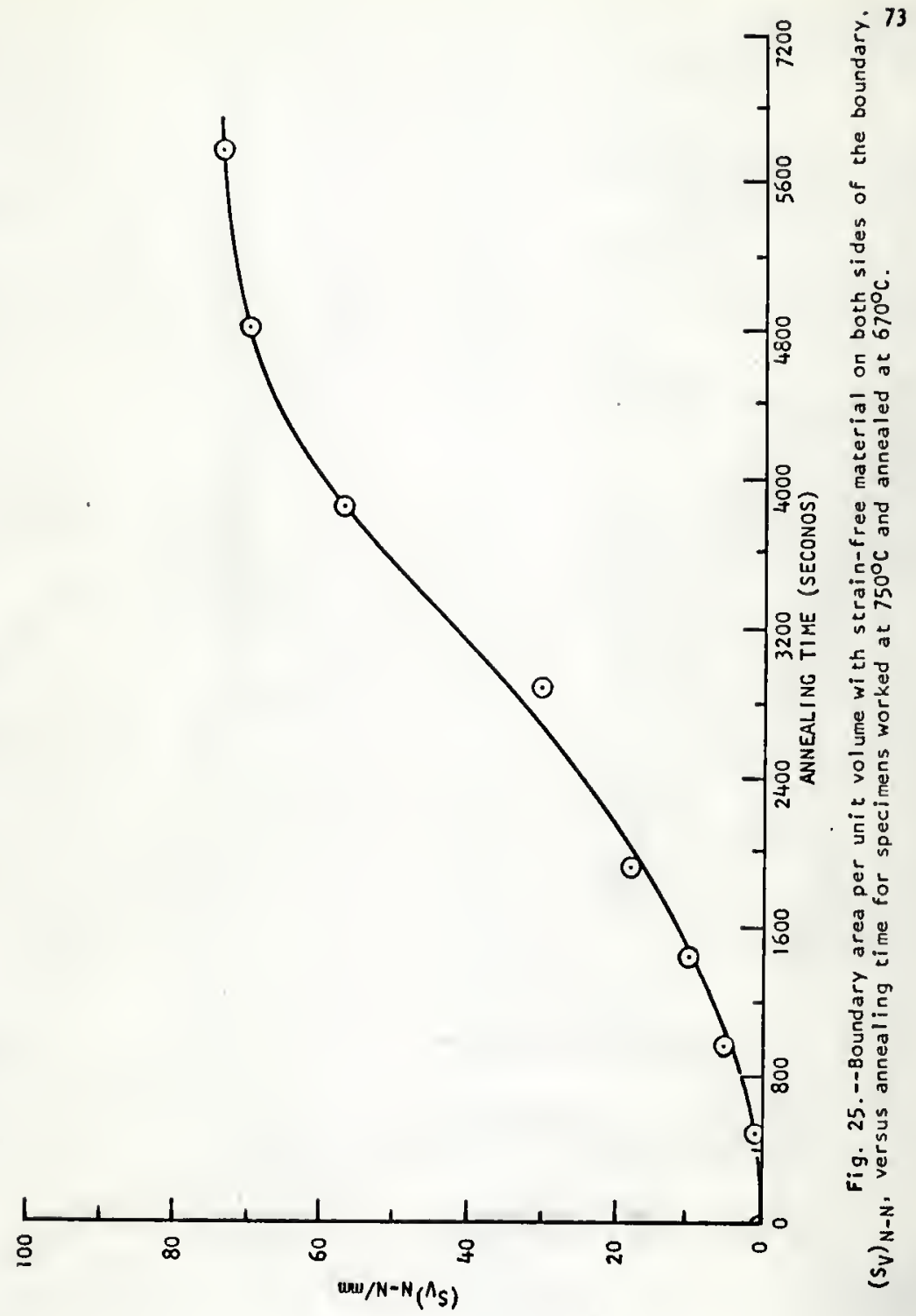




\section{CHAPTER IV}

\section{DISCUSSION}

The purpose of this chapter is to present a coherent description and characterization, based upon experimental data and observations, of the evolution from as-hot-worked material to a structure essentially free of distortions not associated with the grain boundary network.

Experimental results and observations from this investigation, as well as those from preliminary work and other investigations, will be presented from a particular viewpoint. Basically, this viewpoint is that the driving force provided by surface energy is of primary importance both during hot working and during annealing subsequent to hot working. The fundamental idea is not new. In $1951 \mathrm{C}$. Smith suggested an analogy between recrystallization and ordinary grain growth which was formulated on the same basis (40). The essence of Smith's proposal is that highangle boundaries possessed by strain-free grains move through a matrix containing small, well-developed subgrains. The driving force for migration is simply the energy associated with the subgrain boundaries. This idea apparently has received little additional attention, possibly because of results obtained by the techniques of transmission electron microscopy. These results indicated that well-defined subgrains usually are not formed during cold working $(41,42)$, and that subgrain formation and recrystallization during annealing after cold working can be concurrent rather than totally sequential (42). 
Hot working, however, presents a different situation. There is considerable evidence that well-defined subgrains will form even during relatively rapid hot working in materials of moderate and high stackingfault energy, e.g., in copper, nickel and aluminum (16). This observation, as well as others to be mentioned later, suggest that a consideration of surface energy will result in a clearer and more concise exposition of the phenomena which occur during and after hot working than would otherwise be possible.

For clarity, the remainder of this chapter is divided into three sections. The first of these will consider the working process itself and will discuss the various microstructural aspects of hot-worked materials. The second section is concerned with the evolution of strain-free grains during the annealing period. The third section is a discussion of the agreement obtained between predicted effects of the experimental variables and the results from other studies of annealing after hot working.

\section{Aspects of the Hot-worked Structure}

This section will characterize the hot-working process through a consideration of the microstructural changes which are known to occur during it. The most important of these changes are:

1. The grain boundary network* experiences distortions.

*A network in general is a configuration composed of nodes connected by branches. In the present discussion grains are thought of as nodes and grain boundaries as branches. A topologically equivalent network may be constructed from triple lines formed by the intersection of three grain boundaries (branches) and the quadruple points formed by the intersection of four triple lines (nodes). 
2. Lattice bending and twisting not associated with grain or subgrain boundaries appear as soon as working begins.

3. A subgrain boundary network begins to form very early in the working process.

4. Grain boundary serrations are formed and develop under the influence of the deformation and the driving force due to surface tension.

5. New grains are initiated and grow during the working process.

These changes will be considered in the following subsections.

\section{Distortion of the grain boundary network}

The microstructural result of distortions involving the grain boundary network is grain elongation. Note that no changes in the total number of triple lines and quadruple points, in the number of boundaries which meet at a triple line, or in the number of triple lines which meet at a quadruple point result from these distortions. During working, however, movement away from the equilibrium distribution of angles (as required by surface tension) will occur at both triple lines and quadruple points.

Perhaps the simplest way to express grain elongation is as a grain boundary anisotropy computed from the ratio of the number of grain boundary intercepts perpendicular to the stress axis, $\left(N_{L}\right)_{T}$, and the number parallel to the stress axis, $\left(N_{L}\right)_{L}$. This ratio can then be used to calculate an apparent total strain in the grains, $e_{g}$, by inserting it into an expression derived for tensile deformation by Rachinger (43). This expression is:

$$
e_{g}=\left[\left(N_{L}\right)_{T} /\left(N_{L}\right)_{L}\right]^{2 / 3}-1
$$


A derivation of this expression based on that given by Rachinger has been included as Appendix D.

Some quantitative measures of the changes in grain boundary anisotropy as they depend upon the working conditions are available from work by Rhines, et al. (9) on Nickel 200. This information appears in Figures 26 and 27 and in Table 12 .

TABLE 12.--Influence of rate of extension on the apparent total strain in the grains calculated from the expression: $e_{g}=\left[\left(N_{L}\right)_{T} /\left(N_{L}\right)_{L}\right]^{2 / 3}-1$. $\mathrm{Nickel} 200$. Hot-working temperature $=705^{\circ} \mathrm{C}$

\begin{tabular}{ccr}
\hline $\begin{array}{c}\text { Rate of } \\
\text { Extension (/min.) }\end{array}$ & $\begin{array}{c}\text { Measured } \\
\text { Extension (\%) }\end{array}$ & eq $(\%)$ \\
\hline 0.75 & 35 & 16 \\
0.07 & 31 & 2 \\
0.009 & 26 & 0 \\
0.0009 & 31 & \\
\hline
\end{tabular}

Data included as Table 12 show a predictable trend in the calculated values of $e_{g}$ as a function of rate of extension; $1 . e .$, for an essentially constant total extension $e_{g}$ decreases with decreasing rate of extension. This dependence could be rationalized on the basis of the time available for surface tension forces to affect a return to the required angular distribution. Microstructural, hardness, and boundary area data available for the same specimens, however, indicate that this viewpoint is an oversimplification. These data show that all values of $e_{g}$ listed in Table 12 are complicated by the formation of new grains during the working period. In fact, the results included as Table 12 can be 


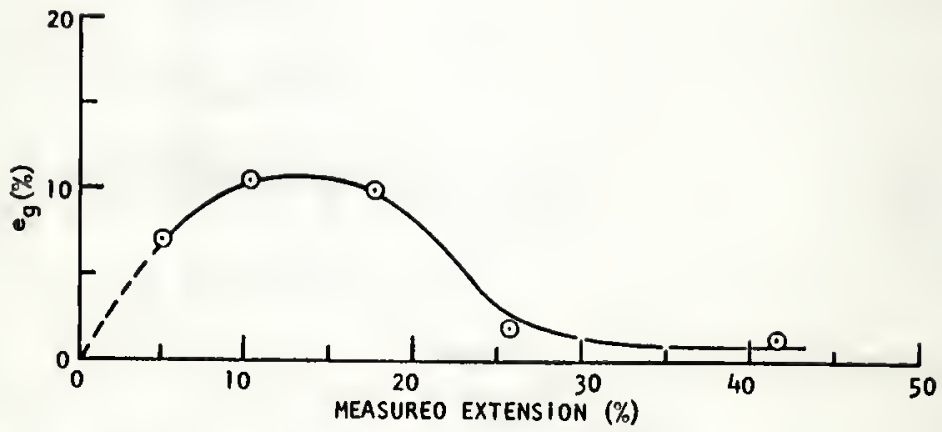

Fig. 26. - A plot of measured totai extension versus caiculated $e_{g}$ for Nickel 200 . Specimens extended at $705^{\circ} \mathrm{C}$ and $0.009 /$ minute. 


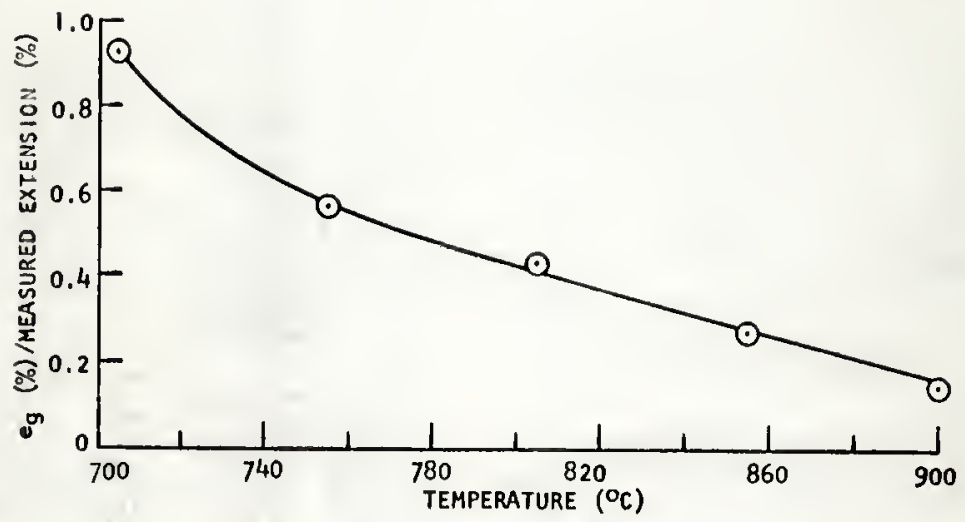

Fig. 27. - -A plot of the ratio of the calculated $e_{g}$ to the measured total extension versus hot-working temperature. Nickel 200. Rate of extension $-0.75 / \mathrm{minute}$. Total extension $\sim 37$ per cent. 
explained qualitatively on this basis. The data plotted as Figure 26 also may be rationalized on the same basis. That is, the departure of the calculated values of grain elongation, $e_{g}$, from those expected on the basis of the total extension is due to the initiation and growth of new grains during the working period. This point will be covered in more detai 1 in the subsection on strain-free grains later in this section. Data plotted as Figure 27 indicate that, under the experimental conditions utilized, at about $950^{\circ} \mathrm{C}$ the amount of grain elongation due to the working approaches zero or some small value. On the other hand, below about $700^{\circ} \mathrm{C}$, the grain elongation is essentially the same as the total extension experienced by the specimen. Within the temperature region between $700^{\circ} \mathrm{C}$ and $950^{\circ} \mathrm{C}$, however, the measured degree of grain elongation depends, for a constant rate and amount of elongation, on the hotworking temperature. Microscopic observations indicate that this result cannot be completely explained on the basis of the initiation and growth of new grains during working. At the highest temperatures another mechanism, possibly readjustment under the influence of the forces resulting from an imbalance of surface tensions, is operative.

one should not be misled into believing that equiaxedness, per se, constitutes an annealed state. Microstructures and hardness values yield ample evidence to the contrary. The hardness of a specimen deformed at $900^{\circ} \mathrm{C}$ is still roughly halfway between that of the completely annealed material and that of a specimen deformed the same amount at $750^{\circ} \mathrm{C}$. Working at $950^{\circ} \mathrm{C}$ would be expected, therefore, to yield a material considerably harder than the annealed specimens. The microstructural differences in the two structures are the subjects of the following subsections. 


\section{Dislocations not associated with}

a boundary network

In the category of dislocations not associated with a boundary network are included all those dislocations which are present in the structure after working but which are not part of an organized boundary network. The number and distribution of these dislocations have been found to be a function not only of the stacking-fault energy of the material, but also of the working conditions.

Hot torsion experiments performed by 0 rmerod and Tegart (16) showed clearly that the number of dislocations of the type referred to above decreases with increasing stacking-fault energy. This study also showed that with increasing temperature of working the dislocations not associated with a boundary become fewer in number and tend to arrange themselves into a poorly defined cell structure.

Since all arrangements are formed under the simultaneous influence of mechanical and thermal driving forces, one would expect them to exhibit considerable stability, with respect to similar arrangements, against dissolution or even marked alteration due to thermal energy alone. That is, the cell structure and other arrangements of dislocations which obtain at the cessation of working should not possess any marked energetic advantage over similar arrangements. Thus, they would persist until removed by a migrating high-angle boundary with an attendant decrease in the total energy of the system.

Data included as Table 4 as well as photomicrographs obtained from specimens annealed long times at $750^{\circ} \mathrm{C}$ (Figure 48, Appendix B) clearly show that a small fraction of the worked material does persist to 
long annealing times. Even at these long times, the distortion within the worked grains is easily noticed and quite often does not appear to be associated with subgrain boundaries. That is, a study under polarized light of the extinctions experienced by these grains leads to the conclusion that in many cases the residual distortion is not present in the form of subgrain boundaries, but as a bending or twisting of the crystal lattice due to sessile dislocations and restraints imposed by surrounding grains.

\section{Formation of a subgrain boundary network}

Subgrain formation during creep and during annealing after cold working has been the subject of numerous investigations since about 1950 . Subgrain formation during hot working, however, has not been thoroughly studied.

As a first approximation, one can envision a network of subgrain boundaries forming during hot working by the migration of dislocations within each grain into ordered arrangements which become connected to form a network. With continued working the subgrain boundaries and hence the network become better defined. In addition, the degree of misorientation between subgrains increases. The subgrain boundary network intersects the grain boundary network and the two much be considered together. A schematic diagram of the evolution described above is included as Figure 28. Excellent examples of the evolution of subgrain boundary networks during high temperature deformation are given by Busboom et al.

(44) and by Yim and Grant (45).

The techniques of transmission electron microscopy applied to hot worked (in torsion) copper, nickel, and aluminum leave no doubt that 

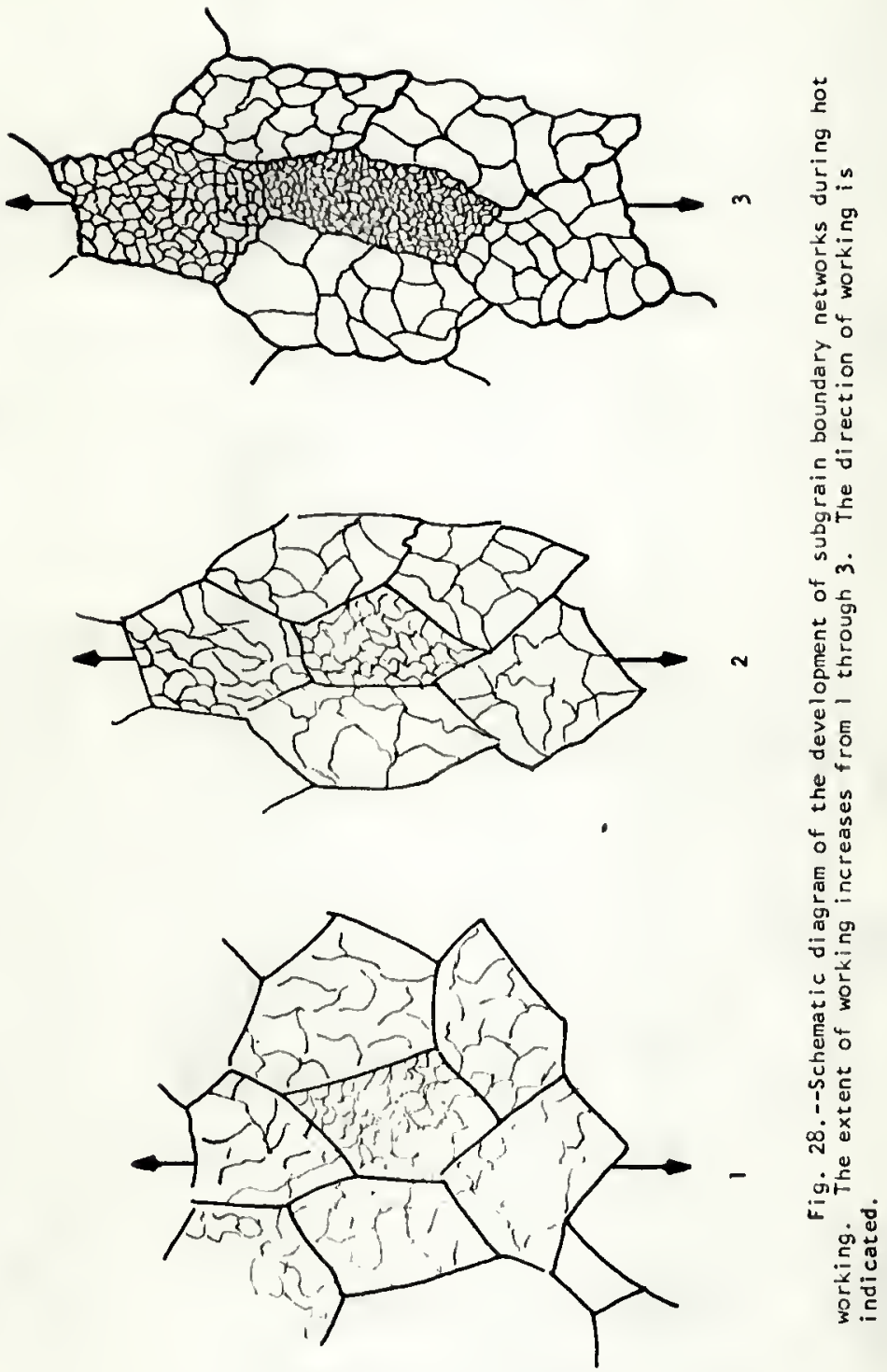
well-defined subgrains are formed during working (16). Although no quantitative data were obtained from this investigation, it was shown for an increasing temperature of working that the subgrain boundary network becomes better defined and that the individual subgrains increase in size. Quantitative data on the effects of working temperature (deformation in tension and by rolling and forging) on subgrain size from the investigations of Warrington (46) and Dillamore and Roberts (4) are included as Figure 29. This figure shows very clearly that subgrain size increases with increasing working temperature. Unfortunately, the data obtained by the various working procedures cannot be directly compared. The trend for a decrease in subgrain size wi th increasing rate of working is, however, undoubtedly correct.

The etching technique used in this investigation (along with most others which permit examination under polarized light) does not reveal subgrain boundaries as well as one might desire. However, there is ample evidence in the photomicrographs presented in Figures 48, 49, and 50 (Appendix B) that in many grains a subgrain boundary network has developed to a considerable degree. Close study of specimens within the series annealed at $750^{\circ} \mathrm{C}$ (Figure 48, Appendix B) also indicates that this network does not, to a detectable degree, become better developed during the annealing period. It is also apparent that not only subgrain development but also subgrain size varies considerably from grain to grain.

Although it was not possible to obtain measurements of the amount of subgrain boundary area, a crude estimate of the amount at zero annealing time was obtained in the following manner: 


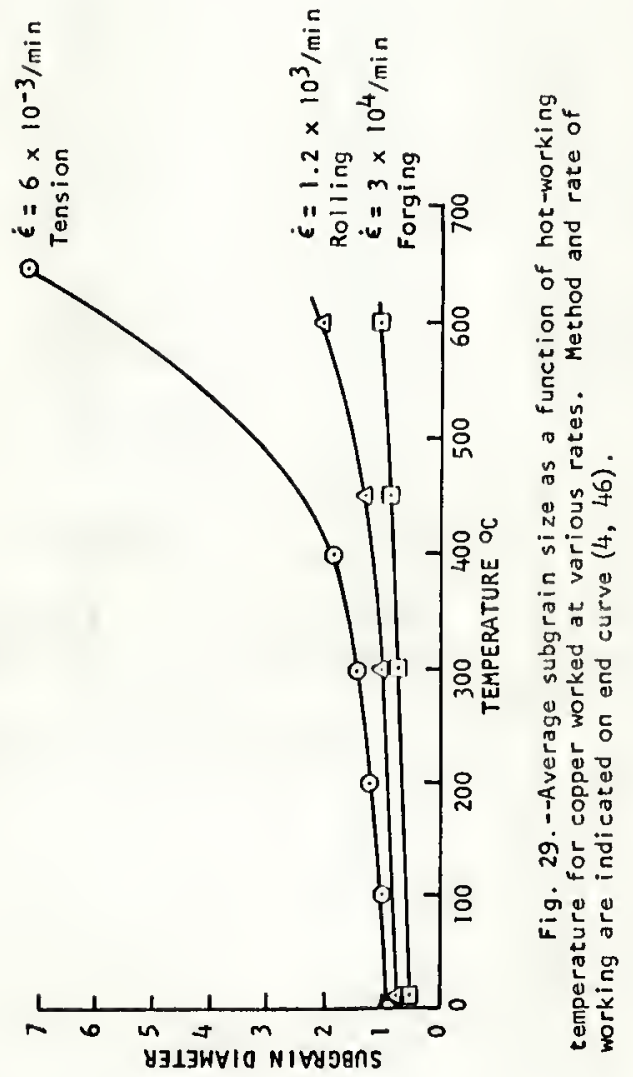


1. The assumption was made that the increase in hardness of the as-hot-worked material over a similar, completely annealed specimen with the same total of grain plus twin boundary area was due completely to subgrain boundaries. Of course, this condition can be only approached.

2. The hardness of a number of fully annealed specimens containing different amounts of grain plus twin boundary area was obtained. A plot of hardness versus boundary area proved to be a straight line. Extrapolation of this line yielded a hardness at zero boundary area.

3. The hardness at zero boundary area subtracted from the as-hot-worked hardness gave the total boundary hardening. From this value was subtracted an amount corresponding to the total measured grain plus twin boundary area. The remainder is the hardness due to subgrain boundaries.

4. With the aid of a reasonable assumption for the relative effect of grain and subgrain boundaries on hardness, the amount of subgrain boundary was calculated.

The final result was a subgrain boundary area of approximately $200 / \mathrm{mm}$.

This value is indicated on Figures 17, 18, and 19. From this information it was estimated that the maximum average subgrain size was 10 microns and the most probable average value between 2 and 5 microns. The latter values agree fairly well with the estimate of approximately one micron obtained from the work of Yim and Grant (45).

\section{Serrated boundaries}

Although serrated boundaries have been noted in a wide variety of hot-worked materials and in a number of creep studies, the manner in which they are formed and develop is far from clear. Many observations suggest, however, that serrations are the result of the formation of slip bands. Their shape may be modified subsequently or concurrently by boundary migration due to surface tension forces. 
Metal lographic observations have indicated that serrated boundaries exhibit the following characteristics:

1. Serrated boundaries are observed only within a temperature range characteristic of the material. Working at too low a temperature does not result in serrated boundaries and working at too high a temperature results in the initiation and growth of new (and possibly strain-free) grains along old grain edges and boundaries.

2. Within the temperature range of their existence, the shape of the serrations is a function of the working conditions. At low temperatures or high rates of extension, serrations tend to be straight-sided, but with increasing temperature or decreasing rate of extension they tend to be wavey or scalloped.

3. Serrations become more widely separated as the working temperature is increased.

4. Serrations have been observed to be associated with subgrain boundaries in creep studies involving materials as different as aluminum $(47,48)$, siliconi ron (49) and magnesi um $(11,12)$.

Specific observations which suggest that the initial formation of serrated boundaries is a result of slip band formation during hot working were made by Siutkina and Yakovleva (6), by Wyon and Crussard (50) and by Chang and Grant (48). In all three papers the formation of serrations was attributed to the intersection of grain boundaries by slip bands. The investigation by Siutkina and Yakovleva involved the tensile deformation of 99.99 per cent nickel between $500^{\circ} \mathrm{C}$ and $700{ }^{\circ} \mathrm{C}$ and at a

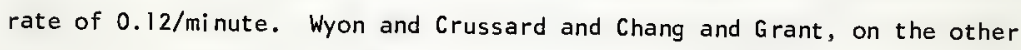
hand, investigated the creep behavior of 99.99 per cent aluminum. In addition, Forsyth $(51,52)$ has noted the formation of serrated boundaries in fatigued high-purity aluminum. This author attributed the formation of serrations to boundary migration at positions where slip striations intersected a grain boundary. All of the above evidence indicates that 
it is quite possible at high temperatures for a large amount of slip within a narrow band of material to result in visible perturbations of the grain boundary. These perturbations originally would take the form of a shear across the grain boundary where it is intersected by the slip band.

At high temperatures and lower rates of deformation, the straightsided nature of the serrations gives way to a wavey or scalloped form. There are two reasons for this change. The first is the fact that grain boundaries tend to assume a position of minimum energy, i.e., surface tension forces tend to minimize the total boundary area. If the temperature is high enough or the time long enough, then straight-sided serrations are replaced by a more rounded, wavey shape which represents a smaller amount of boundary area and hence a lower total energy.

The second reason for the change in shape is the formation and development of a network composed of subgrain boundary and serrated boundary. As the subgrain boundaries become better developed during working, surface tension forces associated with the quadruple points of intersection with serrated grain boundary become appreciable. The adjustments dictated by these forces will alter the shape of the serrations in the direction of their becoming scalloped, or cusp shaped, with the subgrain boundary at the apex of the cusp. The dihedral angle formed by the serrated grain boundary and the subgrain boundary depends upon the relative energies of the several boundaries that meet at the quadruple point. Since the energy (angle) of the subgrain boundary will increase as long as the material is being deformed, or until the boundary obtains the maximum possible energy, the equilibrium dihedral angle must 
constantly change. To the extent that this factor is determining, the shape of the grain boundary serration must constantly change.

A number of authors have noted that cusp-shaped serrations quite often are intersected at the apex of the cusp by a subgrain boundary. Photomicrographs illustrating this phenomenon are included in the papers by Chang and Grant (48), Namdar (49), and Suiter and Wood (12)

\section{Strain-free grains*}

This investigation and simi lar work preliminary to it (performed by the author) have established that, under the experimental conditions utilized, some strain-free grains exist in Nickel 200 at the completion of hot working. It is obvious from a comparison of the structures immediately before and immediately after working (Figure 7 (a) and (b)) that these grains originated during the working period. The manner in which they are formed is qualitatively evident from metallographic observations which permit the conclusion that they originate as a result of boundary migrations caused by a tendency for the system to minimize its boundary energy.

Boundary migration will occur naturally at positions of maximum energy gradient, or in other words, in regions of maximum local difference in density of quadruple points. Upon this basis two types of positions would be preferred as growth sites: (1) old grain boundaries (interfaces) and (2) old grain edges (triple lines). Of these, grain edges are the most energetically feasible since they are intersected by

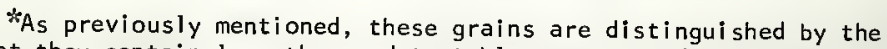
fact that they contain less than a detectable amount of deformation. 
three sets of subgrain boundaries, each with a different average spacing. Another factor which may be of importance is the fact that the intersection of one subgrain boundary with a triple line will form a new quadruple point, while at least two subgrain boundaries must intersect a grain boundary in order to form one new quadruple point.

One would expect a section of old high-angle boundary to move into that region containing the smallest subgrains, the highest energy subgrain boundaries, or both. This movement will generate new* grains which may be expected to grow at least to impingement with each other. In other words, high-angle boundaries are increasing in area at the expense of subgrain boundaries. The major restriction to growth is that the decrease in free energy due to the destruction of subgrain boundary area must be larger than the increase in free energy due to the creation of high-angle boundary.

The initiation of new grains during working is a dynamic process which depends for its inception upon the development of a subgrain boundary network beyond a certain degree. Once this degree has been reached locally and a difference in density of subgrain boundary network quadruple points exists in the same region new grains will be initiated by the boundary migration process described above. As new grains grow they too will begin to accept deformation and to form a subgrain boundary network. Since continued growth by boundary migration depends on the existence of a gradient in quadruple point density across the migrating boundary, the formation and development of a subgrain boundary network within

*The adjective strain-free henceforth will be used to describe only those grains which contain less than a detectable amount of deformation. 
the growing grain will impede growth or stop it completely. The development of a subgrain boundary network beyond a certain degree in the "growing grain" may also eventually result in the formation of new grains at its edges and boundaries.

Application of the above description to an actual structure which has experienced more than the degree of working necessary to begin the formation of new grains would lead one to expect the following:

1. The structure will contain original grains with various degrees of subgrain boundary network development and grain elongation depending upon the amount of deformation experienced by each grain.

2. A fraction of the structure will be composed of grains which originated and grow various amounts during working. Some of these grains may have developed a subgrain boundary network which has impeded or stopped growth, and may even have begun to form more new grains at edges and boundaries. Other grains in this class either will not have grown appreciably and will not have experienced much deformation or possibly just not have experienced a detectable degree of deformation and therefore will appear to be strain free.

The rate of working plays a very important role in the formation of a hot-worked structure. Very fast rates will not permit the formation of a subgrain boundary network and new grains during deformation. Thus, the as-worked structure will contain a more or less uniform dislocation cell structure throughout. This structure will closely resemble those arrangements found in cold-worked materials. Slower rates of working will result in the formation of a subgrain boundary network and new grains. The extent to which both develop increases with decreasing rate (for a constant total extention). For high total extensions at very slow rates all the original grains are replaced by those which continually 
formed and grew during working. Some of these may contain a welldeveloped subgrain boundary network.

The process of new grain formation outlined above should impart a number of observable characteristics to the over-all structural evolution both during and after working. These characteristics will be outlined in the following subsections. Also included in the appropriate subsections are observations which pertain to the characteristic being discussed.

The initiation of new grains during working.--All grains which eventually comprise the fully annealed structure originated at some time during the working process. Thus, all are descended either from grains formed well within the working period and which maintained some growth advantage until the end of working or from grains which obtained a growth advantage during the very last stages of working. This conclusion follows directly from the suggestion that new grains are formed in regions containing well-developed subgrains and from the fact that the subgrain boundary network does not change noticeably after hot working (during annealing). Evidence for the correctness of this conclusion will be considered in the second section of this chapter.

The microstructural positions at which new grains form. --New grains should be preferentially associated with old grain edges and to a lesser degree with old grain boundaries. It is at these positions that the gradient in the density of quadruple points, and hence the driving force, is greatest. Thus, at all but the slower rates of working the number of potential new grains should be a function of the amount of old grain boundary and/or old grain edge possessed by the structure. 
Microscopic observations (see especially Figure 8 and the data in Table 3) indicate clearly that the large majority of strain-free grains are indeed associated with (at least initially) either old grain boundaries or old grain edges. An indication that most of the strain-free grains with a growth potential are associated with old grain edges not only initially but throughout the annealing period was obtained by replotting the data contained in Figures 9,10 , and 11 with $\ln \ln \left(1 / 1-V_{V}\right)$ as the ordinate and $\ln t$ as the abscissa. Plots of this type for all three annealing temperatures are contained in Figure 30 . Slopes of the three major lines are 2.4, 2.1, and 1.9 for annealing temperatures of $750^{\circ} \mathrm{C}, 700^{\circ} \mathrm{C}$, and $670^{\circ} \mathrm{C}$, respectively. The fact that the slopes are close to two is a strong indication that the strain-free grains which contribute to the increase in amount of strain-free material during annealing are associated with the edges of old grains. The reason for this interpretation lies in the position assumption made in the derivation which relates $V_{V}$ to the annealing time. This derivation, due to Cahn (53), results in an equation of the form $V_{V}=1-e^{-k t^{2}}$ if the assumption is made that the strain-free grains are initiated and grow at old grain edges. The fact that the process under consideration fulfills all other conditions of the derivation allows one to draw the above conclusion. This point will be discussed in more detail in the second section of this chapter.

The shape of the strain-free grains.--Prior to impingement with other strain-free grains, the growing grains should have scalloped boundaries indicative of nonequilibrium quadruple point angles. This form reflects the necessity that all sections of the boundary possessed by a growing grain move towards their centers of curvature. 


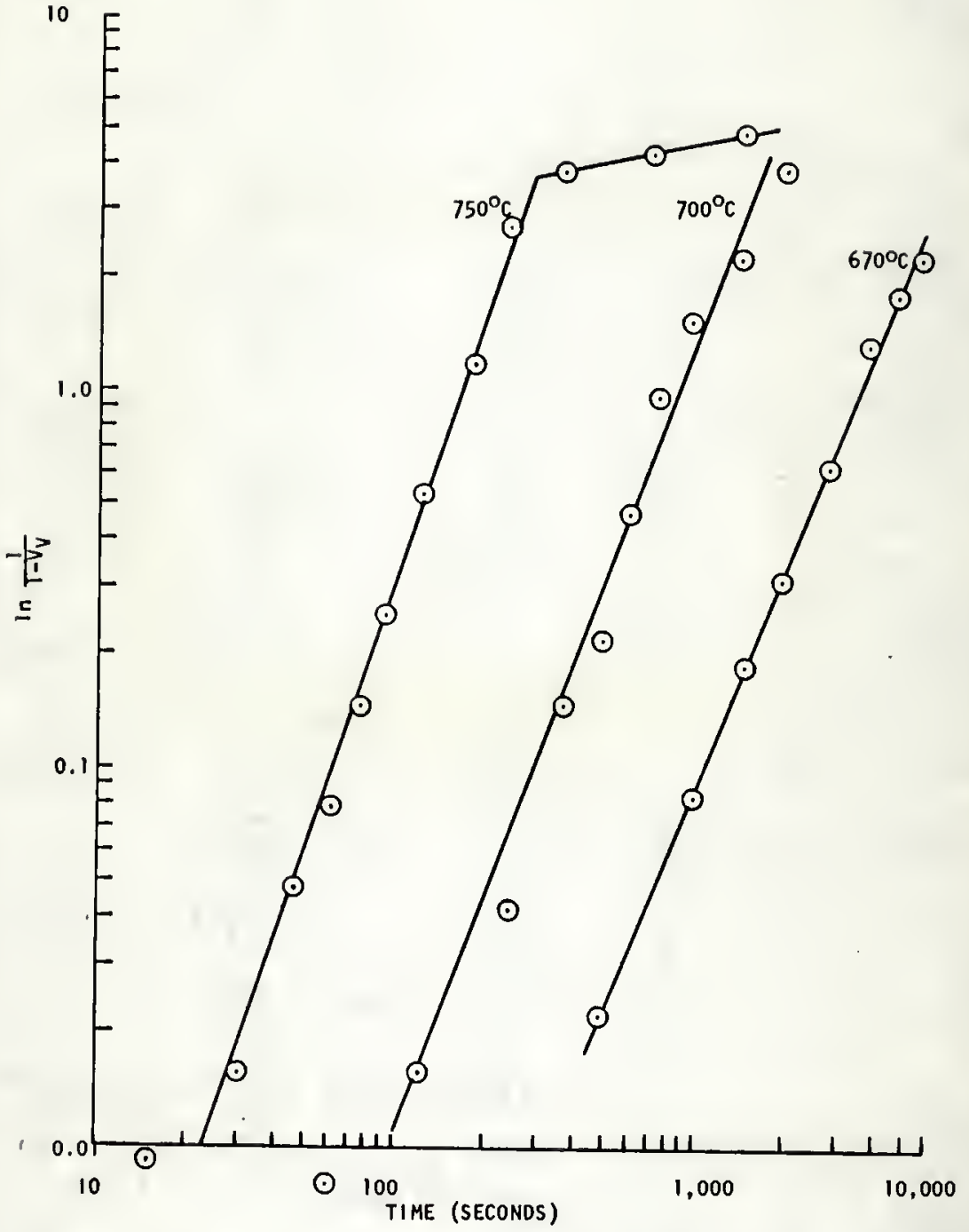

FIg. 30. - A plot of $\ln \left(1 / 1-V_{V}\right)$ versus anneallng $t$ Ime for specimens worked at $750^{\circ} \mathrm{C}$ and annealed at $750^{\circ} \mathrm{C}, 700^{\circ} \mathrm{C}$ and $670^{\circ} \mathrm{C}$. 
The shape of these boundaries is particularly well illustrated by the circled strain-free grain in Figure 8 (b) and to a lesser degree by the circled strain-free grain in 8 (a). An electron photomicrograph, obtained from the same specimen that provided Figure 8 (a) and (b), which shows a similarly shaped grain believed to be strain free, is included as Flgure 31. Each cusp in the boundary of the grain circled in Figure 31 is believed to represent an intersection of the migrating high-angle boundary with a subgrain boundary. In fact, the cusp in the center of the figure apparently shows such an intersection. The shape of the scalloped boundary is thus dictated by the tendency to maintain a balance between the surface energies of the boundaries involved.

The orientation relationship between the strain-free grains and the surrounding strained grains. --1 t can be concluded that a considerable number of the strain-free grains should have an orientation very close to that of one of the surrounding strained grains. This conclusion follows di rectly from the supposition that new grains originate by migration of a section of pre-existing high-angle boundary into the neighboring grain which contains the greatest density of subgrain boundary network quadruple points (smallest subgrains). Migration is away from a grain containing relatively large subgrains and one would expect the atoms which migrate across the boundary (and result in movement of the boundary) to assume an orientation close to that of the large subgrains. A photomicrograph, which shows a strained grain and a strain-free grain which apparently exhibit the expected orientation relationship, is included as Figure 32 . The strain-free grain lies completely within the circled area and is 


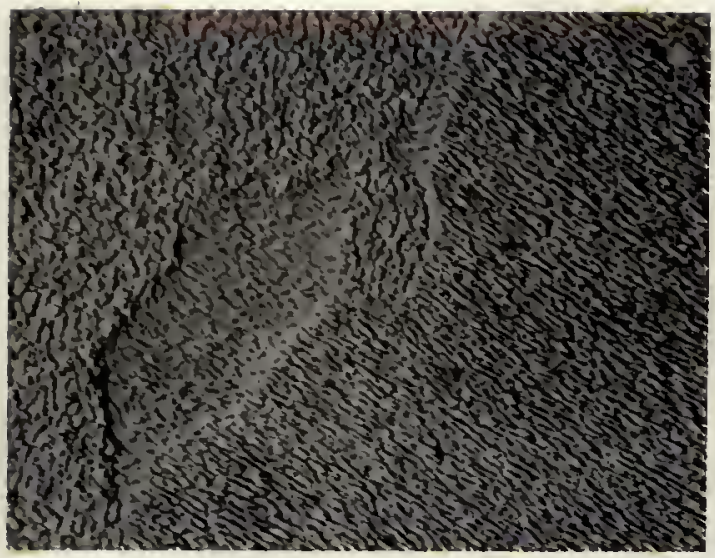

Fig. 31.--An electron photomi crograph of a presumably strain-free grain with a scalloped boundary growing at an old grain boundary. $10,000 x$. 


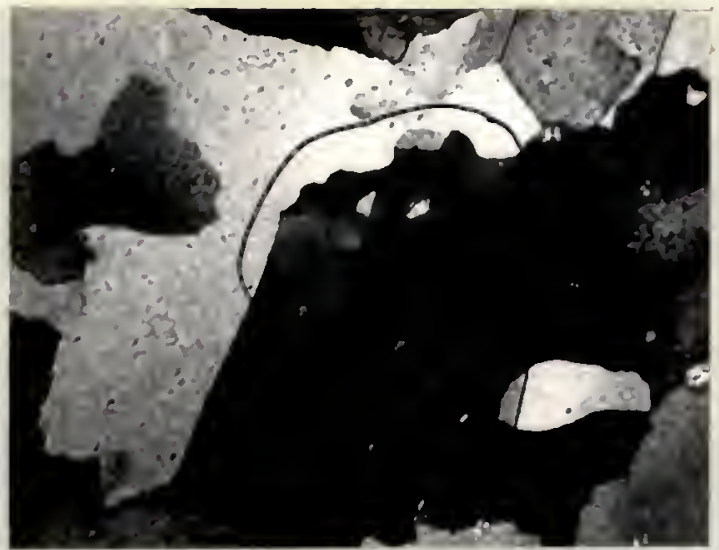

Fig. 32,--A photomicrograph illustrating the growth of a strain-free grain from a strained grain apparently of nearly the same orientation. Polarized light. 1000X. 
apparently growing from the large, dark, strained grain of nearly the same orientation.

It is not possible, however, to obtain unequivocal photographic evidence for the conclusion that the growing, strain-free grains have an orientation close to that of one of the surrounding strained grains. Although the etch tends to form grooves with walls composed of $\{100\}$ planes, the observed deviations from this simple relationship are large enough to mask appreciable orientation differences between the two grains (28).

\section{Directional inhibition in the growth of strain-free grains.--The} growth of strain-free grains should be inhibited in certain directions. This prediction follows from the supposition that growth is preferentially in the direction of the greatest driving force, i.e., the largest difference in density of quadruple points. Direct confirmation of this prediction was obtained from the photomicrographs which appear as Figure 8. In many cases it is quite obvious that the strain-free grains are growing preferentially into one of the strained grains which share a boundary. Figure $8(\mathrm{e}),(\mathrm{g})$, and (h) are good examples of this phenomenon.

The growth rate of the strain-free grains. --Each new grain is considered to be growing essentially into one old grain which usually possesses a nearly constant density of quadruple points. Since the driving force during the annealing period is essentially constant (except for very short annealing times) the growth rate should also be essentially constant. Note, however, that it is possible to have a considerable variation in growth rates among the various growing grains. This variation 
is a reflection of the great differences in subgrain size observed from grain to grain within a particular specimen.

Changes in the number of strain-free grains during the annealing period. --The number of strain-free grains but not their total volume should decrease during the annealing period. This conclusion follows from a consideration of the fact that if strain-free grains all have their origin at old grain boundaries or old grain edges, then impingement must occur very early in the annealing process. It is to be expected that some of the impinged grains will possess a growth advantage over the strain-free grains with which they are in contact. As a result of this advantage some strain-free grains will eventually disappear. A good example of an impinged group of small, strain-free grains is the three grains circled in Figure 8 (b). Data presented as Figure 12 for all three annealing temperatures indicates that the number of strain-free grains does actually experience an initial decrease with increasing annealing time. This observation will be discussed further in a subsequent section.

\section{Summary}

The structure which obtains at the completion of hot working depends not only on the conditions of working but also on the stackingfault energy of the material. If discussion is limited to materials of high and moderate stacking-fault energy, e.g., aluminum, nickel, and copper, then the structural evolution during hot working can be described in terms of concepts introduced earlier in this chapter.

Working at any rate and in any amount results in the introduction into the structure of dislocations which at high temperatures may 
manifest themselves in a number of ways. The most important of these are as grain elongation, as sessile dislocations and a poorly developed cell structure, and as a subgrain boundary network. These structural features in turn result in the appearance of grain boundary serrations and new grains. Variations in the relative proportions of the dislocations which appear as subgrain boundaries and as sessile dislocation or similar arrangements as a function of rate and amount of working are shown schemati cally by Figure 33. Note that at very slow rates of working essentially all dislocations will be associated with the subgrain boundaries while at very fast rates practically no subgrain boundaries will be formed.

All of the above manifestations, since they result from a dynamic process (hot working), are not only sensitive to the working conditions but also capable of continual change during the working period. Thus, serrated boundaries may be straight sided at high rates and low temperatures of working, while at high temperatures and slow rates they tend to be wavey or scalloped. The latter shape is due largely to the development of a subgrain boundary network and therefore is a function of the degree to which this network has developed.

The development of a subgrain boundary network also plays an important role in the initiation and growth of new grains during working. New grains are initiated only after the subgrain boundary has formed a connected network which in turn has produced local differences in the density of quadruple points across a section of pre-existing boundary. It is this density difference which provides the driving force for the growth of new grains by migration of the pre-existing boundary. 0ld grain boundaries and edges are seen to be preferred sites for the 


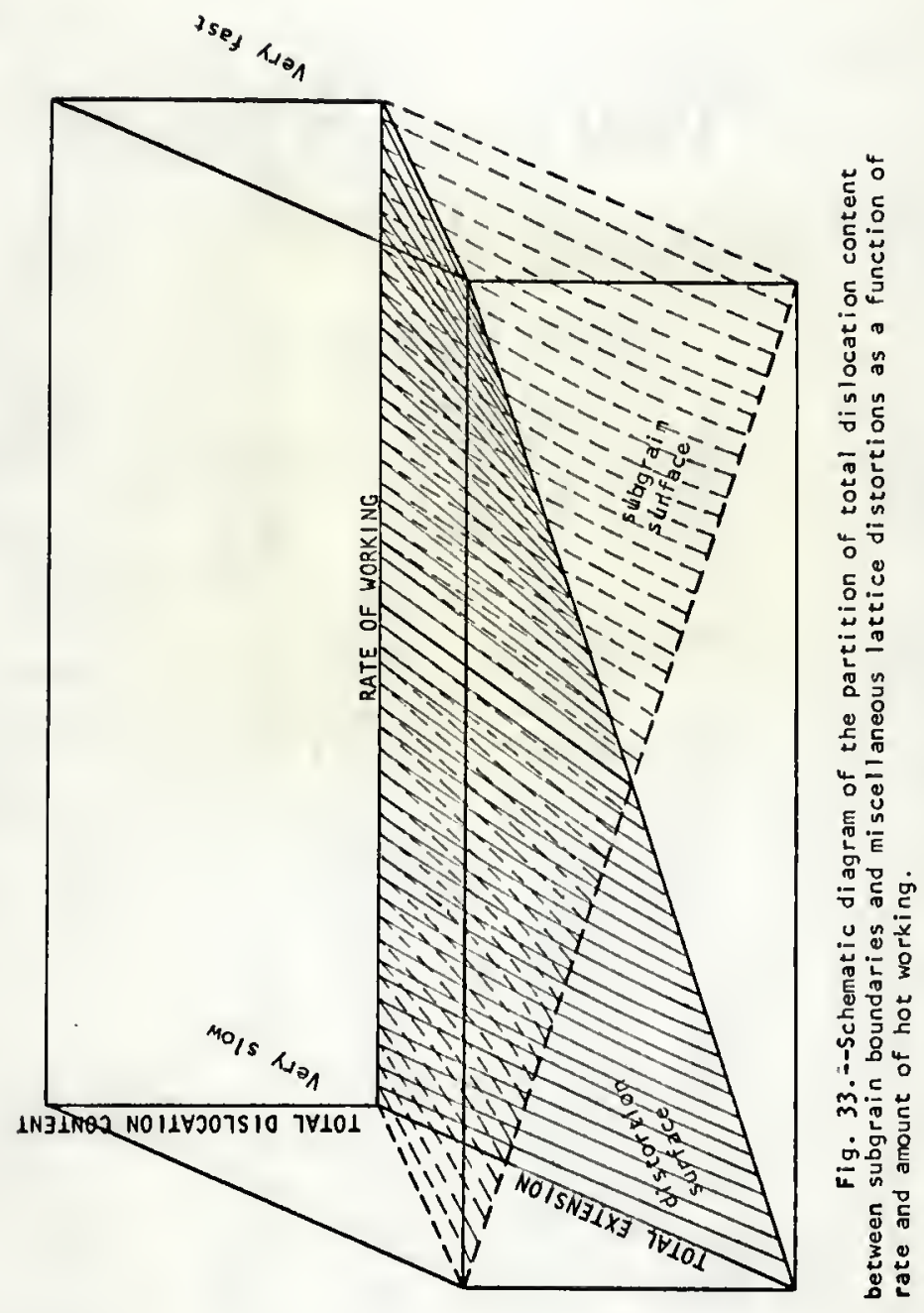


initiation and growth of new grains. The growth rate is proportional to the local difference in density of quadruple points. Since new grains are formed during working, they in turn may be subject to deformation. Thus, the formation of new grains is a dynamic process and several generations of new grains may be present in a particular structure.

At the cessation of working, then, there exists in the structure a large number of new grains which were formed and grew during working. Some of these may be essentially strain-free and capable of further growth during the annealing period, while others will have developed a subgrain boundary network which destroyed their growth advantage.

\section{Annealing after Hot Working}

In the previous section the principal microstructural aspects of the hot-worked structure were discussed. This section, then, will be concerned with the microstructural changes which occur during the annealing period after hot working. Data which re-enforce the conclusion that all strain-free grains which appear in the fully annealed structure have their origin during the working period will be considered first. Growth of strain-free grains and the effects of temperature upon growth will be discussed in the final subsection.

The initiation of strain-free grains during working and their growth during annealing

This investigation has established that the new grains formed during hot working which are identifiable as strain-free upon completion of working are at least as numerous as the strain-free grains present at most (later) annealing times. This is apparent from Figure 12 . It is 
tempting to conclude from this fact that there is no initiation of strain-free grains during the annealing period; however, it is not possible to provide a direct proof for this supposition. Although the number of strain-free grains decreases early in the annealing period there is no direct proof that the extent of this decrease is not greater than that actually measured. The difference between the true and apparent decreases, if such a difference exists, would result from the initiation of strain-free grains during the annealing period.

The strongest argument against the initiation of strain-free grains during the annealing period was obtained from "activation energies' ${ }^{\prime *}$ calculated from the expressions $1 / t_{c}=A e^{-Q_{T}} / R T$ and $G=B e^{-Q_{G} / R T}$ (54), where $t_{c}$ is the time at which a certain fraction of the structure is strain free, $Q_{T}$ and $Q_{G}$ are "activation energies," and $A$ and $B$ are constants. The former equation ylelds an "activation energy" for the evolution from strained to strain-free material and the latter equation yields an "activation energy" for boundary migration. Graphs of $\ln 1 / t_{c}$ and $\ln G$ versus $1 / T\left({ }^{\circ} K\right)$ therefore should be straight lines with slopes Q/R. Plots of this type are included as Figures 34 (for $t_{c}$ at $V_{V}=0.05$ ) and 35. Calculated "activation energies" are 29,000 cal/mole for $Q_{T}$ (at $\left.V_{V}=0.05\right)$ and $32,000 \mathrm{cal} / \mathrm{mole}$ for $Q_{G}$. Values obtained for $Q_{T}$ at $V_{V}=$ 0.45 and $V_{V}=0.60$ were very close to that obtained at $V_{V}=0.05$. If the initiation of strain-free grains (or any other process in addition to boundary migration) were occurring during annealing, then the "activation

"The term "activation energy" will be used throughout this sec$t i o n$ to describe the temperature dependence of the process under consideration. No specific mechanism is implied. 


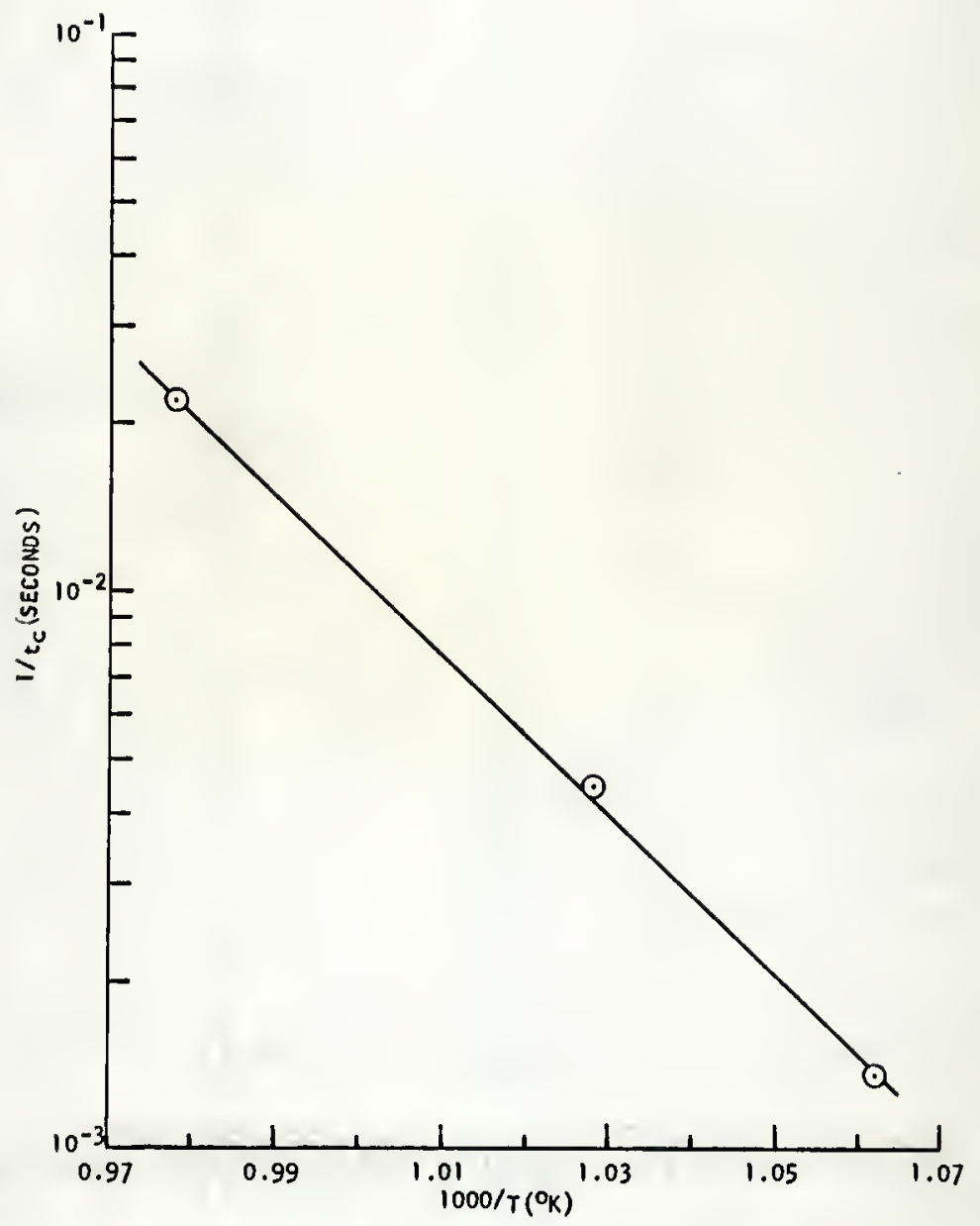

Fig. 34.--A plot of $1 / t_{c}$ versus $1 / T\left(O_{K}\right)$ for $V_{V}=0.05$. 


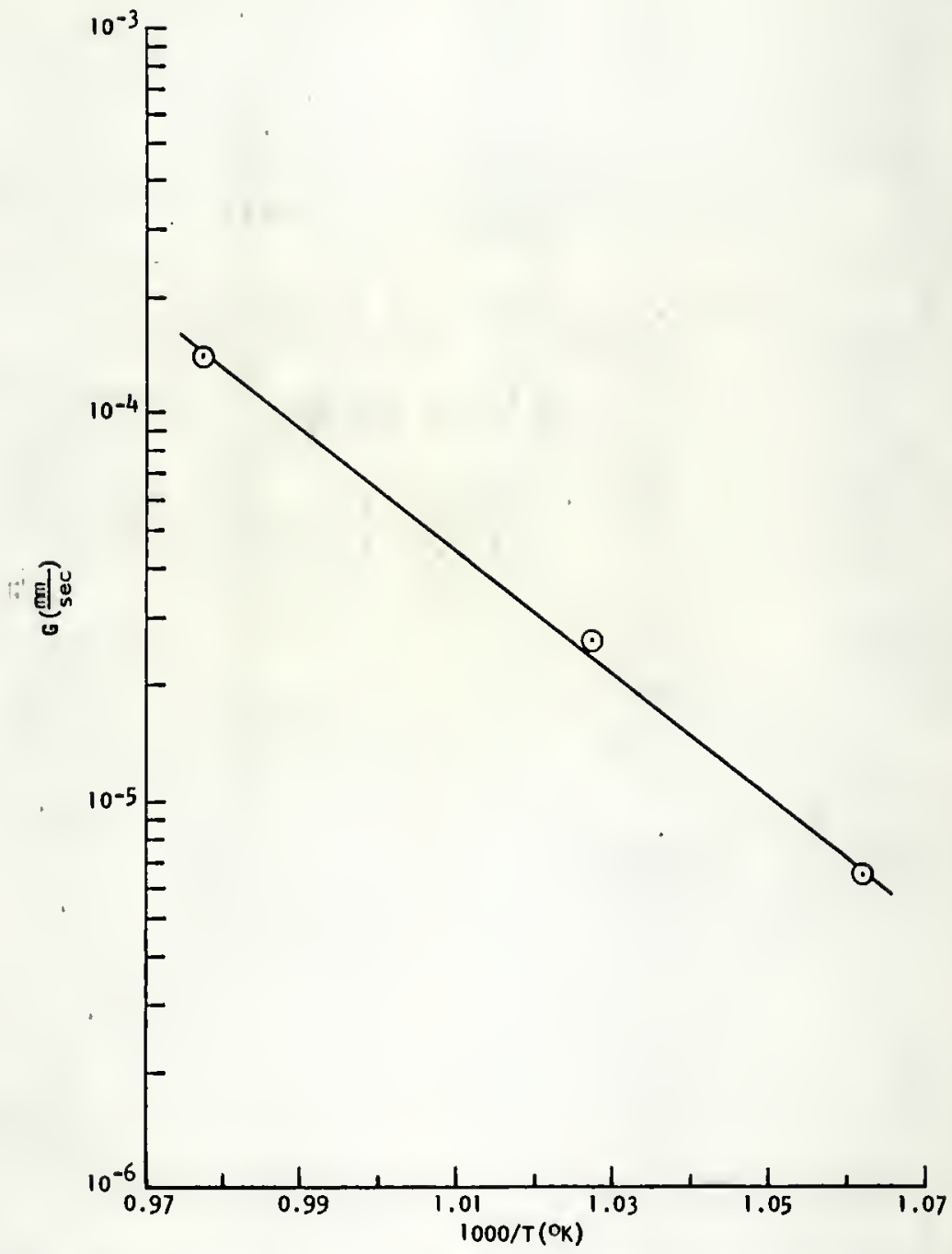

Fig. 35.-A plot of experimental growth rates (calculated from $\left.G \cdot\left(S_{V}\right)_{O-N}=d V_{V} / d t\right)$ versus $\left.I / T(O K)\right)$. 
energy" for the over-all reaction $\left(Q_{T}\right)$ would include a term characteristic of the additional process and $Q_{T}$ would be greater than $Q_{G}$. The fact that all three values of $Q_{T}$ are essentially the same and only slightly less than the value obtained for $Q_{G}$ is strong evidence that neither the initiation of strain-free grains nor any process except boundary migration occurs during annealing. Recall that arguments presented in the first section of this chapter also resulted in the conclusion that no strain-free grains are initiated during the annealing period. Some of the preliminary work lends support to the conclusion that the complexity of the annealing process does not change over the range of temperatures investigated. This work involved the measurement of hardness as a function of annealing time for specimens deformed and annealed at 705, 755, and $805^{\circ} \mathrm{C}$. Calculation of residual hardness due to the working for all specimens regardless of annealing time or temperature resulted in values which were a function of the volume fraction strain-free grains but not a function of the annealing temperature. It is unlikely that this result would be obtained if different processes were contributing to the changes in hardness at different annealing temperatures.

The above observations and arguments perhaps are reconciled best by the following description:

1. All grains which exist in the annealed structure had their origin sometime during working.

2. Some of the new grains grow during working (wi thout accepting appreciable deformation) to a size such that at the completion of the process they will be recognized as strain free by the experimental procedures.

3. At each successive annealing period, the number of strain-free grains actually observed is the sum of 
those which survive that particular annealing period and those which grow to a detectable size during this period minus those grains of visible size which were destroyed by aggressively growing grains.

The growth of strain-free grains and the effects of temperature upon growth

Experimental "activation energies" compared to those obtained for other processes.--It is interesting to note that the "activation energy" for boundary migration calculated from data obtained in this study agrees well with the two values of the activation energy for grain boundary self-diffusion in nickel which have appeared in the literature. These values are $26,000 \pm 1500 \mathrm{cal} / \mathrm{mole}$ from the study of Upthegrove and Sinnott (55) and $30,400 \pm 2000 \mathrm{cal} / \mathrm{mole}$ from the work of Shinyayev (56). The experimental value of the activation energy for boundary migration falls very close to the latter of these two values. This is an indication that both processes proceed by the same mechanism. It is also interesting that Detert and Oressler (57) recently have determined the activation energy for boundary migration during the annealing of coldworked nickel to be from 28,000 to $30,000 \mathrm{cal} / \mathrm{mole}$.

The relation between volume fraction strain-free grains and annealing time. --A relation between the volume fraction strain-free grains and the annealing time has been derived by Cahn (53) on the bases that all initiation of strain-free grains is complete at essentially zero annealing time, that the linear growth rate is constant, and that grain edges are the preferred sites for the initiation of strain-free grains. This derivation also includes the assumptions that: (1) strain-free grains grow with equal ease into all the strained grains which share the 
grain edge (triple line), and (2) impingement occurs first with grains growing at the same edge and then with grains from other edges. The resulting equation is $V_{V}=1-\exp -\pi L_{V}{ }^{2} t^{2}$, where $L_{V}$ is the length of "nucleating edge" per unit volume.

The assumption that strain-free grains grow with equal east into all the strained grains which share the grain edge (triple line) at which they have formed is of questionable validity. Inspection of the photomicrographs contained in Figure 8, especially Figure 8 (b), (e), and (h), indicate that strain-free grains quite often grow preferentially into only one of the strained grains. This behavior was predicted from the mechanism for formation of strain-free grains presented in the first section of this chapter. The equation relating $V_{V}$ and the annealing time therefore must be re-derived to correct for this possibility. The correction is based on the assumption that a strain-free grain growing at a grain edge will grow preferentially into one of the strained grains sharing the edge. In addition, it is assumed that only three strained grains share an edge and that they meet to form $120^{\circ}$ angles between each of the three boundaries positioned around the grain edge. The equation which results from these assumptions is: $V_{V}=1-\exp -\left(\pi L v^{2} t^{2}\right) / 3$. The derivation of this modification is included as Appendix E.

Use of the above equation involves obtaining the amount of "nucleating" grain edge, i.e., the length of grain edge at which strain-free grains have formed at essentially zero annealing time. This length was obtained by measuring the number of triple points, $\left(N_{A}\right)_{T}$, (in those specimens annealed the shortest times) at least partially surrounded by strainfree material per unit area of polished and etched section. $L_{V}$ may then 
be calculated from the relationship $\left(N_{A}\right)_{T}=1 / 2 L_{V}$. The value of $L_{V}$ found in this manner was $945 / \mathrm{mm}^{2}$. The probable error of the measurement was estimated at \pm 15 per cent of the given value.

Experimental values of $V_{V}$ should fall somewhere between the limits set by the original equation $\left(V_{V}=1-\exp -\pi L_{V} G^{2} t^{2}\right)$ and the corrected equation $\left(V_{V}=1-\exp -\pi L_{V} G^{2} t^{2} / 3\right)$. Values of $V_{V}$ calculated from these two equations are included as Table 13 and plotted as Figures 36, 37, and 38 . Also included in Table 13 and Figures 36,37 , and 38 are experimental values of $V_{V}$ which have been corrected for the amount of strain-free material present at zero annealing time.

The fact that the experimental points lie between the calculated limits could be predicted on the basis that some of the strain-free material is associated with strain-free grains which form at old grain boundaries as distinguished from those which form at old grain edges. The volume of a strain-free grain growing at a grain edge will increase as $\mathrm{t}^{2}$ while the volume of a grain growing in an old grain boundary increases only as $t$ (assuming impingement has al ready occurred with other grains which originated at the same boundary or edge). That some of the strained material did become strain free due to the growth of new grains which originated at old grain boundaries is obvious from the positions occupied by strain-free grains recorded in the previous chapter (Table 3) and from the photomicrographs of Figure 8.

Changes in the various types of boundary area during annealing. -A complete description of a partially strain-free (annealed) structure with respect to boundary area requires the use of three types of boundary. They are: $\left(\mathrm{S}_{\mathrm{V}}\right)_{0-\mathrm{N}^{--}}$the boundary area separating strained material 


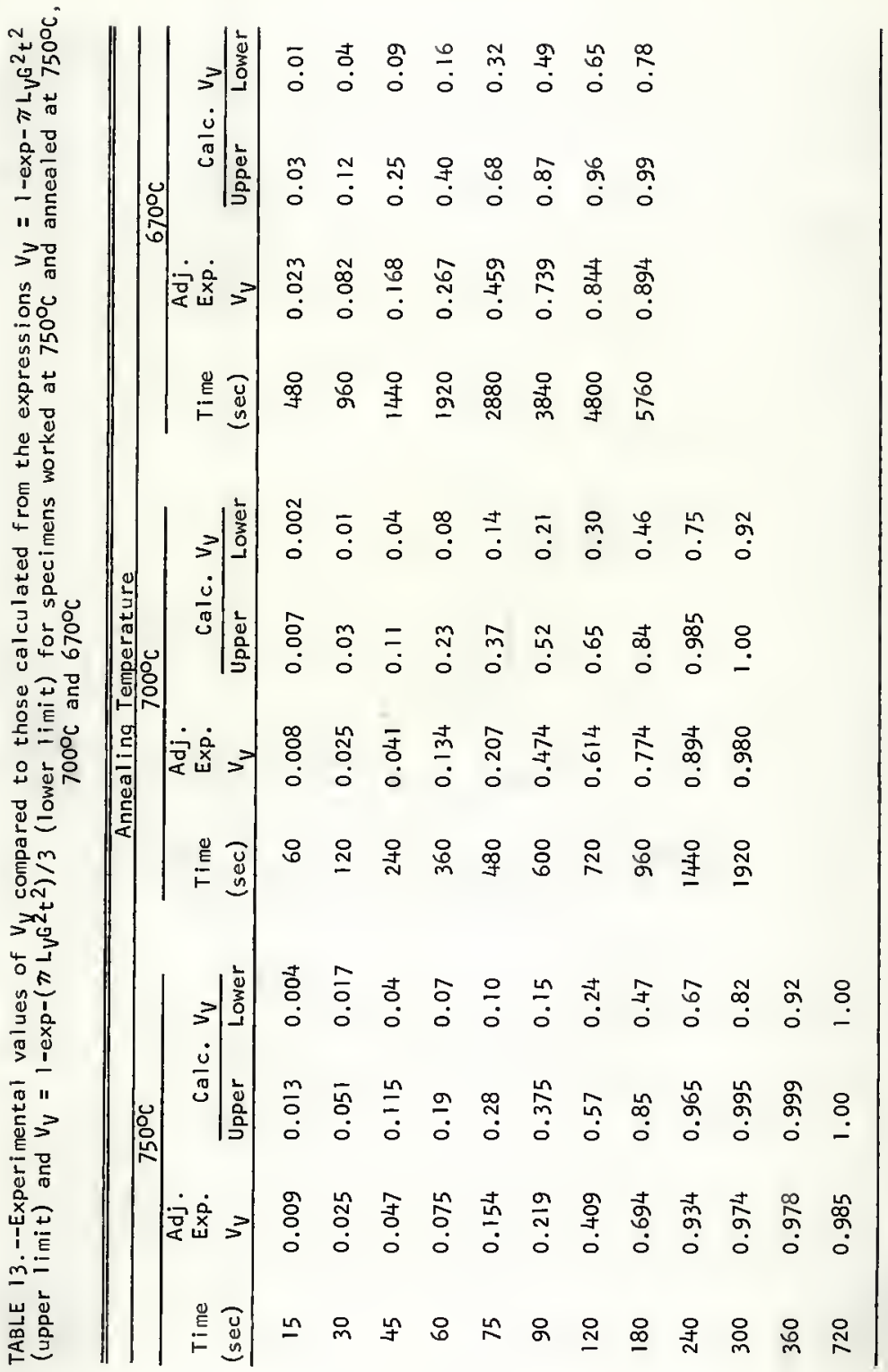




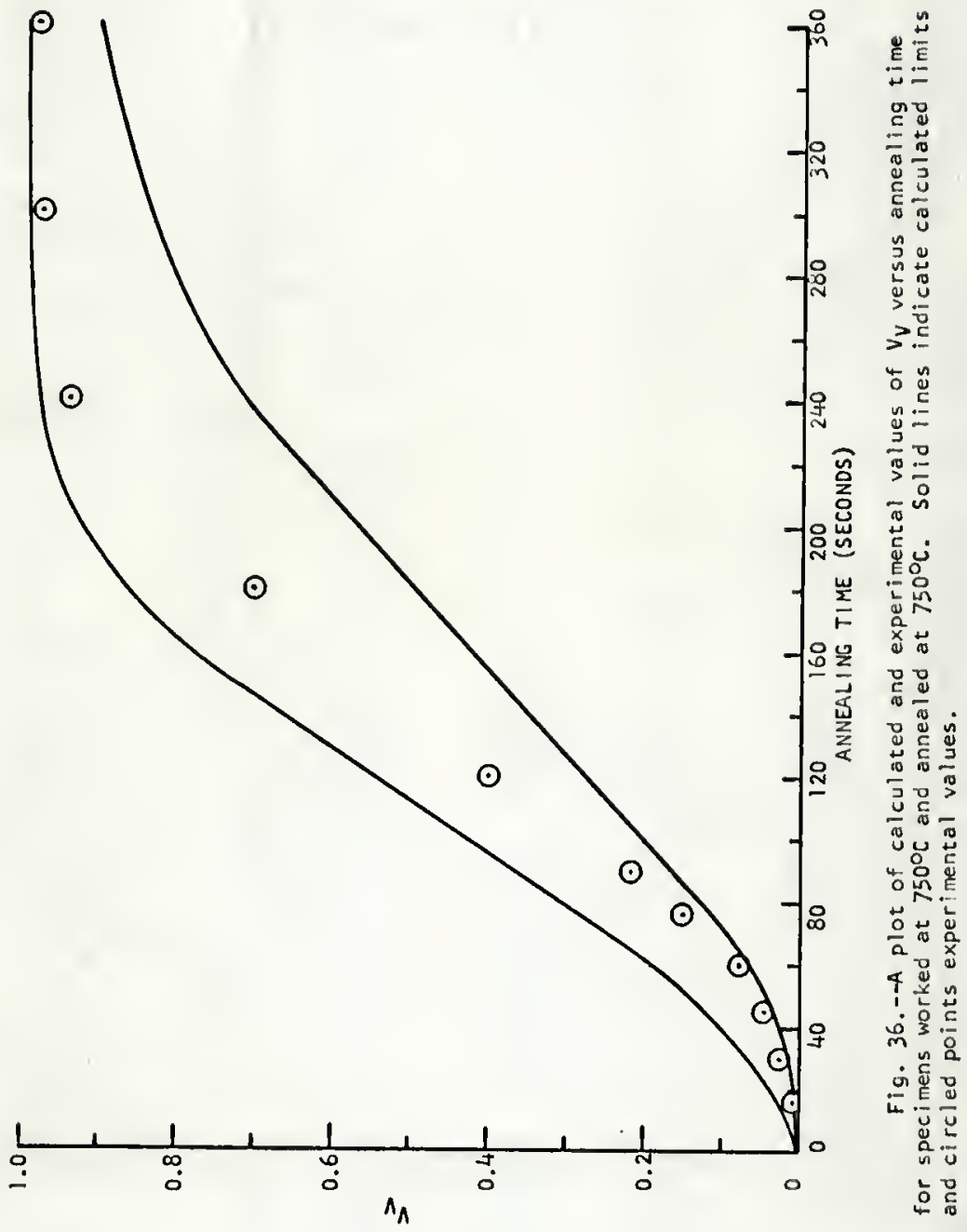




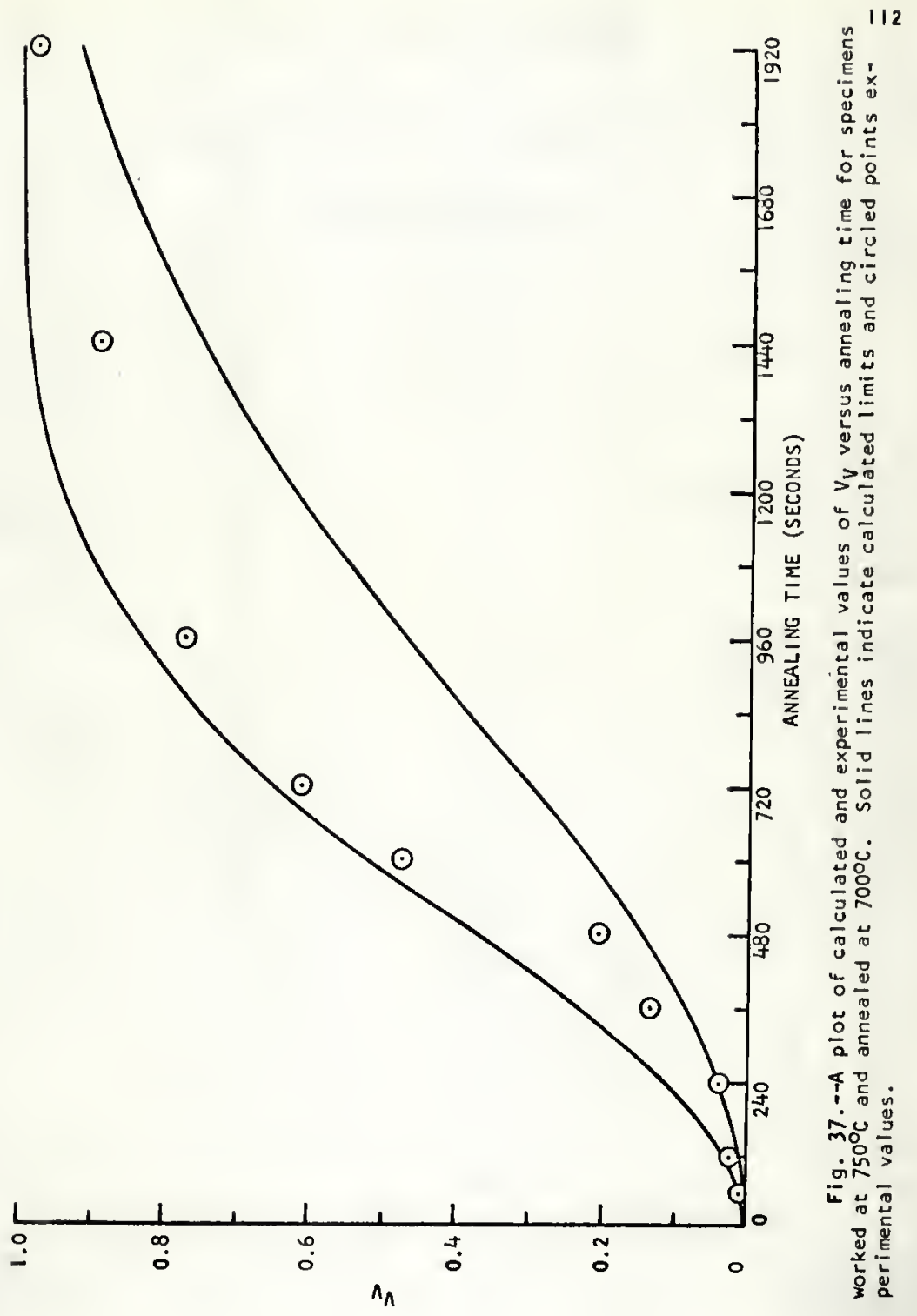




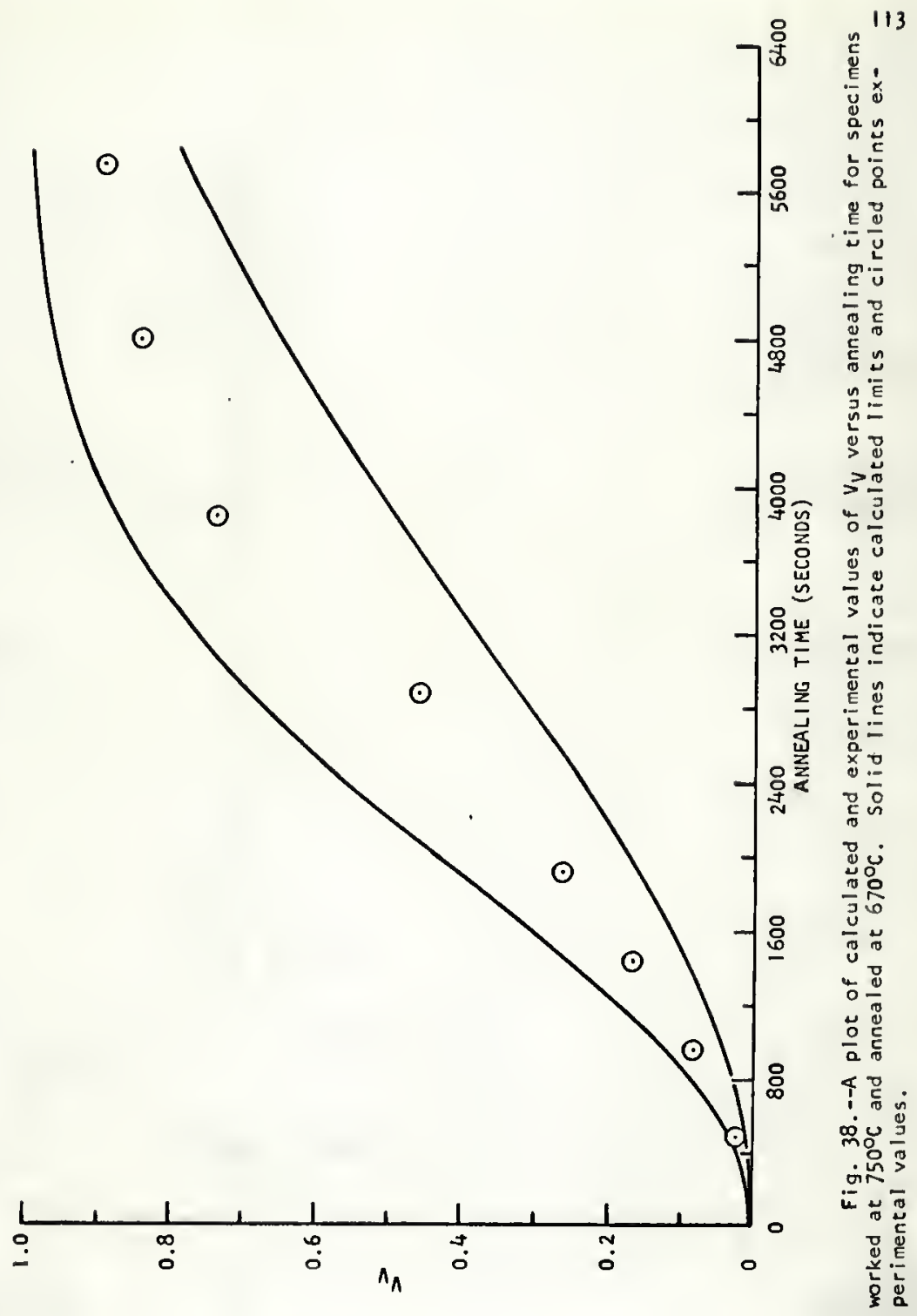




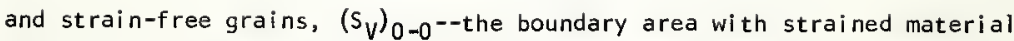

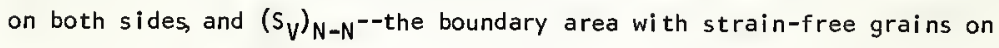
both sides. These three types will be considered in the remainder of this section.

During annealing after hot working, rapid increases occur in $\left(S_{V}\right)_{O-N}$ due to the growth of strain-free grains. These increases begin immediately with annealing and persist until impingement between strain-free grains which originated at different boundaries or edges becomes important. As indicated by Figure $39,\left(S_{V}\right)_{0-N}$ increases wi th increasing $V_{V}$ from some low value to a maximum and then decreases to zero. The values of $\left(s_{V}\right)_{0-N}$ are independent of the annealing temperature.

The values of $\left(S_{V}\right)_{O-N}$ which appear in Figure 39 can be compared with similar data obtained by English and Backofen (26) during their study of the annealing of hot-worked silicon iron. The data presented by these authors is fairly complete for only one temperature $\left(812^{\circ} \mathrm{C}\right)$ and one amount of strain (0.45). This single set has been plotted as Figure 40 . Note the very close resemblance in shape between this plot and that of Figure 39. In fact, almost complete correspondence can be obtained by contracting the ordinate of Figure 40 by an appropriate amount. This correspondence suggests that the evolution of structure in the two cases is similar, at least with respect to the positions at which strain-free grains are formed. It is interesting to note that English and Backofen did find preferential formation of strain-free grains at old grain edge.

There are two processes which may contribute to the observed decreases in $\left(s_{V}\right)_{0-0}$. The most important of these is a result of the tendency for strain-free grains to form at old boundaries and edges. Thus, 


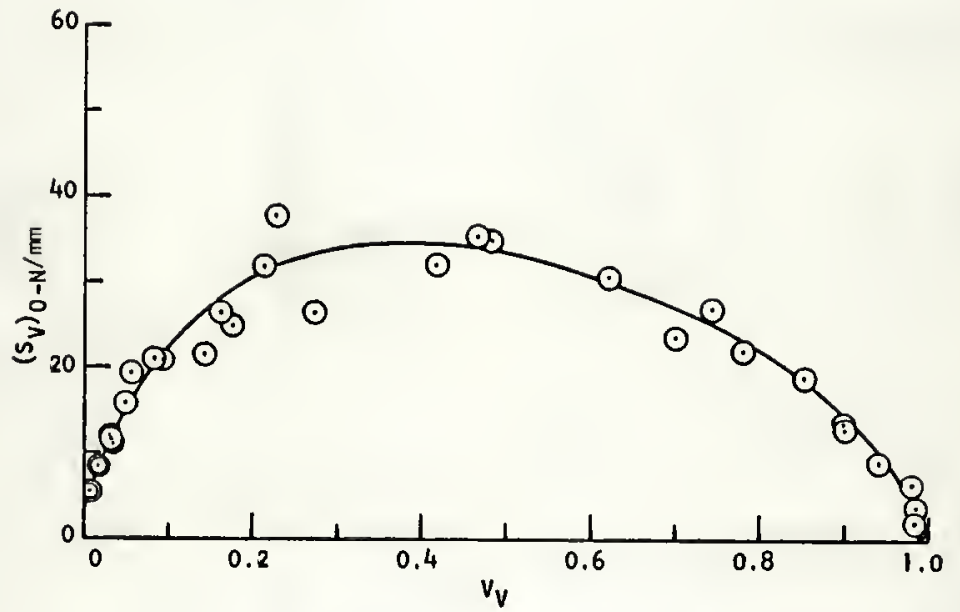

Fig. 39. - -A plot of $\left(s_{v}\right)_{0-N}$ versus $v_{v}$ which includes all values obtained from specimens anneaied at $750^{\circ} \mathrm{C}, 700^{\circ} \mathrm{C}$ and $670^{\circ} \mathrm{C}$. 


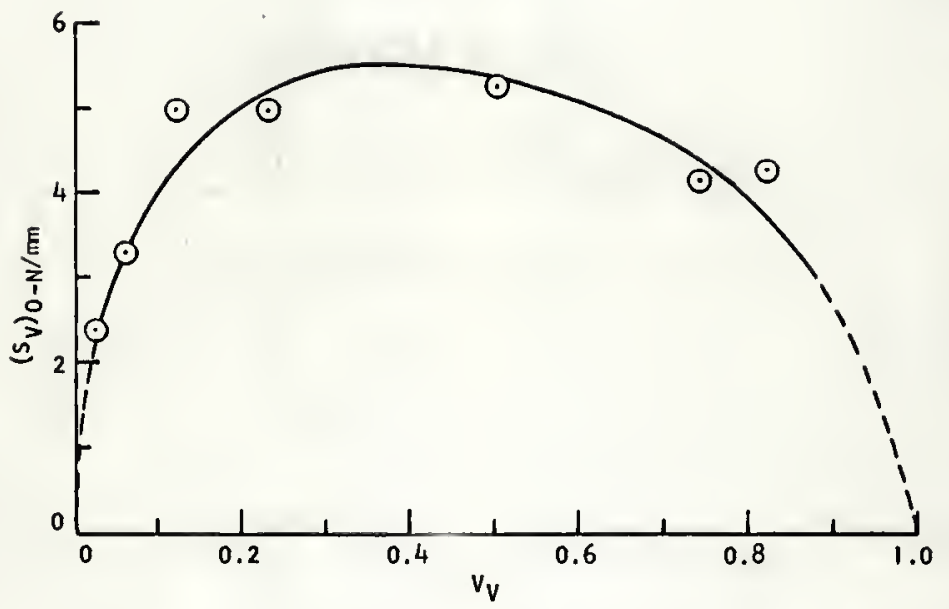

Fig. 40.--A plot of $\left(s_{V}\right)_{0-N}$ versus $V_{V}$ for hot-worked silicon 1 ron deformed to a strain of 0.45 at $812^{\circ} \mathrm{C}$ and annealed at $812^{\circ} \mathrm{C}$. The data were taken from the study by English and Backofen (26). 
boundary of the type $\left(S_{V}\right)_{0-0}$ will be replaced by that designated as $\left(S_{V}\right)_{0-N}$. Decreases may also occur in $\left(S_{V}\right)_{0-0}$ as a result of ordinary grain growth. Due to the serrated nature of the old boundaries and their consequent relative immobility (resulting mainly from the "pinning" effect of subgrain boundaries) it is probable that only small decreases in $\left(S_{V}\right)_{0-0}$ result from this source. The values of $\left(S_{V}\right)_{0-0}$ plotted in Figure 41 as a function of $V_{V}$, however, must be considered to represent remainders after decrements from the above two processes. These values are also independent of the annealing temperature.

It should be noted that boundary area of the type recorded as $\left(S_{V}\right)_{0-0}$ contributes only a fraction of the total pre-existing boundary area which is destroyed during annealing. Roughly two-thirds of the total amount (estimate taken from the first section of this chapter) is believed to be subgrain boundary area which cannot be revealed to a measurable degree by the procedures utilized. This fraction provides a major portion of the driving force for the evolution from strained material to a strain-free structure. The proposed decreases in total boundary area (including subgrain boundary area) as a function of annealing time are indicated in Figures 17, 18 and 19 as dotted lines. The decrease is approximately exponential. Some support for this proposal was found in the preliminary work. Diamond pyramid hardness values from a series of specimens annealed at $755 \pm 3^{\circ} \mathrm{C}$ after 38 per cent extension at $755^{\circ} \mathrm{C} \pm 3^{\circ} \mathrm{C}$ are plotted as Figure 42. The curve is roughly exponential in shape. Assuming that the decreases in hardness are reflecting only decreases in the amount of boundary area present, then the roughly exponential decrease in hardness with annealing time implies a similar decrease in the amount 


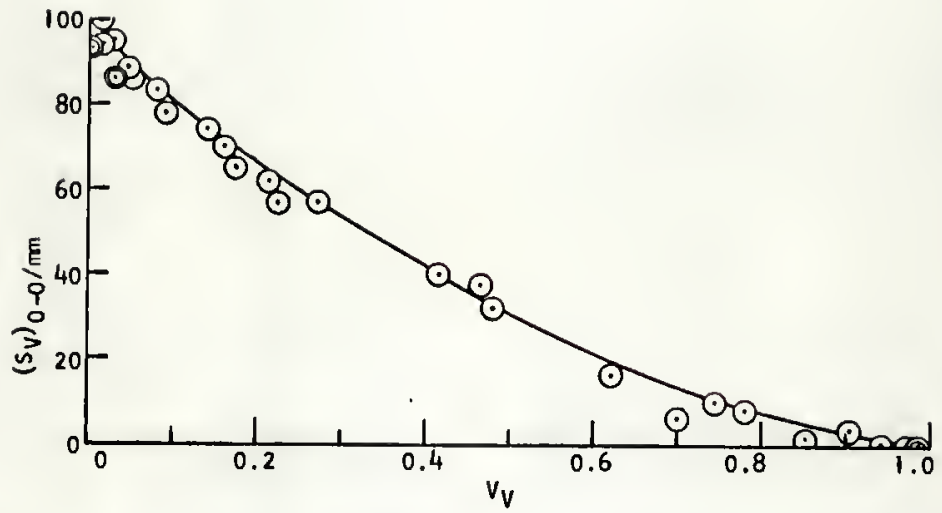

Fig. 41.--A plot of $\left(S_{V}\right)_{0-0}$ versus $v_{v}$ which includes all values obtalned from specimens annealed at $750^{\circ} \mathrm{C}, 700^{\circ} \mathrm{C}$ and $670^{\circ} \mathrm{C}$. 


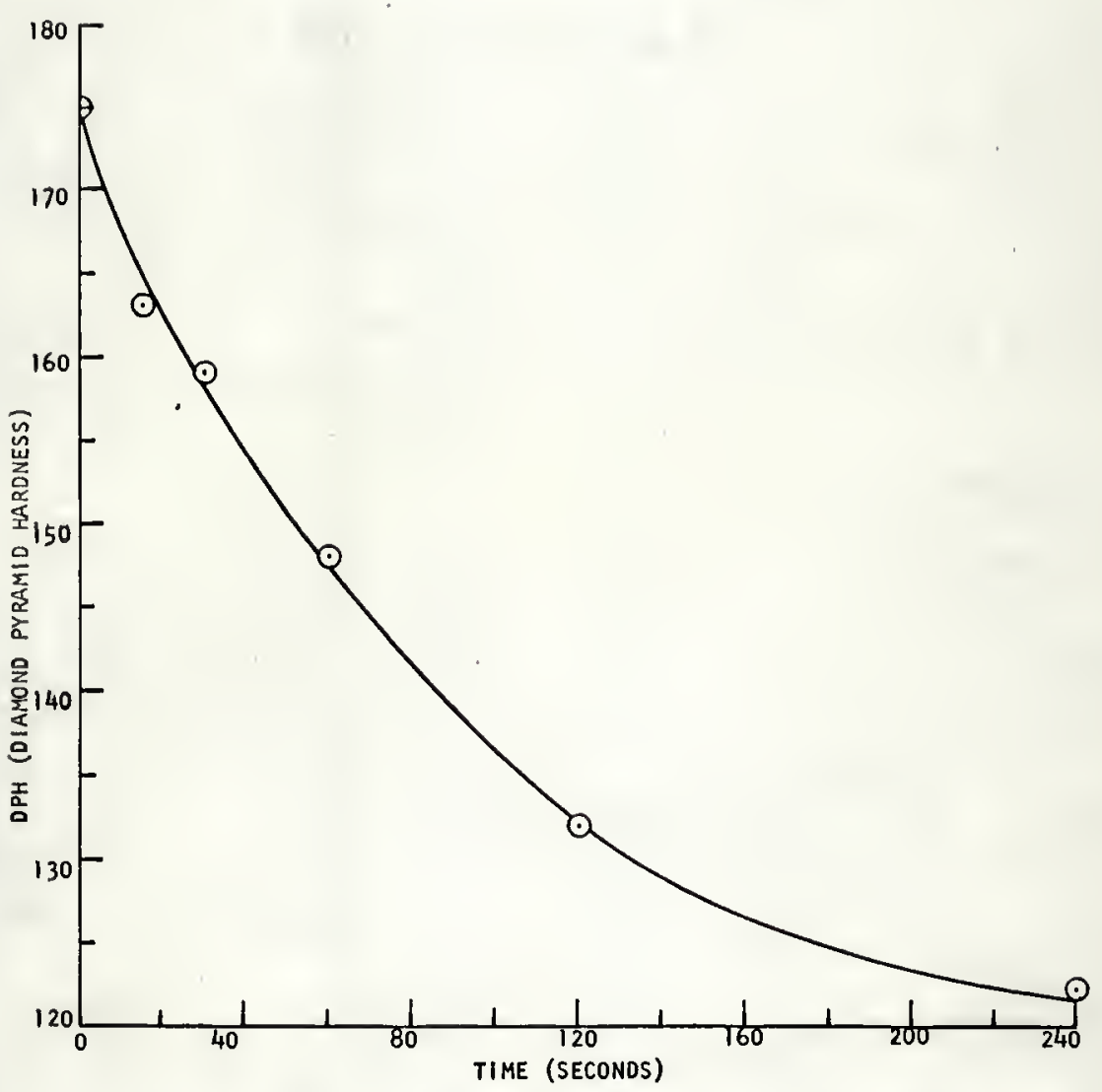

Fig. 42.--A plot of diamond pyramid hardness versus annealing time for specimens extended $38^{\circ}$ per cent at $755^{\circ} \mathrm{C}$ arid annealed at $755^{\circ} \mathrm{C}$. 
of boundary area which contributes to the hardness. This in turn implies a process obeying first order kinetics. That is, the rate of decrease in boundary area of the type $\left(s_{V}\right)_{0-0}$ is proportional to the amount of this type of boundary present, or $-d\left(S_{V}\right)_{0-0} / d t=k\left(S_{V}\right)_{0-0}$.

When strain-free grains originating at the same boundary or edge begin to impinge on each other, boundary of the type measured as $\left(S_{V}\right)_{N-N}$ is formed. This process occurs very early in the annealing period, but the amount of boundary formed (of the type $\left(S_{V}\right)_{N-N}$ ) is small at first. Throughout the range $0.1 \leqslant V_{V} \leqslant 0.95$, however, the plot of $\left(S_{V}\right)_{N-N}$ versus $V_{V}$ which appears as Figure 43 has a constant slope independent of the annealing temperature. Above $V_{V}=0.95$, the slope of the curve rapidly approaches zero, as it must, prior to the large scale destruction of boundary of the type $\left(s_{V}\right)_{N-N}$ by grain growth.

Throughout the period of annealing after impingement, boundary of the type measured as $\left(S_{V}\right)_{N-N}$ will experience rearrangements due to surface tension forces. These rearrangements result in shape changes in the grain boundary network and will tend to decrease the amount of this type of boundary present. However, they will not, per se, result in an increase in grain size. Towards the end of the annealing period the grain size will begin to increase due to the imbalance of surface tension forces. This increase will result in decreases in $\left(S_{V}\right)_{N-N}$. Data from the long annealing times at $750^{\circ} \mathrm{C}$, however, lead to the conclusion that decreases in $\left(S_{V}\right)_{N-N}$ due to grain growth are small.

It is significant that the values of $\left(s_{V}\right)_{O-N},\left(s_{V}\right)_{0-0}$, and $\left(S_{V}\right)_{N-N}$ are functions of $V_{V}$ only and independent of the annealing temperature (see Figures 39,41 , and 43 ). This result indicates that the 


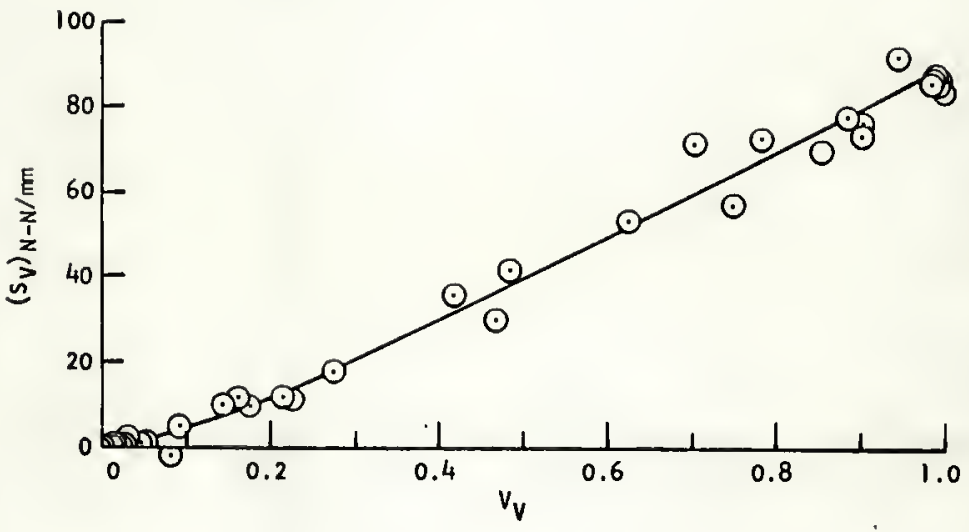

Fig. 43. - - A plot of $\left(S_{V}\right)_{N-N}$ versus $V_{V}$ which includes ali values obtained from specimens annealed at $750^{\circ} \mathrm{C}, 700^{\circ} \mathrm{C}$ and $6700^{\circ} \mathrm{C}$. 
evolution from strained material to a strain-free structure occurs by the same phenomenon or process within the temperature range from $670^{\circ} \mathrm{C}$ to $750^{\circ} \mathrm{C}$.

\section{Summary}

A study of the evolution from strained material to strain-free grains during annealing after hot working provided confirmation for many of the characteristics of the process deduced in the first section of this chapter. Confirmation was obtained from "activation energies," from values of volume fraction strain-free grains versus annealing time, and from hardness values for the following characteristics: (1) all strainfree grains present during the annealing period are initiated during working, (2) strain-free grains are initiated at old grain edges and possibly at old grain boundaries, (3) the growth of strain-free grains is inhibited in certain directions, and (4) the only process which occurs during annealing is an increase in amount of strain-free material by boundary migration. These characteristics coupled with the experimentally determined constant growth rate and the assumption that strain-free grains impinge first upon others growing at the same edge (or boundary) and only later upon those growing at different edges (or boundaries) permit the conclusion that a modification of the relation derived by Cahn (53) between volume fraction new grains and annealing time will describe the actual process.

Measurements of boundary area of the type $\left(s_{V}\right)_{0-N}$ plotted versus $V_{V}$ yielded the same shape curve as did similar data obtained by English and Backofen (26) from the annealing of hot-worked silicon iron. This 
and other observations suggest that the process proposed for the initiation of strain-free grains in hot-worked Nickel 200 may apply to hotworked silicon iron. Other boundary area measurements indicated that the amount of a particular type of boundary present at any time was a resultant of effects due to several processes. Thus, one would expect the relationship between the amount of any of the various types of boundary area and annealing time to be even more complex than the relationship between volume fraction strain-free material and annealing time.

\section{A Review of the Proposed Mechanism and a Discussion of Its Applicability to Other Studies of Annealing After Hot Working and to Studies of Annealing after Cold Working}

\section{A review of the mechanism}

Discussion earlier in this chapter developed a mechanism for the initiation of new grains during working and for their growth into strainfree grains during annealing. In the following paragraphs, the basic features of this mechanism will be reviewed.

The initial, undeformed structure is considered to be equiaxed and to contain only high-angle grain boundaries and twin boundaries. Hot working introduces into this structure dislocations which under the influence of the thermal and mechanical driving forces may assume a number of aspects. If the discussion is restricted to materials of moderate and high stacking-fault energy, then a large fraction of those dislocations which remain in the structure are contained in the subgrain boundary network. This network develops continually throughout working (illustrated schematically by Figure 28 ). It is this development which plays a major role in the initiation of new grains. 
New grains are considered to be initiated at positions of maximum energy gradient. In the present case, since most of the energy (dislocations) introduced into the structure during working appears as a subgrain boundary network, the above criterion reduces to the most favorable positions being those with the greatest difference in density of boundary network quadruple points. These positions are associated with old grain edges and possibly old grain boundaries. They are created by the continual development of the subgrain boundary network during working. If the development has exceeded a certain degree locally and a sufficient difference in density of quadruple points exists, then new grains will be formed by the migration of a section of high-angle boundary into the region containing the greatest density of quadruple points.

The process described above is a dynamic one in that new grains can be initiated any time during working provided that the subgrain boundary has developed locally into a connected network. Growth of new grains will proceed vigorously because the density of quadruple points within the growing grain is zero. Since dislocations are still being introduced into the structure, however, these grains will become deformed and begin to form subgrain boundary while still growing. Continued development of this type of boundary until the formation of a continuous network will destroy the integrity of the parent grain so that its growth can proceed no farther. The whole process of initiation, growth, and deformation may then be repeated.

The structure which obtains on the completion of working depends, then, on the conditions of working, i.e., the temperature, the rate, and the extent of deformation. This structure may contain original grains 
wi th various degrees of subgrain development. It may also contain grains that were initiated and grown at various times during the deformation. These also have subgrains in various stages of maturity depending upon the degree of deformation experienced since the initiation of each parent grain. Some of these grains (not having mature subgrain networks) may remain in active growth into the annealing period.

\section{Predictions based on the proposed}

mechanism compared with results from other studies of hot

working

The proposed mechanism has made possible qualitative predictions of the effects of the experimental variables upon (1) the type of position at which strain-free grains form, (2) the linear growth rate, and (3) the final grain size.* These predictions are discussed and the experimental evidence which applies to each prediction is presented in the following subsections. The experimental variables which will be treated are the initial grain size, working temperature, rate of working, extent of working, and the annealing temperature. The application of the proposed mechanism is limited to materials of moderate and high stacking-fault energy because the mechanism is based upon a material which forms a welldefined subgrain boundary network during hot working. ${ }^{\dagger}$

\footnotetext{
strain free.

"The grain size which exists when the structure first becomes
}

Fote that the structural evolution under consideration must exhibit two characteristics: (1) all strain-free grains are present at essentially zero annealing time, i.e., there is no time dependent nucleation, and(2) the rate at which the boundary between the strained material and the strain-free grains moves into the strained material is constant, i.e., the linear growth rate is constant. 
Before proceeding with the discussion it is necessary to explain two of the symbols which will be used to describe the experimental results. These are the exponent $n$ in the equation $V_{V}=1$-exp-kt $t^{n}$ and $t_{0.5}$ --the time necessary for 50 per cent of the structure to become strain free. The value calculated for $n$ is indicative of the type of microstructural position at which strain-free grains are formed, i.e., if $\mathrm{n}=1$ then strain-free grains are formed at old grain boundaries, if $\mathrm{n}=2$ at old grain edge, and if $\mathrm{n}=3$ at old grain corners. ${ }^{*}$ Values of $t_{0.5}$ permit qualitative comparisons of the growth rates among the various sets of data, provided $n$ and the initial grain sizes are the same for each set. This conclusion follows from the equation $V_{V}=1-\exp -k t^{n}$. If $V_{V}=0.5$, then $\ln 0.5=\mathrm{kt}_{0.5}^{\mathrm{n}}$ and since the constant $k$ contains the growth rate to the power of $n, G>0 / / t_{0.5}$. Since growth rates were directly determined for the three series comprising the present study and for one set of preliminary results, comparisons based on values of $t_{0.5}$. are useful in determining the effects of the experimental variables on the growth rate in other experiments on Nickel 200.

Data from prior studies which can be used to test the predictions made in the following subsections have been collected into Table 14. Included in the table are the initlal and final vaiues of $\mathrm{N}_{\mathrm{L}}$ along with values of $n$ and $t_{0.5}$. Tabulated values of $N_{L}$ and $t_{0.5}$ are fairly precise (the standard error is estimated at less than \pm 10 per cent of the given value). Values of $n$ determined from data obtained during the present

$$
\text { *This point is discussed In more detail in the paper by Cahn }
$$


TABLE 14.--A listing of initial and final grain sizes, values of $n$ from the equation $V_{V}=1-\exp -k t^{n}$, and times necessary for 50 per cent of the structure to become strain free $\left(t_{0.5}\right)$ for all available data on annealing after hot working of $\mathrm{Nickel} 200$

\begin{tabular}{|c|c|c|c|c|c|c|c|}
\hline \multirow{2}{*}{$\begin{array}{c}\text { Total } \\
\text { Extension } \\
(\%)\end{array}$} & \multicolumn{2}{|c|}{ Temperature $\left({ }^{\circ} \mathrm{C}\right)$ of } & \multirow{2}{*}{$\begin{array}{r}\text { Rate of } \\
\text { Working } \\
(/ \mathrm{min})\end{array}$} & \multicolumn{2}{|c|}{$\mathrm{N}_{\mathrm{L}} / \mathrm{mm}$} & \multirow[b]{2}{*}{ n } & \multirow[b]{2}{*}{$\mathrm{t}_{0.5^{(\mathrm{sec})}}$} \\
\hline & Working & Annealing & & Initial & Final & & \\
\hline $31^{*}$ & 750 & 670 & 0.75 & 45 & $45 t$ & 1.9 & 3520 \\
\hline $31^{*}$ & 750 & 700 & 0.75 & 45 & 46 & 2.1 & 685 \\
\hline $11^{*}$ & 750 & 750 & 0.75 & 45 & 44 & 2.4 & 145 \\
\hline $36 \neq$ & 705 & 705 & 0.75 & 43 & 39 & 1.8 & 290 \\
\hline $37^{\not F}$ & 705 & 705 & 0.75 & 41 & 46 & 2.4 & 250 \\
\hline 37 & 755 & 755 & 0.75 & 39 & 34 & 1.8 & 100 \\
\hline 37 & 805 & 805 & 0.75 & 31 & 39 & 2.0 & 18 \\
\hline 37 & 855 & 855 & 0.75 & 17 & 30 & 1.3 & 13 \\
\hline 24 & 705 & 705 & 0.75 & 18 & 18 & 1.1 & 24,000 \\
\hline 36 & 705 & 705 & 0.75 & 18 & 24 & 1.8 & 960 \\
\hline 47 & 705 & 705 & 0.75 & 18 & 26 & 2.6 & 600 \\
\hline 41 & 705 & 705 & 0.009 & 40 & 29 & 1.3 & 2500 \\
\hline
\end{tabular}

*Oata from present study.

FAt $V_{V}=0.90$

Nickel 200.

FEach of these sets of data was obtained from a different heat of 
study have approximately the same precision. All other values of $n$, however, have an estimated standard error of 0.4 , e.g., $2.4 \pm 0.4$.

The remainder of this discussion is divided into six subsections. Each of the first five of these is concerned with the effects resulting from changes in one of the experimental variables. Contained in each of these subsections are statements of the predicted effects, an outline of the arguments which resulted in these predictions, and experimental evidence which is relevant to the effect being discussed. The sixth subsection is a summary of the predicted and observed effects.

\section{Effects of initial grain size. --Initial grain size is predicted}

to have no effect on the type of position at which strain-free grains are preferentially formed. This prediction is based on the fact that the formation of strain-free grains at old grain edge or boundary is fundamental to the proposed mechanism. As long as the material is polycrystalline, sites of these types are available. Values of $n$ included in Table 15 confirm this prediction. That is, the value of $n$ for an initial

TABLE 15.--0ata which illustrate the effects of initial grain size upon the type of position at which strain-free grains are formed and upon the final grain sizes

\begin{tabular}{ccccccc}
\hline $\begin{array}{c}\text { Total } \\
\begin{array}{c}\text { Extension } \\
(\%)\end{array}\end{array}$ & \multicolumn{2}{c}{ Temperature $\left({ }^{\circ} \mathrm{C}\right)$ of } & & \multicolumn{2}{c}{$\mathrm{N}_{\mathrm{L}} / \mathrm{mm}$} & \\
\cline { 2 - 3 } & Working & Annealing & & Initial & Final & $\mathrm{n}$ \\
\hline $36^{*}$ & 705 & 705 & 43 & 39 & 1.8 \\
$37^{*}$ & 705 & 705 & 41 & 46 & 2.4 \\
36 & 705 & 705 & 18 & 24 & 1.8 \\
\hline
\end{tabular}
Nickel 200.

*Each of these sets of data was obtained from a different heat of 
$N_{L}$ of $43 / \mathrm{mm}$ is the same as for an initial $N_{L}$ of $18 / \mathrm{mm}$. Additional confirmation was obtained from the photomicrographs of the series with initial $N_{L}$ 's of $18 / \mathrm{mm}$ and $41 / \mathrm{mm}$. One photomicrograph of a partially annealed structure from each of these series is included as Figure $44 .^{*}$ In both structures, but especially in Figure 44 (a), note the formation of strainfree grainst at old grain edge (triple points in two dimensions).

It is predicted that changes in initial grain size will not change the growth rate. This statement is made on the basis that growth rate depends upon the driving force (density of subgrain boundary network quadruple points) and the annealing temperature, neither of which is a function of initial grain size. None of the available data are suitable for determining the validity of the above conclusion.

If the initial grain size is decreased, then the final grain size is predicted to decrease. This effect is a result of a change in extent of old grain edge and boundary with a change in initial grain size. A change in extent of the old grain edge and boundary changes the number of possible positions for the formation of strain-free grains and hence the final grain size. In agreement with the above prediction, values of $N_{L}$ included in Table 15 show that if the initial $N_{L}$ is decreased from $41 / \mathrm{mm}$ to $18 / \mathrm{mm}$, then the final $N_{L}$ is decreased from $46 / \mathrm{mm}$ to $24 / \mathrm{mm}$. A similar

*The two photomicrographs of Figure 44 and those of Figures 45 and 46 were obtained using the Sensitive Tint Plate of the Bausch and Lomb Research Model Metal lograph.

tStrain-free grains are distinguished in this and the two subsequent figures (as well as in all photomicrographs obtained using polarized $1 \mathrm{ight}$ ) by the lack of variations in shading within the grain. For a more complete explanation of this phenomenon see the section on etching procedures in Chapter 11. 


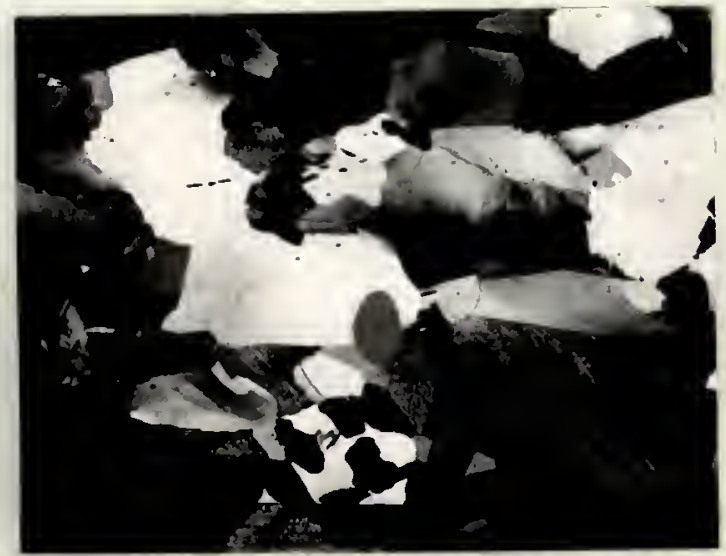

(a)

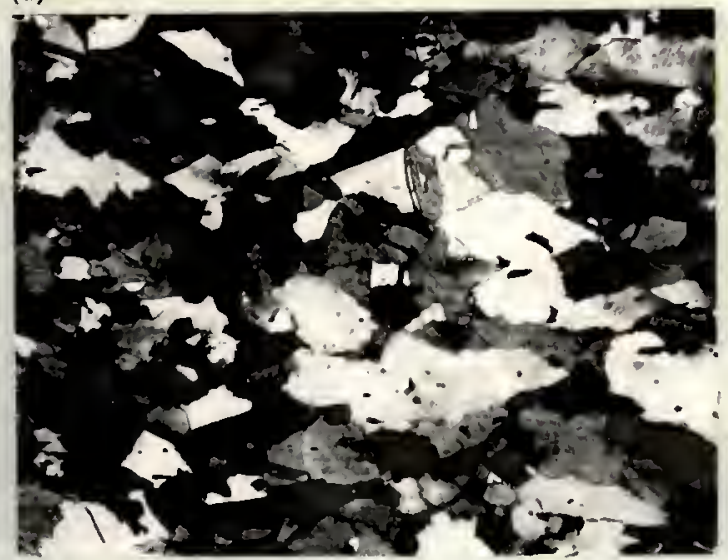

(b)

Fig. 44.--Photomicrographs obtained from partially annealed specimens (worked and annealed at $705^{\circ} \mathrm{C}$ ) having initial $\mathrm{N}_{\mathrm{L}}$ 's of (a) $18 / \mathrm{mm}$, and (b) $41 / \mathrm{mm}$. Note the number of strainfree grains which have formed at old grain edges (triple points in two dimensions). $200 x$. 
relationship was observed by Kornfeld (24) and by Kornfeld and Hartleif (25) in studies of an Armco I ron hot worked in the $\alpha$-field.

Effects of working temperature. - At high hot-working temperatures, strain-free grains will form at the old qrain boundary rather than at the old grain edge. This prediction is made on the basis that at high hotworking temperatures edge positions are deactivated during the working period. Deactivation results from the formation at old grain edges of many rather large and almost strain-free grains during the working period. These grains will usually contain a subgrain boundary network which is well enough developed to eliminate their growth advantage, but not developed enough to allow their participation in the initiation of new grains. Thus, only boundary positions remain able to participate in the formation of strain-free grains during annealing. A photomicrograph which reenforces this reasoning is included as Figure 45 . It was obtained from a specimen which had been worked at $855^{\circ} \mathrm{C}$ and then quenched (no anneal). Note the number of old grain triple points (edge in three dimensions) which are occupied by large, nearly strain-free grains. The data contained in Table 16 provide confirmation of the above prediction. For working temperatures up to and including $805^{\circ} \mathrm{C}, \mathrm{n}$ is approximately two (indicating preferential formation of strain-free grains at old grain edge); however, for a working temperature of $855^{\circ} \mathrm{C} n$ is close to one (indicating preferential formation of strain-free grains at old grain boundary).

An increase in working temperature will decrease the growth rate. The basis for this prediction is the well-established increase in subgrain size with increasing working temperature. An increase in subgrain 


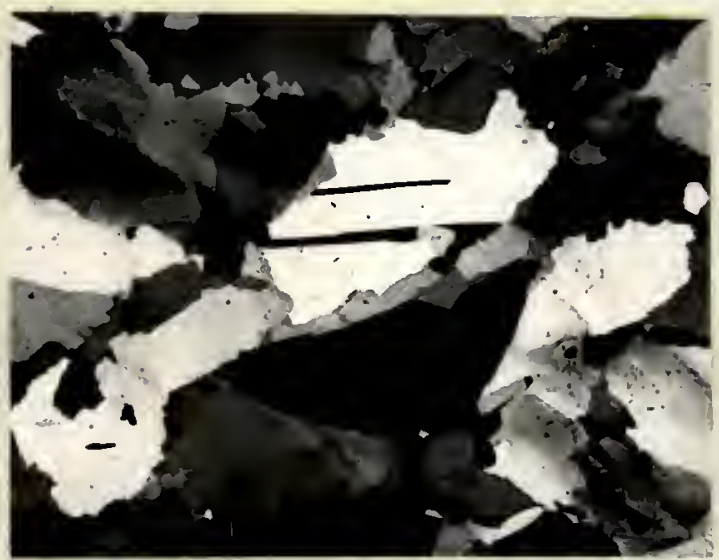

Fig. 45. - -A photomicrograph obtained from a specimen of Nickel 200 worked at $855^{\circ} \mathrm{C}$ but not annealed. Note the presence of strain-free or nearly strain-free grains at many of the old grain triple points (edge in three dimensions). $200 \mathrm{x}$. 
TABLE 16.--Data which illustrate the effects of working temperature upon: (1) type of positions at which strain-free grains are formed, (2) growth rate and (3) final grain sizes

\begin{tabular}{|c|c|c|c|c|c|c|}
\hline \multirow{2}{*}{$\begin{array}{c}\text { Total } \\
\text { Extension } \\
(\%)\end{array}$} & \multicolumn{2}{|c|}{ Temperature $\left(^{\circ} \mathrm{C}\right)$ of } & \multicolumn{2}{|c|}{$\mathrm{N}_{\mathrm{L}} / \mathrm{mm}$} & \multirow[b]{2}{*}{$n$} & \multirow[b]{2}{*}{$\mathrm{t}_{0.5}(\mathrm{sec}$} \\
\hline & Working & Annealing & Initial & Final & & \\
\hline 31 & 750 & 700 & 45 & 46 & - & 685 \\
\hline 36 & 705 & 705 & 43 & 39 & 1.8 & 290 \\
\hline 37 & 705 & 705 & 41 & 46 & 2.4 & 250 \\
\hline 37 & 755 & 755 & - & - & 1.8 & - \\
\hline 37 & 805 & 805 & - & - & 2.0 & - \\
\hline 37 & 855 & 855 & - & - & 1.3 & - \\
\hline
\end{tabular}

size decreases the density of subgrain boundary network quadruple points and hence the driving force for the growth of strain-free grains will also decrease. Although no direct information on the variation of growth rate with working temperature is available, it is possible to infer from the values of $t_{0.5}$ in Table 16 that the growth rate does indeed decrease with increasing working temperature. Note that working at $750^{\circ} \mathrm{C}$ and annealing at $700^{\circ} \mathrm{C}$ resulted in $t_{0.5}=685$ seconds, while working and annealing at $705^{\circ} \mathrm{C}$ resulted in $t_{0.5}=290$ to 250 seconds. Since it is unlikely that the small variations in total extension ( 31 versus 36 per cent) could account for this difference, growth rates in the two cases must be different.

\section{The proposed mechanism predicts an increase in final grain size}

with an increase in working temperature. The bas is for this prediction is that the increase in subgrain size due to an increase in working temperature will result in the formation of fewer strain-free grains. However, 
data included in Table 16 do not show a marked change in final grain size with a change in working temperature. On the other hand, Rossard and Blain (27) have reported that the final grain size of an annealed hotworked ferritic stainless steel decreases with decreasing temperature of working. Note that this material would be expected to form well-defined subgrains during hot working.

Effects of rate of working. --At low rates of working, strain-free grains will form at old grain boundaries rather than at old grain edges. The argument which resulted in this prediction is similar to that presented for the effect of temperature in the previous subsection; namely, the formation at old grain edges during working of new grains which do not preserve a growth advantage into the annealing period essentially deactivates the edge positions. Some confirmation of this reasoning is avai lable from the photomicrograph included as Figure 46 . This photograph was obtained from a specimen quenched immediately after working (at $705^{\circ} \mathrm{C}$ and at a rate of $0.009 /$ minute). Note the large number of triple points (edges) occupied by almost strain-free grains which formed during working. It is suggested that these grains neither participate in the formation of new grains nor grow during the annealing period. Thus, only boundary positions are available to contribute to the growth of strainfree grains during the annealing period. Values of $n$ included in Table 17 confirm the above prediction. For a rate of $0.75 / \mathrm{minute}$, these values range from 1.8 to $2.6,{ }^{*}$ while for a rate of $0.009 /$ minute $n$ is 1.3 .

*Oata for the large-grained material are included since it was previously shown that grain size does not have an appreciable effect on the type of position at which strain-free grains are formed. 


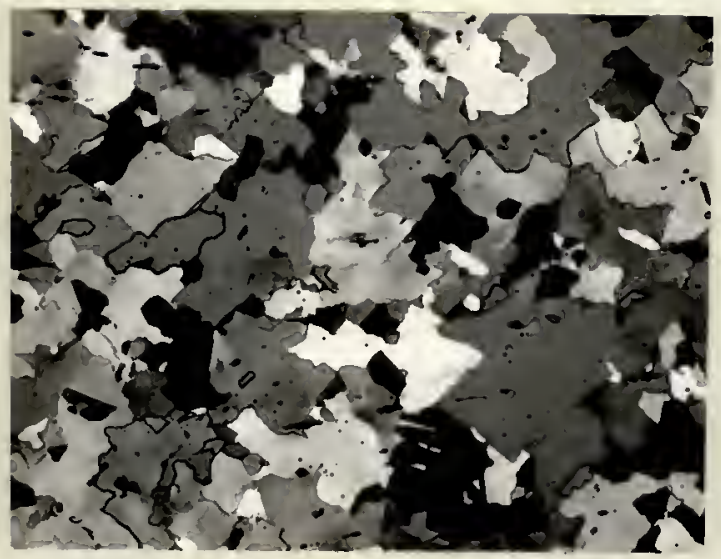

Fig. 46. - -A photomicrograph obtained from a specimen of Nickel 200 worked at a rate of $0.009 /$ minute but not annealed. Note the larger number of strain-free or nearly strain-free grains which have formed at old grain triple points (edges). 200x. 
TABLE 17. - Data which illustrate the effects of rate of working upon the type of positions at which strain-free grains are formed and upon the

final grain sizes

\begin{tabular}{|c|c|c|c|c|c|c|}
\hline \multirow{2}{*}{$\begin{array}{c}\text { Total } \\
\text { Extension } \\
(\%) \\
\end{array}$} & \multicolumn{2}{|c|}{ Temperature $\left({ }^{\circ} \mathrm{C}\right)$ of } & \multirow{2}{*}{$\begin{array}{l}\text { Rate of } \\
\text { Working } \\
\text { (/min) }\end{array}$} & \multicolumn{2}{|c|}{$\mathrm{N}_{\mathrm{L}} / \mathrm{mm}$} & \multirow[b]{2}{*}{$n$} \\
\hline & Working & Annealing & & Final & Initial & \\
\hline 36 & 705 & 705 & 0.75 & 43 & 39 & 1.8 \\
\hline 37 & 705 & 705 & 0.75 & .41 & 46 & 2.4 \\
\hline 42 & 705 & 705 & 0.75 & 18 & 26 & 2.6 \\
\hline 41 & 705 & 705 & 0.009 & 40 & 29 & 1.3 \\
\hline
\end{tabular}

A decrease in the rate of working will result in a decrease in

growth rate. This effect is predicted on the same basis as the effect of increasing working temperature discussed in the previous subsection. No data are available with which to test this prediction.

A decrease in rate of working will result in an increase in final grain size. This prediction also follows from the fact that subgrain size increases with decreasing rate of working. The increase in subgrain size results in a decrease in the number of strain-free grains formed and hence in an increase in final size. This effect is illustrated by the data in Table 17 which show that, for the same initial grain size, a rate of $0.75 / \mathrm{minute}$ resulted in a final $\mathrm{N}_{\mathrm{L}}$ of $46 / \mathrm{mm}$ while a rate of $0.009 /$ minute resulted in a final $N_{L}$ of $29 / \mathrm{mm}$. A similar observation was reported by Rossard and Blain (27) in their study of a ferritic stainless steel.

Effects of extent of working. - The proposed mechanism predicts that if the extent of working is below a certain value, then a connected network of subgrain boundaries does not exist and no strain-free grains 
will be formed during annealing. Experiments performed prior to the main study confirmed that a mi nimum amount of working is necessary before strain-free grains will form during annealing. These experiments involved working large-grained $\left(N_{L}=18 / \mathrm{mm}\right)$ specimens of Nickel 200 to total extensions of $6,12,24,36$, and 42 per cent at $705^{\circ} \mathrm{C}$ and then annealing at $705^{\circ} \mathrm{C}$. Specimens extended at least 24 per cent underwent a structural evolution during annealing, those extended 12 per cent experienced no noticeable microstructural change in annealing times up to approximately 12,000 seconds. Rossard and Blain (27) also have noted that a certain minimum amount of working is necessary before "recrystallization" occurs during the annealing of a hot-worked ferritic stainless steel.

It is also predicted on the basis of the proposed mechanism that the extent of working will have no effect on the type of position at which strain-free grains are formed, provided the extent of working has been great enough to permit a structural evolution during annealing. However, data included in Table 18 do not support this prediction. Note

TABLE 18.--Data which illustrate the effects of extent of working upon the type of position at which strain-free grains are formed and upon the final grain sizes

\begin{tabular}{ccccccc}
\hline $\begin{array}{c}\text { Total } \\
\text { Extension } \\
(\%)\end{array}$ & Temperature & $\left({ }^{\circ} \mathrm{C}\right)$ of & & \multicolumn{2}{c}{$\mathrm{N}_{\mathrm{L}} / \mathrm{mm}$} & \\
\cline { 2 - 3 } & Working & Annealing & Initial & Final & $\mathrm{n}$ \\
\hline 36 & 705 & 705 & 18 & 18 & 1.1 \\
42 & 705 & 705 & 18 & 24 & 1.8 \\
\hline
\end{tabular}


that the value of $n$ drops from 1.8 for a total extension of 36 per cent to 1.1 for a total extension of 24 per cent. Thus it appears that strainfree grains form at old grain boundaries at low total extension, but at old grain edges at moderate total extensions.

A decrease in the extent of working will decrease the growth rate. This prediction is based on the observations that the subgrain boundaries are less well developed and the subgrains are larger for the lower extents of working. Both effects will decrease the driving force for the growth of strain-free grains. No information is available which can be applied to a test of this prediction.

\section{Decreasing the extent of working will increase the final grain}

size. The basis for this prediction is the increase in subgrain size and the resulting decrease in number of strain-free grains formed with decreasing extent of working. Data included in Table 18 show that a specimen extended 24 per cent yielded a final $N_{L}$ of $18 / \mathrm{mm}$ while a specimen extended 42 per cent yielded a final $N_{L}$ of $26 / \mathrm{mm}$. This observation is consistent with the early work of Hanemann and Lucke (21) and Hanemann (22). Data presented by these authors (of which Figure 47 is an example) indicate that above a critical extent of working the final grain size decreases with increasing extent of working. A similar observation was made by Rossard and Blain (27) in their study of a hot-worked ferritic stainless steel.

Effects of annealing temperature. --The effects of annealing temperature on the type of position at which strain-free grains are formed, on the growth rate, and on the final grain size are part of the foundation of the proposed mechanism. Therefore, these effects are consistent 


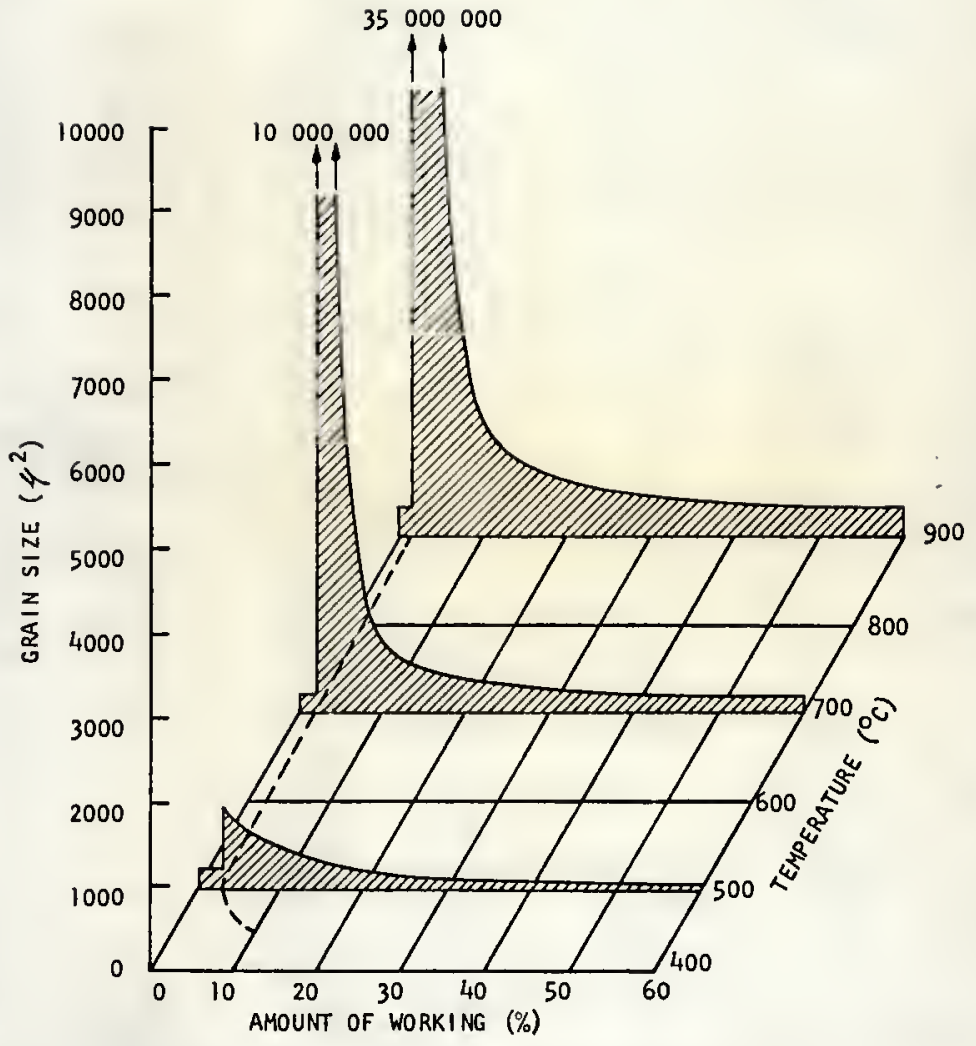

Fig. 47.--A three-dimensional representation of the relationship between grain size, working temperature and degree of working for electrolytic copper fully annealed after working (from reference 21 ). 
with this mechanism and are reviewed here only for the sake of completeness. The annealing temperature has no effect on either the type of position at which strain-free grains are formed or on the final grain size. Growth rates, however, due to the great increase in atomic mobility with temperature, are strongly dependent upon the annealing temperature. The exact dependence is: $G=A \exp -Q_{G} / R T$ with $Q_{G}=32,000 \mathrm{cal} / \mathrm{mole}$.

Summary.--A summary of the predicted effects of the experimental variables on the type of position at which strain-free grains are formed, on the growth rate, and on the final grain sizes is included as Table 19. Capital letters are used for effects confirmed by experimental results, lower case letters are used for predicted but unconfirmed effects, and underlining to Indicate either predicted effects not confirmed by the available results, or effects for which the available data are cont radictory.

\section{Application of the proposed mechanism} to annealing after cold working

The mechanism proposed in this study for the initiation and growth of strain-free grains depends upon the development of a welldefined subgrain boundary network during working. Since a well-defined subgrain boundary network is generally not formed during cold working, the proposed mechanism would be expected to apply to annealing after cold working in only three special cases (provided the material is one of high stacking-fault energy):

1. The material is of such high purity that subgrain formation can occur during cold working, e.g., very high purity aluminum which may have a recrystallization temperature as low as $-40^{\circ} \mathrm{C}(58)$. 


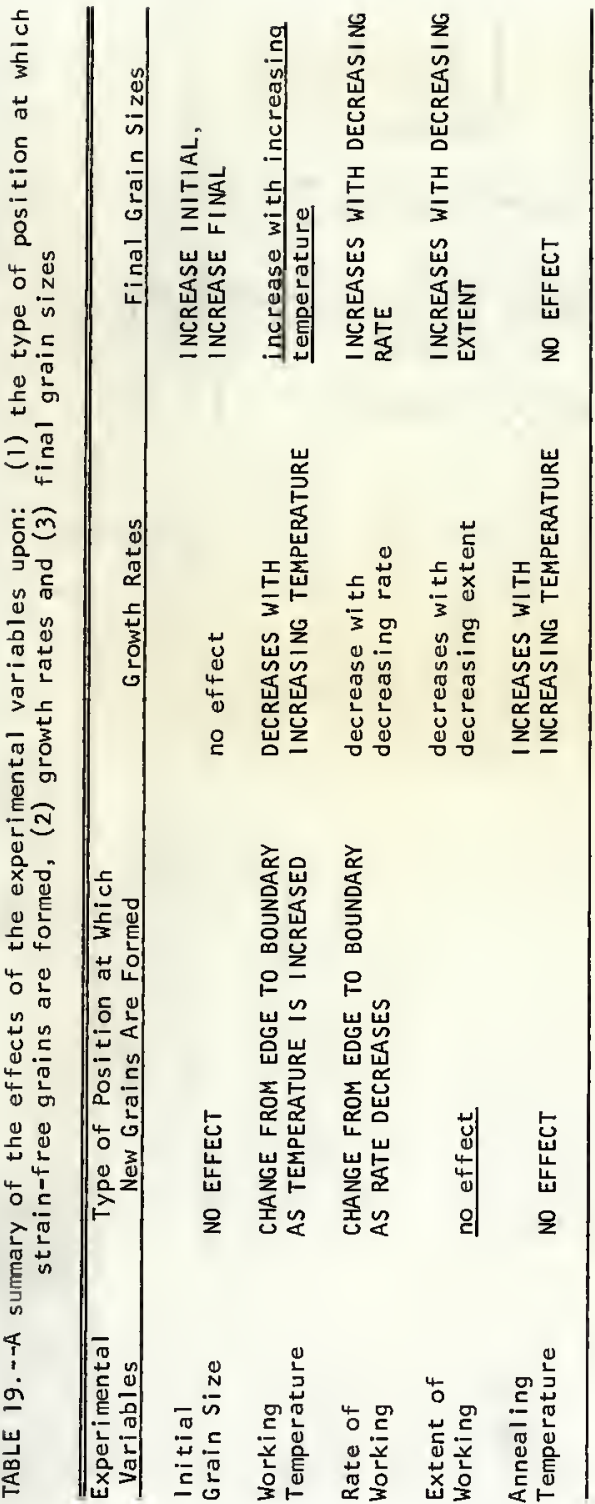


2. The heat generated during working is sufficient to cause the formation of a subgrain boundary network.

3. Subgrain boundary formation occurs so rapidly that a network is formed during the time required to heat to the annealing temperature.

On the above bases, one might expect to find cases in which the proposed mechanism is operative among studies of annealing after cold work involving high purity aluminum.

An example of a study of this type is the one performed by Vandermeer and Gordon (31) on the recrystallization of high purity aluminum (99.999 to $99.9999 \mathrm{Al}$ ) alloyed with 0.008 weight per cent copper. Recrystallization of this material was described as being edge-nucleated and growth controlled, i.e., all new grains were formed at essentially zero annealing time. In addition, growth rates were found to be constant and plots of $\ln \ln \left(1 / 1-V_{V}\right)$ versus $\ln t$ yielded slopes of two. These four conditions are also characteristic of the present study. This correspondence suggests an identity of mechanism. 
CHAPTER $V$

CONCLUSIONS

The principal conclusions of this study appear below.

1. The as-hot-worked structure of Nickel 200 is characterized by the following features:

(a) grain elongation.

(b) dislocations not associated with a boundary network.

(c) subgrains.

(d) serrated boundaries.

(e) new grains formed during working.

The relative importance and even the appearance of these features is a function of the working conditions.

2. The evolution from a strained material to strainfree grains which occurs in Nickel 200 during annealing after hot working is governed to a great extent by the structure which exists at the completion of working. Of particular importance are the subgrains and the new grains formed during working.

3. The evolution from a strained material to strainfree grains which occurs during annealing after hot working is best described as follows:

(a) All strain-free grains originate at essentially zero annealing time. The number of these grains decreases slightly at short annealing times.

(b) Strain-free grains are preferentially formed at old grain edges and to a lesserdegree at old grain boundaries.

(c) Strain-free grains have a tendency to grow into only one of the old grains which share an edge or boundary. 
(d) The only process which occurs during annealing is boundary migration.

(e) The linear growth rate of the strain-free grains calculated from the expression $G=\left(d V_{V} / d t\right) /$ $\left(S_{V}\right)_{O-N}$ is constant throughout the annealing period. The temperature dependence of this growth rate is given by $G=A$ exp $-Q_{G} / R T$ with $Q_{G}=32,000 \mathrm{cal} / \mathrm{mole}$.

4. The initiation of new grains during hot working and their growth as strain-free grains during annealing after hot working in Nickel 200 can be rationalized in terms of a mechanism which may be outlined as follows:

(a) Most dislocations introduced into the structure during hot working form a subgrain boundary network which develops continually throughout working.

(b) This development results in differences in density of subgrain boundary network quadruple points across grain boundaries.

(c) The difference in density of subgrain boundary network quadruple points creates an energy gradient. The positions of maximum energy gradient are associated with grain edge and grain boundary.

(d) New grains form during working at positions of maximum energy gradient by migration of a section of high-angle boundary into that grain with the smallest subgrains, the highest angle boundaries, or both.

(e) A fraction of the new grains formed during working will maintain a growth advantage into the annealing period. These grains then grow by boundary migration and consume the strained matrix.

5. The mechanism proposed above allows predictions of the effects of the experimental variables upon the structural evolution during annealing. The majority of these predictions are confirmed by results from other studies of annealing after hot working. 
APPENDICES 
APPENDIX A

AN OUTLINE OF PREVIOUS INVESTIGATIONS

OF HOT WORKING 


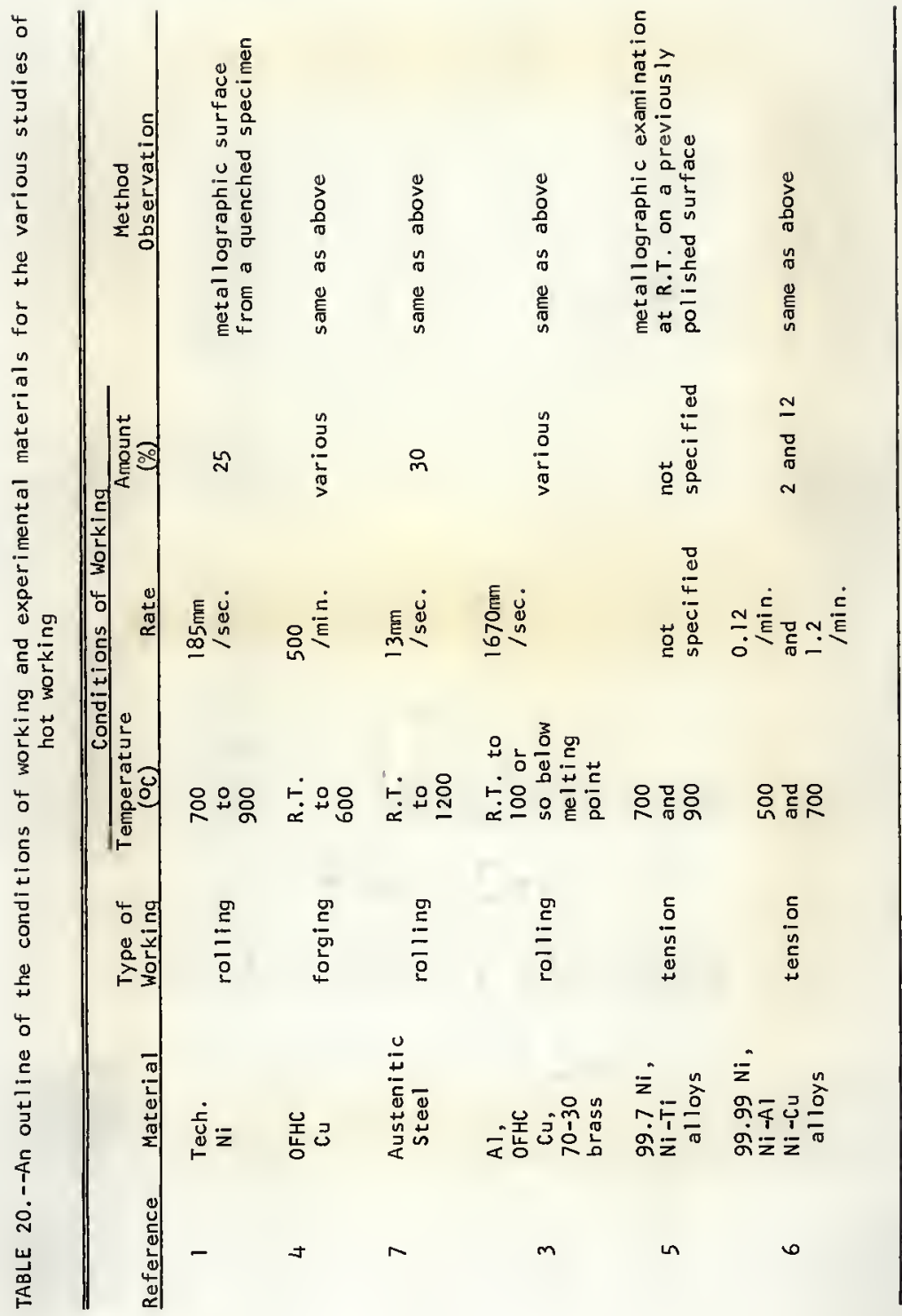




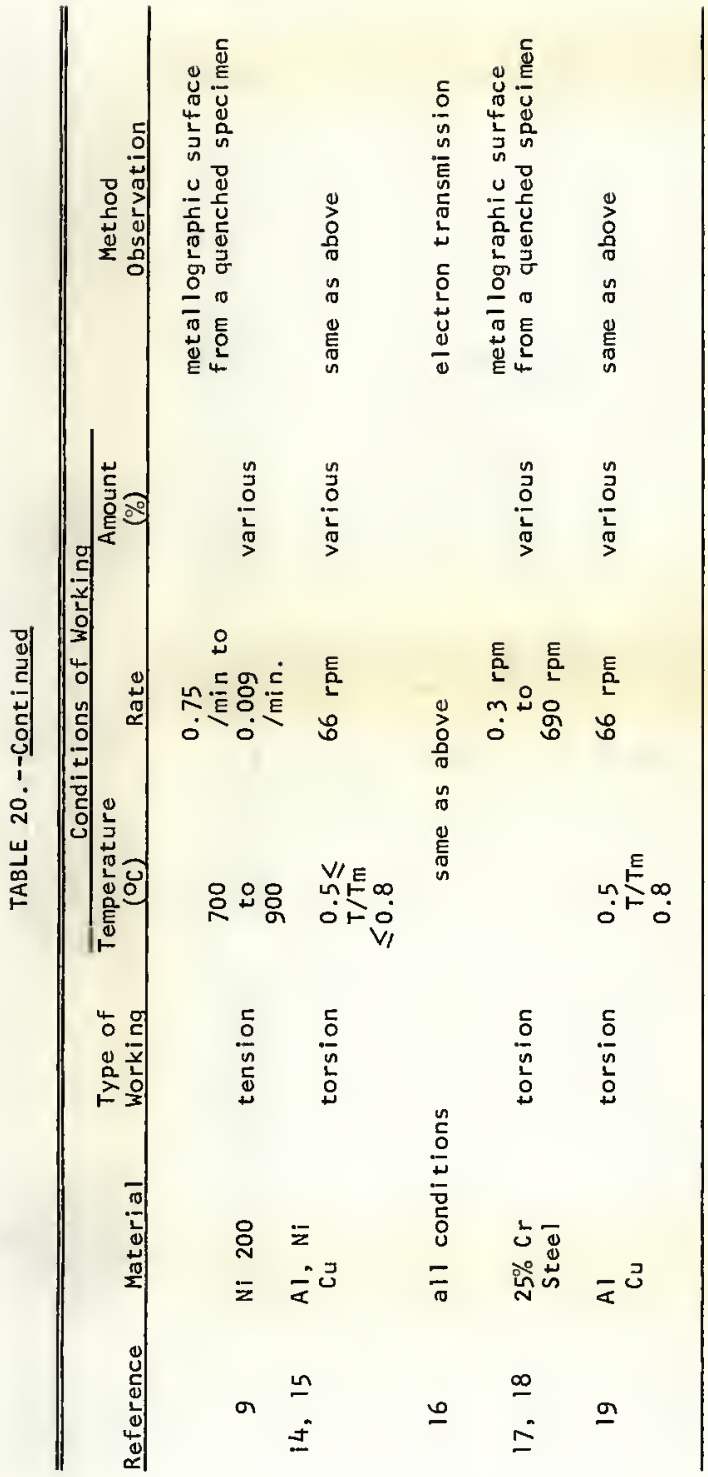


APPENDIX B

PHOTOMICROGRAPHS OBTAINED FROM SPECIMENS

WORKED DURING THE STUDY 

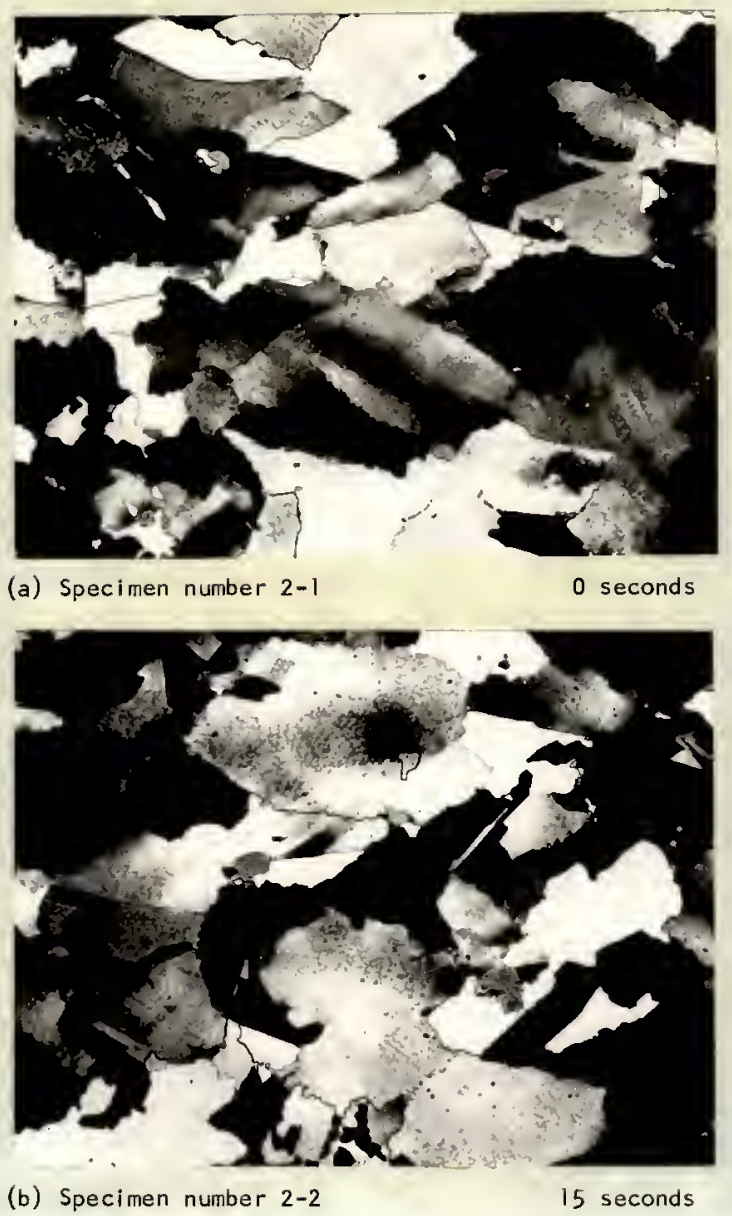

Fig. 48.--Photomicrographs of specimens worked at $750^{\circ} \mathrm{C}$ and annealed at $750^{\circ} \mathrm{C}$. Annealing times are indicated. Polarized light. $400 x$. 


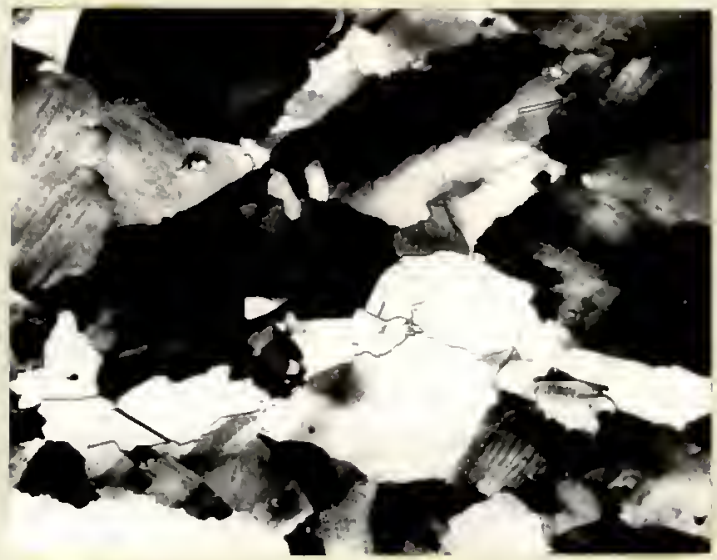

(c) Specimen number 3-1

30 seconds

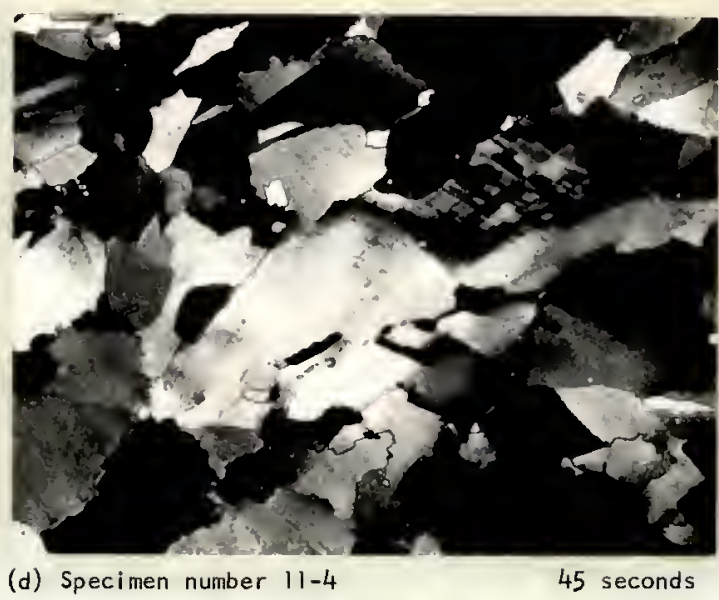

Fig. 48.--Continued 


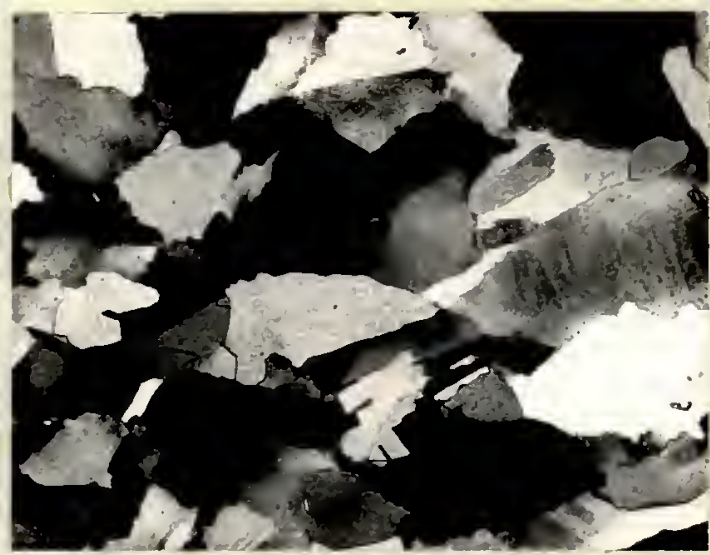

(e) Specimen number 3-4

60 seconds

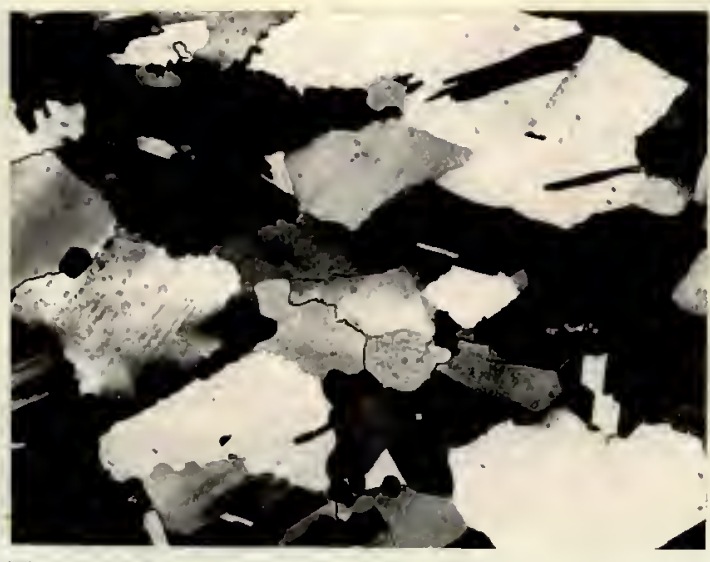

(f) Specimen number 11-1

75 seconds

Fig. 48.-- - Contínued 


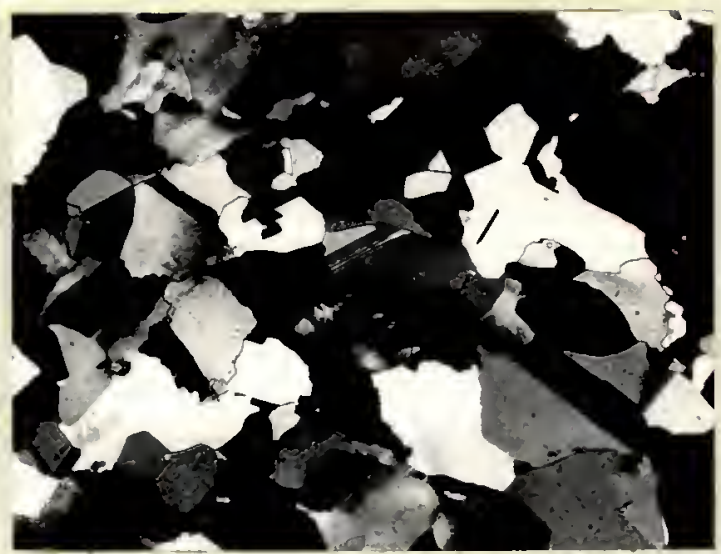

(g) Specimen number $1-3$

90 seconds

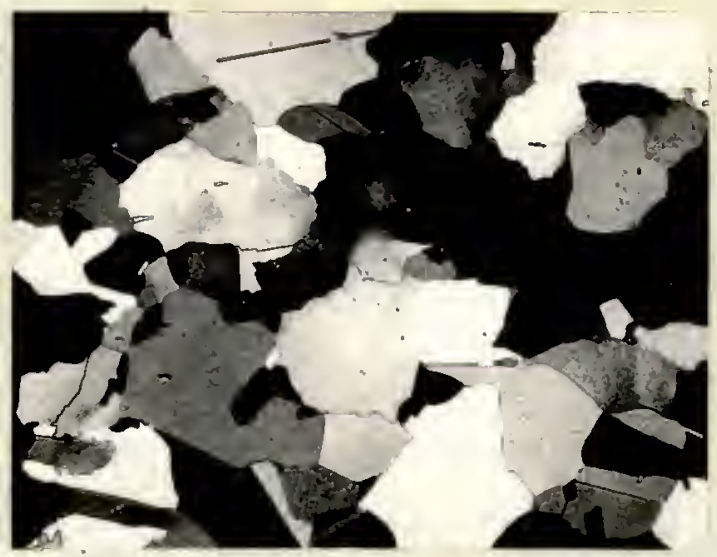

(h) Specimen number 2-3

120 seconds

Fig. 48.---Continued 

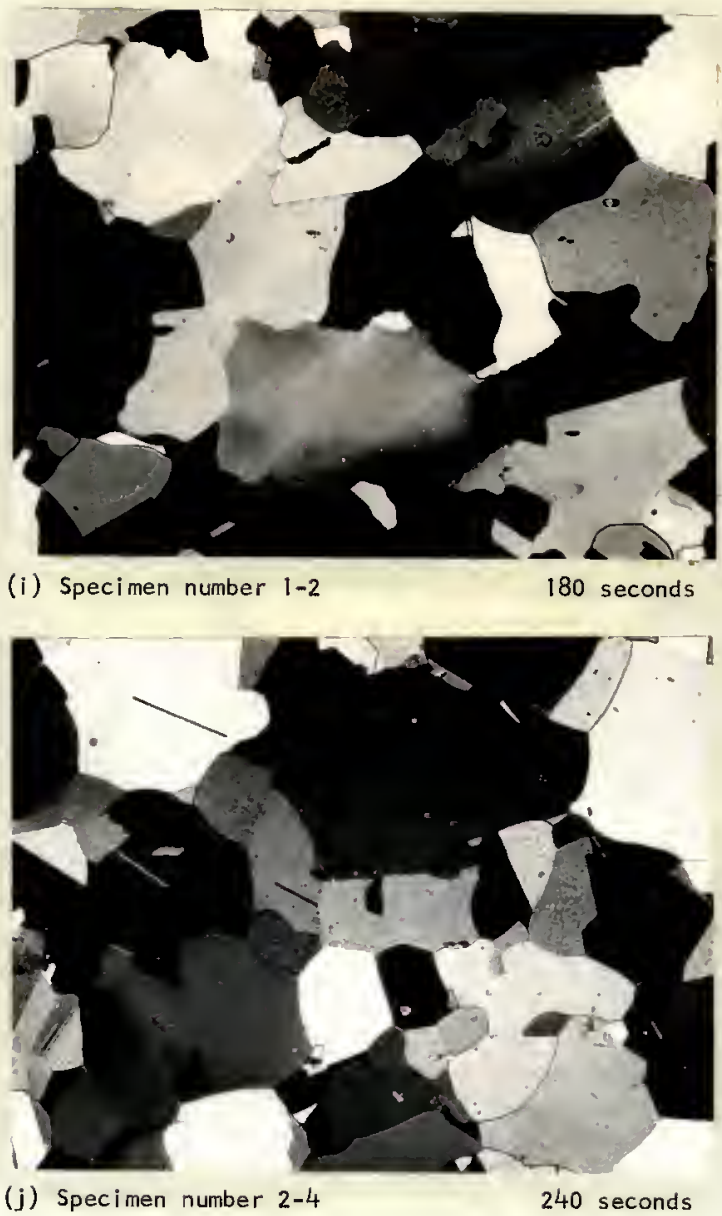

Fig. 48.-- Conti nued 

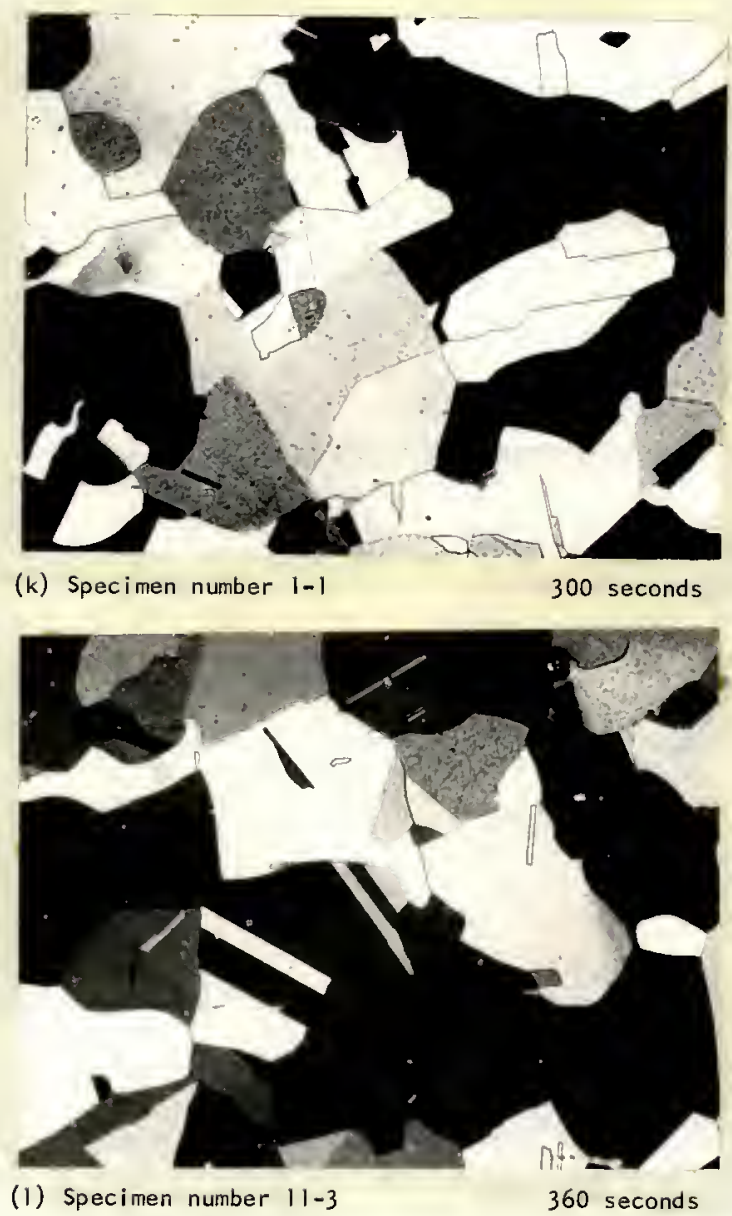

Fig. 48.--Continued 


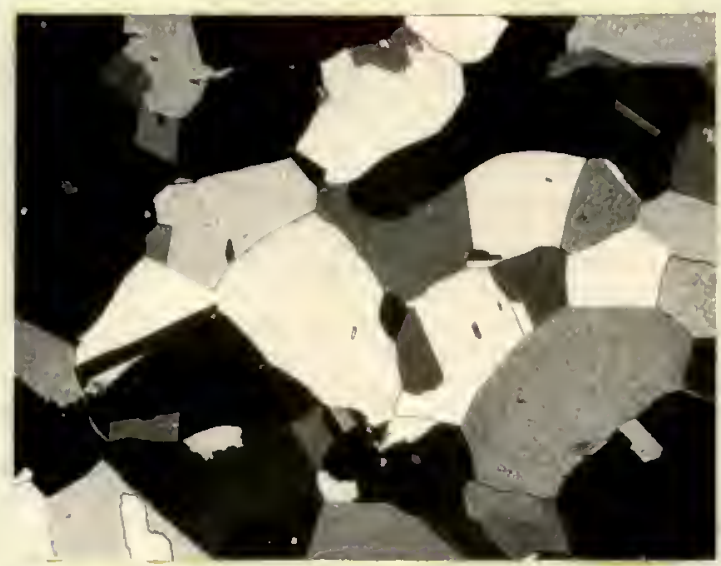

(m) Specimen number $11-5$

720 seconds

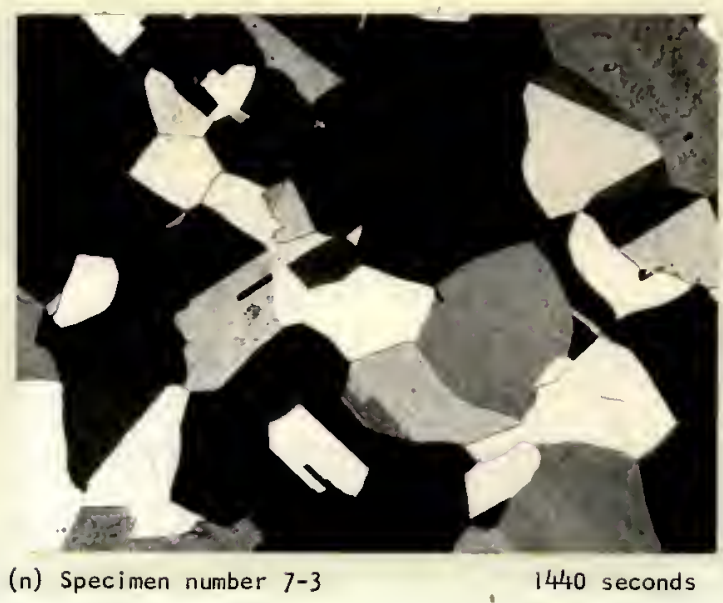

Fig. 48. - - Continued 

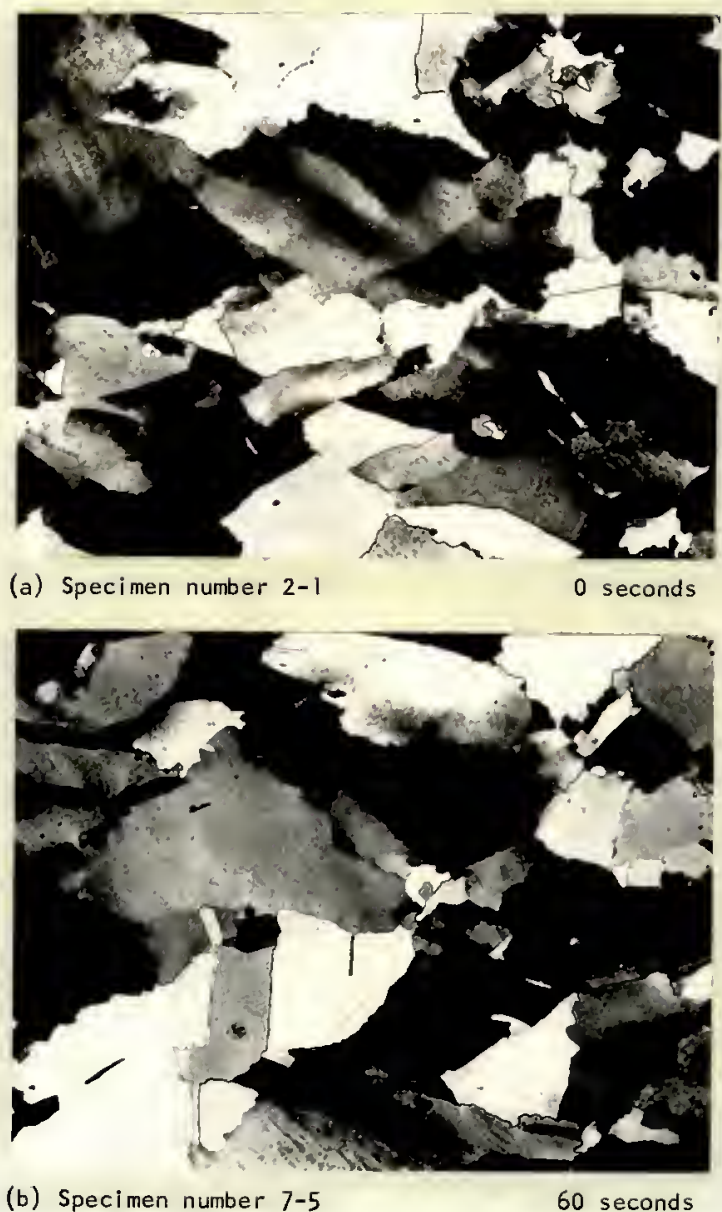

Fig. 49.--Photomi crographs of specimens worked at $750^{\circ} \mathrm{C}$ and annealed at $700^{\circ} \mathrm{C}$. Annealing times are indicated. Polarized light. 400x. 


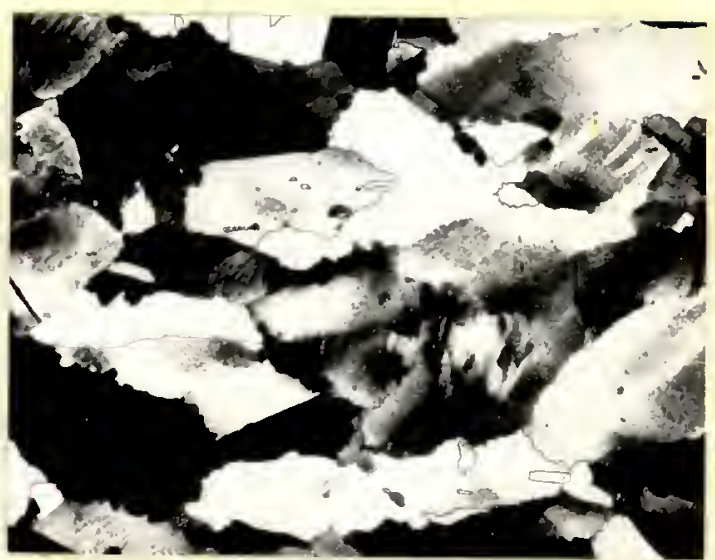

(c) Specimen number 6-2

120 seconds

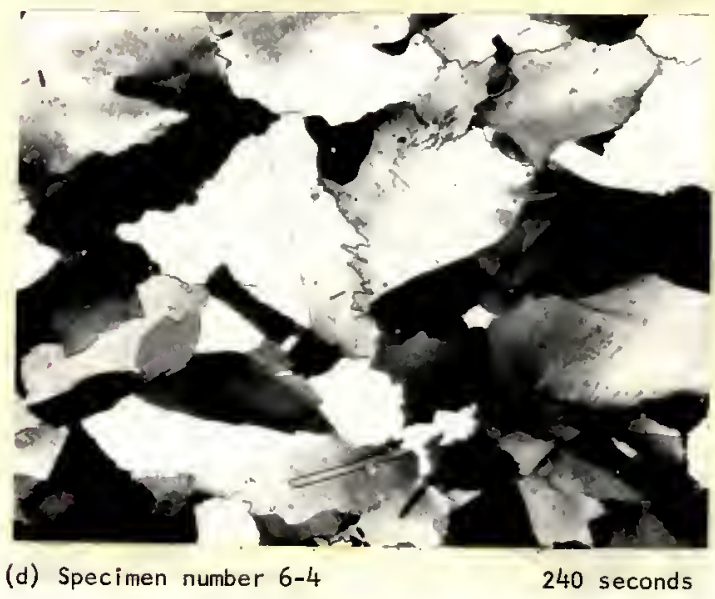

Fig. 49.--Continued 

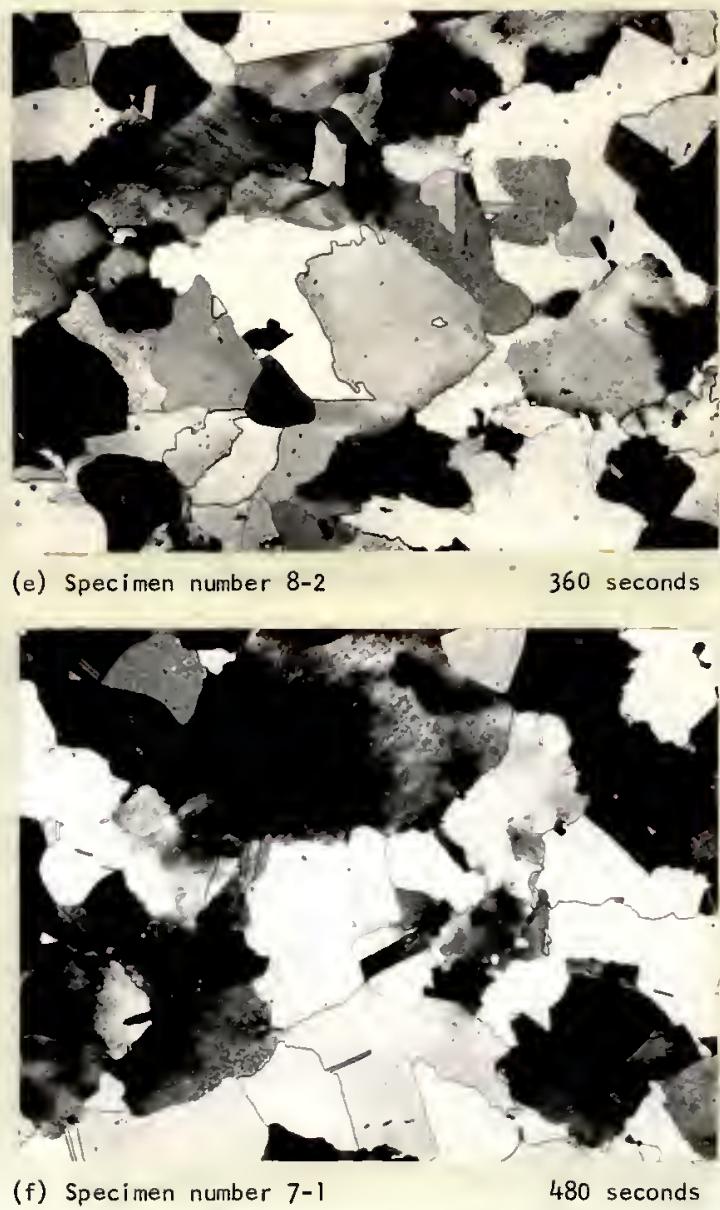

Fig. 49.--Continued 


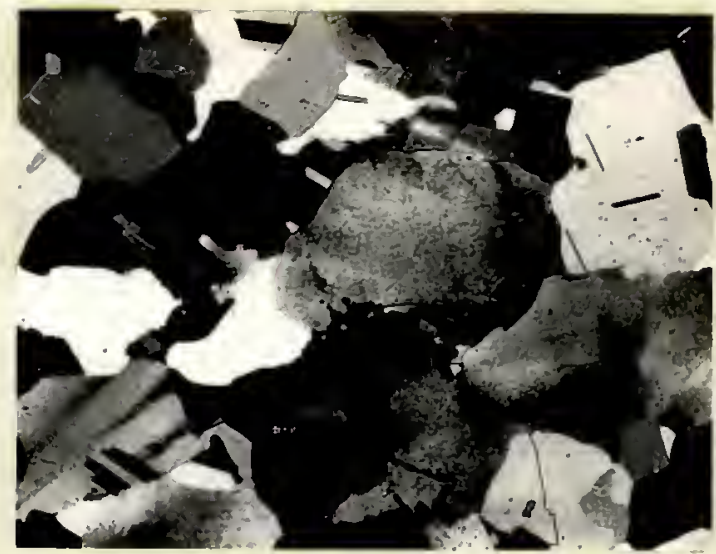

(g) Specimen number 8-4 600 seconds

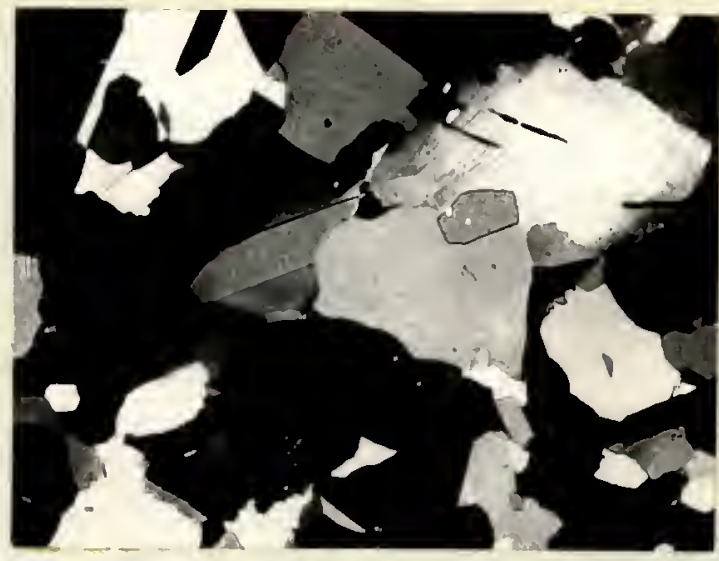

(h) Specimen number 7-2

720 seconds

Fig. 49 .--Continued 


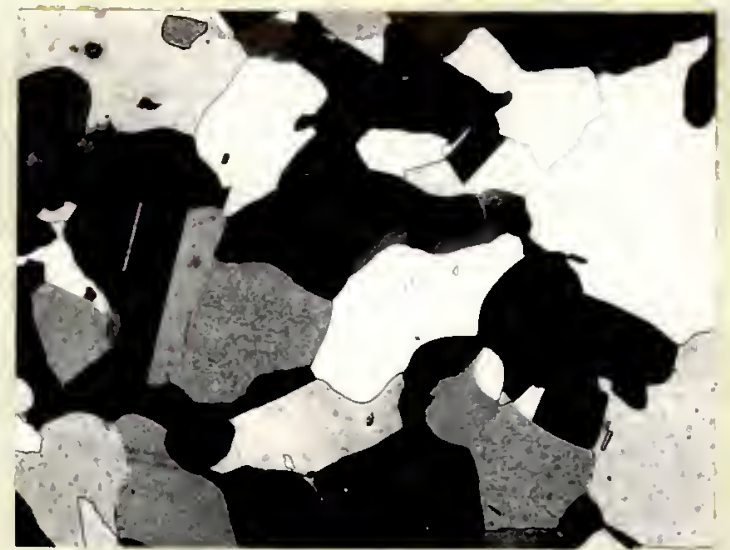

(i) Specimen number 8-5

960 seconds

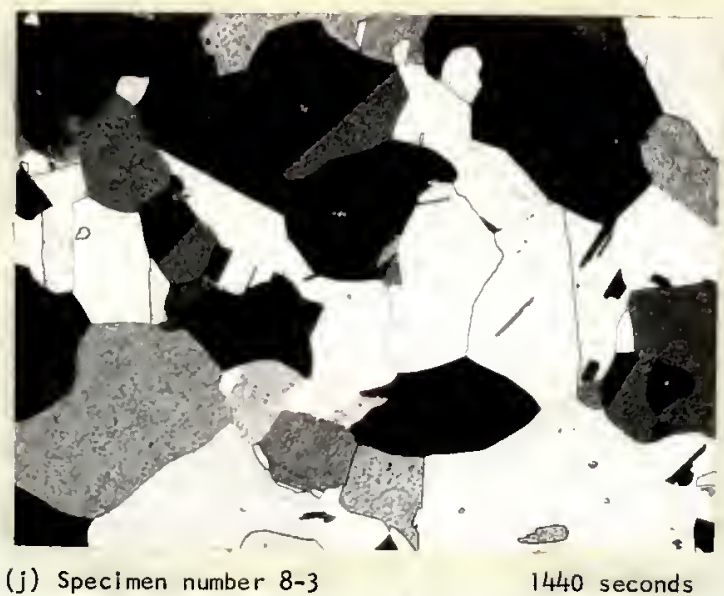

Fig. 49.-- Continued 


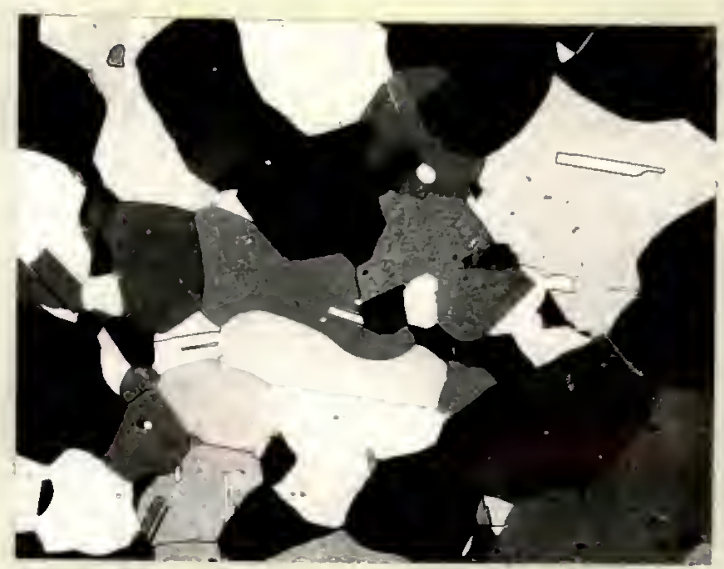

(k) Specimen number 8-1

1920 seconds

Fig. 49.--Continued 

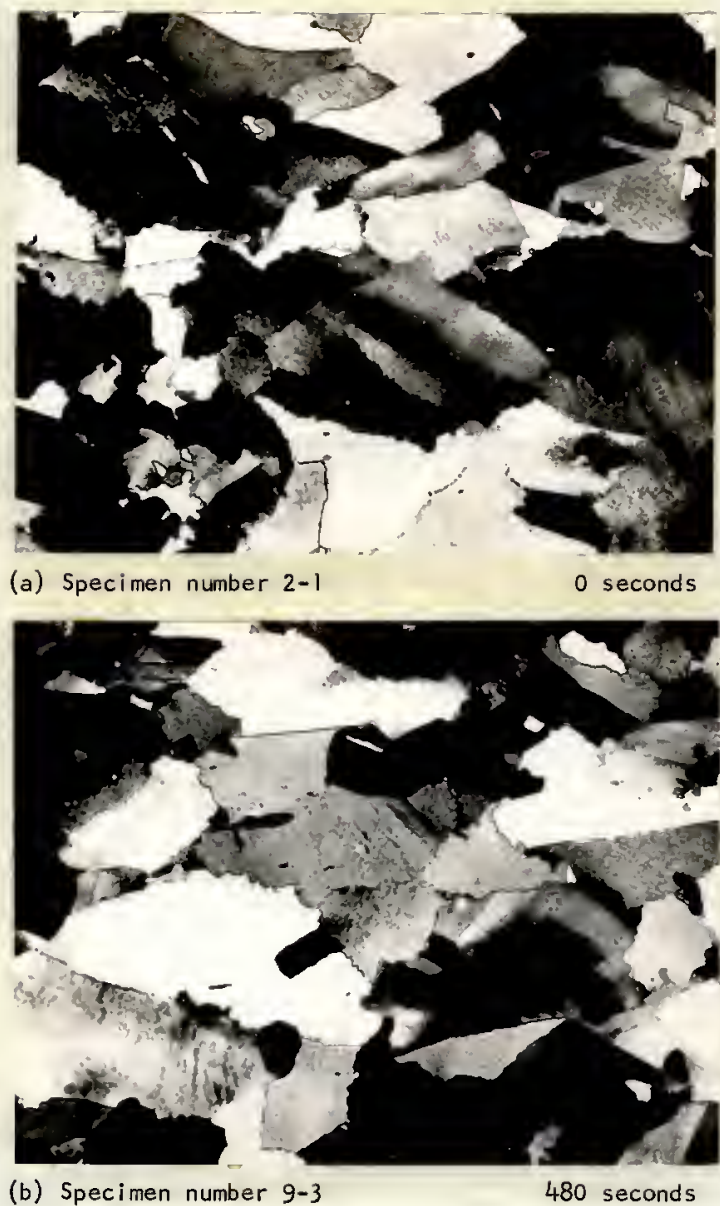

Fig. 50.--Photomi crographs of specimens worked at $750^{\circ} \mathrm{C}$ and annealed at $670^{\circ} \mathrm{C}$. Annealing times are indicated. Polarized light. 400X. 


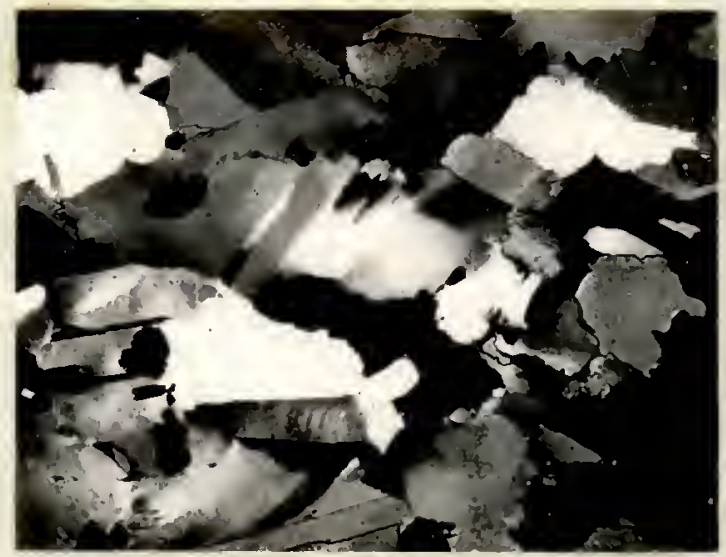

(c) Specimen number 12-4

960 seconds

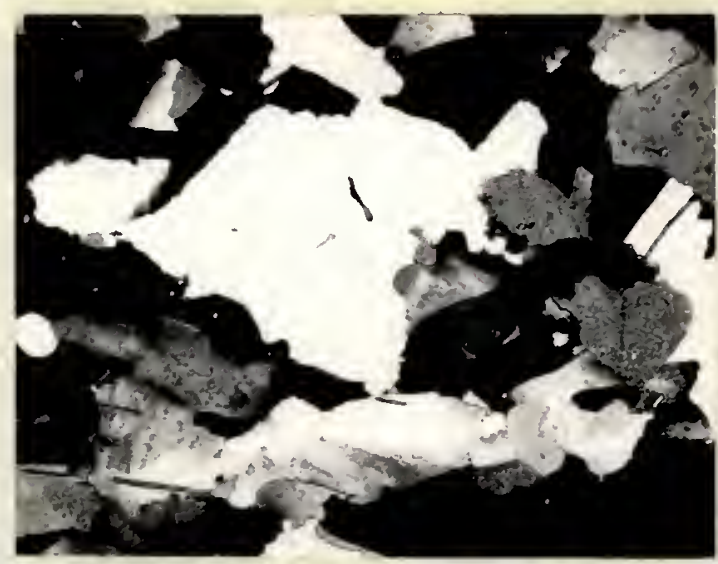

(d) Specimen number 10-2

1440 seconds

Fig. 50.--Continued 


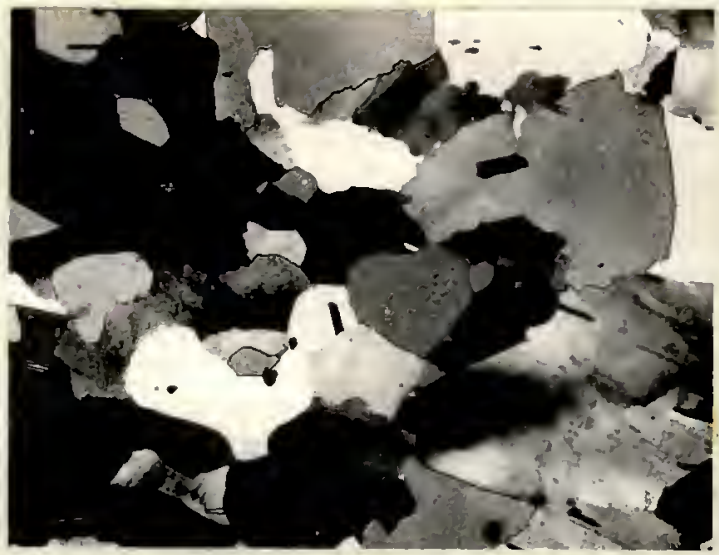

(e) Specimen number 9-4

1920 seconds

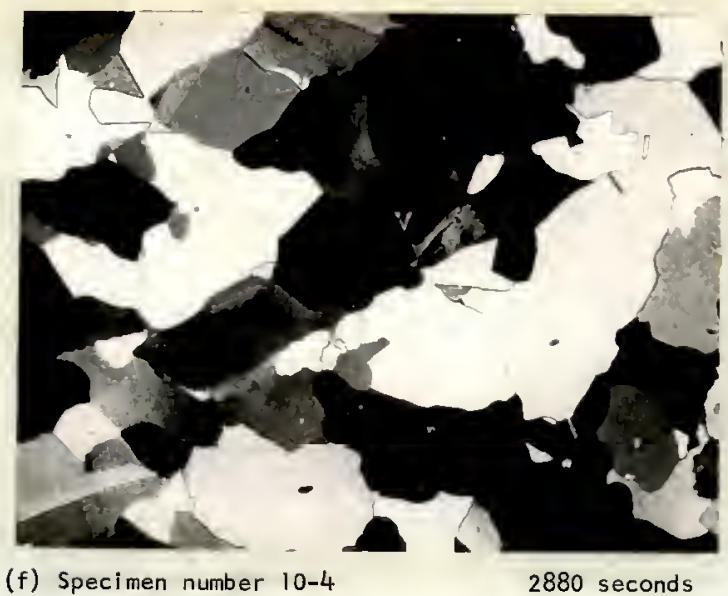

Fig. 50.--Continued 


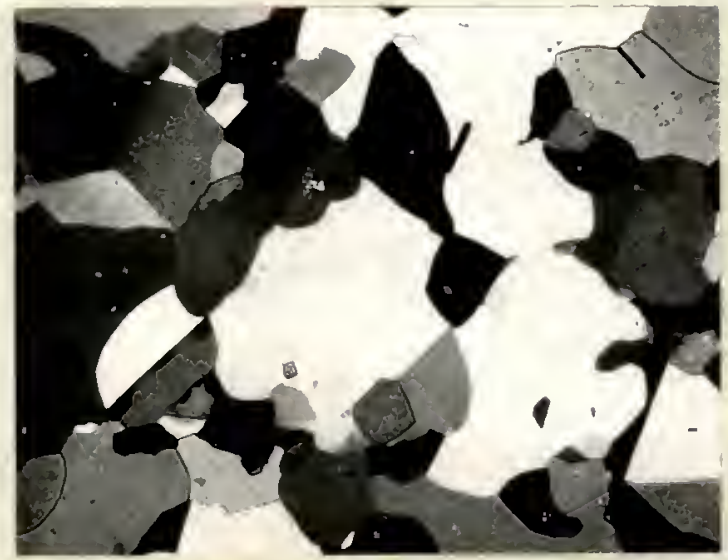

(g) Specimen number 10-3

3840 seconds

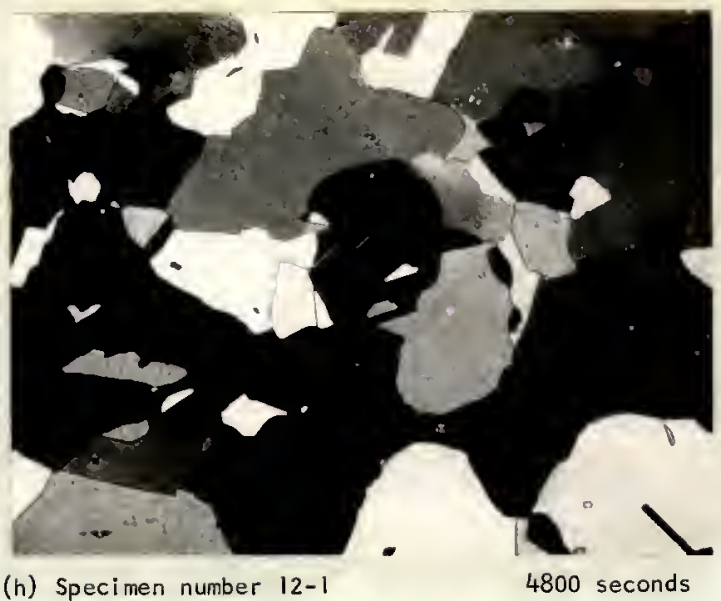

Fig. 50.--Continued 


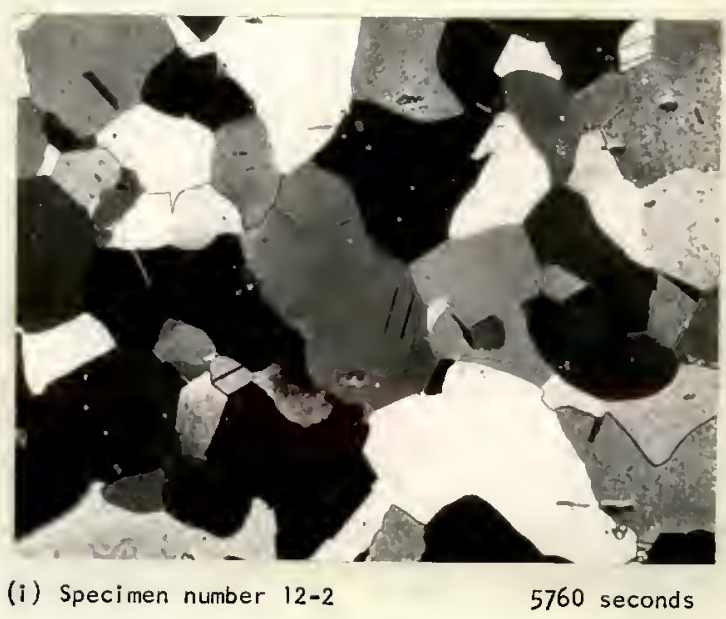

Fig. 50.-- - Continued 
APPENDIX C

CALCULATION OF GRAIN SIZE DISTRIBUTION BY THE METHOD OF SPEKTOR AS OESCRIBED BY UNDERWOOD (38) 
A total of 428 chord lengths were measured for specimen 11-1. Measurements were performed with a fillar eyepiece on a Bausch and Lomb Research Model Metal lograph. Total traverse length was $62 \mathrm{~mm}$. The data obtained and the calculated number of grains appear in Table 21.

TABLE 21.--Measured chord lengths and calculated values for the number of grains per $\mathrm{mm}^{3}$ having a certain average diameter

\begin{tabular}{|c|c|c|c|c|c|c|}
\hline$k$ & $\frac{\text { Interval }}{\text { Upper }}$ & $\begin{array}{r}\text { Limits }(y) \\
\text { Lower }\end{array}$ & $\begin{array}{c}\text { Interval } \\
\text { Mean } \\
(\gamma)\end{array}$ & $\begin{array}{c}\text { Number of } \\
\text { Chords }\end{array}$ & $\begin{array}{c}\text { Chords } \\
/ \mathrm{mm}\end{array}$ & $\underset{1 / \mathrm{mm}^{3}}{\operatorname{Grains}}$ \\
\hline 1 & 0 & 8.74 & 4.37 & 160 & 2.58 & 133,000 \\
\hline 2 & 8.74 & 17.48 & 13.11 & 107 & 1.73 & 22,600 \\
\hline 3 & 17.48 & 26.22 & 21.85 & 74 & 1.19 & 9,300 \\
\hline 4 & 26.22 & 34.96 & 30.59 & 42 & 0.678 & 3,800 \\
\hline 5 & 34.96 & 43.70 & 39.33 & 24 & 0.387 & 1,800 \\
\hline 6 & 43.70 & 52.44 & 48.07 & 11 & 0.178 & 400 \\
\hline 7 & 52.44 & 61.18 & 56.81 & 8 & 0.129 & 530 \\
\hline 8 & 61.18 & 69.92 & 65.55 & 2 & 0.032 & 130 \\
\hline
\end{tabular}

The number of grains per $\mathrm{mm}^{3}$ in a certain size range can be calculated from the equation (26):

$$
\left(N_{V}\right)_{k \Delta}=\frac{4}{\pi \Delta^{2}} \quad \frac{n_{k-1}^{k}}{2 k-1}-\frac{n_{k}^{k+1}}{2 k+1}
$$

where $\left(N_{V}\right)_{k \Delta}$ is the number of grains with mean diameter $k \Delta, k$ is the interval number, $\Delta$ is the interval length, $n_{k-1}^{k}$ is the number of chords per unit length in the kth size class and $n_{k}^{k+l}$ is the number of chords per unit length in size class $k+l$. 
In order to determine if the size distribution was log normal, the cumulative per cent of the total number of grains with a certain mean diameter was plotted on a probability scale with the logarithm of the mean grain diameter as the other coordinate. This plot is included as Figure 51. The fact that all points, except one, fall reasonably close to the straight line indicates that the distribution is close to log normal. The deviation of the point for the smallest grain size is due to a lack of resolution which transforms the experimental data from a singlehumped skewed distribution into an essentially parabolic distribution. 


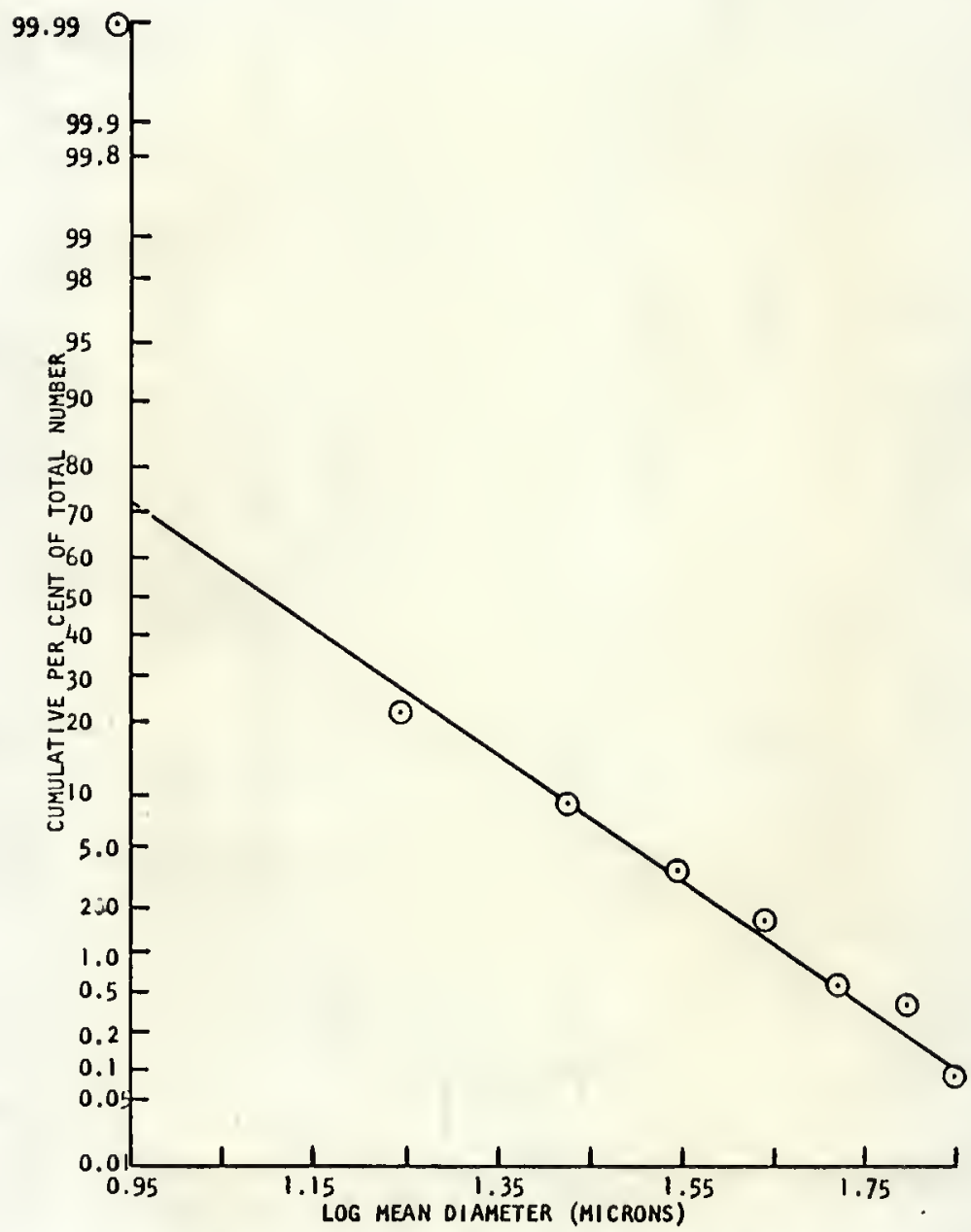

FIg. SI.--A plot of cumulative per cent of total numbar of gralns with. certain mean dlaneter versus $\log$ or the mean di ameter. 
APPENDIX D

A OERIVATION OF THE EXPRESSION $e_{g}=\left[\left(N_{L}\right)_{T} /\left(N_{L}\right)_{L}\right]^{2 / 3}-1$ FOLLOWING THAT ORIGINALLY GIVEN BY RACHINGER (43) 
The desired result is an equation relating $e_{g}$, the average longitudinal tensile strain in the grains, to the easily measurable quantities $\left(\mathrm{N}_{\mathrm{L}}\right)_{T}$ and $\left(\mathrm{N}_{\mathrm{L}}\right)_{\mathrm{L}}$. The derivation is restricted to deformation in tension, by drawing or by swaging in which it can be assumed that the change in shape experienced by the "average" grain can be described by only two parameters. In other words, the change in shape measured in any direction on a plane perpendicular to the extension axis is the same. In the present case, the complications which would be introduced by di rectional grain growth, recrystallization, etc., are neglected.

Consider an equiaxed structure wi th a grain size described by specifying that a unit length of random line will intersect $n$ grain boundaries per unit length. If each grain now experiences a tensile strain of amount $\mathrm{e}_{\mathrm{g}}$, then the number of grain boundary intercepts per unit length of line parallel to the tensile axis is decreased by a corresponding amount, or $\left(N_{L}\right)_{L}=n / l+e_{g}$. Considering any element of volume originally a unit cube, one easily calculates that the number of intercepts perpendicular to the tensile axis is increased by an amount $\left(1+e_{9}\right)^{1 / 2}$ and therefore $\left(N_{L}\right)_{T}=n\left(1+e_{g}\right)^{1 / 2}$. The above statement becomes obvious from a study of the diagrams given below. 


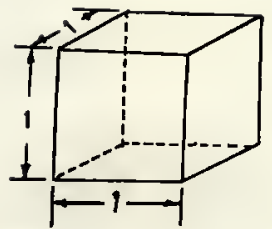

Original

$$
v_{0}=i^{3}
$$

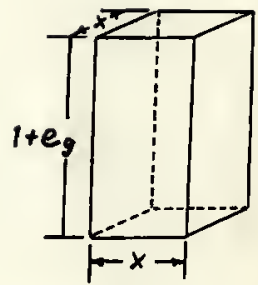

Final

$$
\begin{aligned}
& v_{f}=x^{2}\left(1+e_{g}\right)=v_{o}=1 \\
& x=1 /\left(1+e_{g}\right)^{1 / 2}
\end{aligned}
$$

Solution of the above expressions involving $N_{L}, N_{T}$ and $e_{g}$ for $e_{g}$ yields $e_{g}=\left[\left(N_{L}\right)_{T} /\left(N_{L}\right)_{L}\right]^{2 / 3}-1$.

This equation permits a calculation of the average strain experienced by the grains from measured values of $\left(N_{L}\right)_{L}$ and $\left(N_{L}\right)_{T}$. 
APPENDIX E

MODIFICATION OF CAHN'S EQUATION (53) FOR THE VOLUME FRACTION STRAIN-FREE GRAINS VERSUS

ANNEALING TIMES 
The original equation was derived on the following bases:

I. A constant linear growth rate.

2. All strain-free grains are initiated at essentially zero annealing time.

3. Strain-free grains are initiated and grow at old grain edges.

4. The growth of strain-free grains occurs equally in all directions from the edge at which it originated.

5. Impingement of strain-free grains occurs first among grains originating at the same edge and then with grains originating at different edges.

These bases are retained in the modification with the exception of number four which is changed to read: growth of strain-free grains occurs into the one grain sharing the edge which possesses the greatest density of quadruple points. The derivation then proceeds as follows:

1. Consider a straight length of edge $E$ of infinite extent having a specific nucleation rate $I_{e}$. The arbitrary line $F$ is parallel to $E$ at a distance $r$.

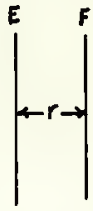

A new grain which begins to grow at time $\boldsymbol{T}$ from $E$ will intercept on $F$ a length $W=2\left[G^{2}(t-r)^{2}-r^{2}\right] 1 / 2$ at time $t$.

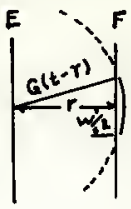


2. The extended length fraction (calculated wi thout regard for impingement) at time $t$ due to strain-free grains starting to grow in the time between $\mathcal{F}$ and $\tau+d \tau$ is

$$
d z_{e}=21 e^{d \tau\left[G^{2}(t-\tau)^{2}-r^{2}\right]^{1 / 2}} \text {. }
$$

3. Let $x=r / G t$ and note that $t-r / G$ is the time elapsed after the growing grain impinges on line $F$, then

$$
z_{e}=\int_{0}^{t} d z_{e}=21 \text { e } \int_{0}^{t}\left[G^{2}(t-r)^{2}-r^{2}\right]^{1 / 2} d \gamma
$$

and on performing the substitution and the integration, one finds that

$$
z_{e}=1 e^{G t^{2}\left[\sqrt{1-x^{2}}-x^{2} \log \frac{1+\sqrt{1-x^{2}}}{x}\right]}
$$

4. The volume occupied by new grains originating from unit length of $E$ is

$$
v_{0}=\int_{0}^{\infty} 2 \pi r z d r=2 \pi G^{2} t^{2} \int_{0}^{1} x\left(1-e^{-z} e\right) d x
$$

letting $r=G t x$. The assumption that the strain-free grains grow equally in all directions from the edge at which they originate is introduced in the above expression. However, if this assumption is replaced by the one that growth is preferentially into one of the grains which share the edge, then instead of

$v_{0}=\int_{0}^{\infty} 2 \pi r z d r$, one finds that $v_{0}=\int_{0}^{\infty}(2 \pi / 3) r z d r$

since the grain boundaries which share an edge are considered to subtend an angle of $120^{\circ}=2 \pi / 3$. The relation between the extended line fraction and the actual line fraction, $z=1-e^{-Z_{e}}$ is also introduced at this point.

5. With the above change, one finds that

$$
v_{0}=(2 \pi / 3) G^{2} t^{2} \int_{0}^{1} x\left(1-e^{-z_{e}}\right) d x
$$

6. If the structure contains a randomly distributed edge length $L_{V}$ per unit volume, then

$$
\left(V_{V}\right)_{e}=L_{V} V_{0}=(2 \pi / 3) L_{V} G^{2} t^{2} \int_{0}^{1} x\left(1-e^{-Z_{e}}\right) d x
$$


7. For large values of $I_{e}$ (all strain-free grains originate at essentially zero annealing time) the above expression reduces to

$$
\left(V_{V}\right)_{e}=(2 \pi / 3) L_{V} G^{2} t^{2} \int_{0}^{l} x d x=\frac{\pi}{3} L_{V} G^{2} t^{2}
$$

since $e^{-Z_{e}} \rightarrow 0$ as $1_{e} \rightarrow \infty$.

8. Making use of the expression between the extended volume fraction and the actual volume fraction, $V_{V}=1-e^{-\left(V_{V}\right)_{e}}$ one arrives at the expression $V_{V}=1-\exp -(\pi / 3) L_{V} G^{2} t^{2}$. 


\section{LIST DF REFERENCES}

1. S. Petrova, M. Gaidakov and L. Smi rnov, "Effect of Thermo-Mechanical Treatment on the Long-Time Strength of Nickel," Phys. Of Metals and Metallog. (1962) 13 [3] 59-64.

2. D. Whitwham and J. Herenguel, "Recuit Partial après Ecrouissage Restauration et/ou Recristallisations Successives," Rev. Met. Tech. Art. (1962) 59 155-165.

3. R. Leguet, D. Whi twham and J. Herenguel, "Sur la Rétention de 1 'Écroui ssage Après Deformation à Chaud," Rev. Met. Mem. Sci . (1962) 59 649-655.

4. I. Dillamore and W. Roberts, "Research on Hot Working of Metals with Particular Reference to Microstructure, Mechanical Properties and Texture," Dept. Ind. Met., Univ. of Birmingham, Tech. Rep., Apri 1, 1964.

5. V. Rosenberg and L. Gradova, "Modifications in the Structure of Nickel and of the Titanium Solid Solutions in Nickel during a High Temperature Deformation," Phys. Metals and Metallog. (1959) Z [5] 78-86.

6. B. Siutkina and E. Yakoleva, Mechanism of High Temperature Deforma$\mathrm{tion}$ of $\mathrm{Ni}-\mathrm{Al}$ and $\mathrm{Ni}-\mathrm{Cu}$ in Solid Solution," Phys. of Metals and Metallog. (1959) Z [6] 123-129.

7. K. Malyshev, G. Bogacheva and V. Sadovski i, "The Effect of Plastic Deformation Temperature on the Structure and Resilience of Austenitic Steel," Phys. Metals and Metallog. (1959) Z [1] 95-102.

8. H. Conrad, "Experimental Evaluation of Creep and Stress Rupture," in Mechanical Behavior of Materials at Elevated Temperatures, ed. J. Dorn, McGraw-Hi 11 Book Co., Inc., New York, N. Y. (1961) 149-217.

9. F. Rhines, R. Reed-Hill, C. Smeal, L. Lee and W. Converse, "Evolution and Control of the Grain Structure in Nickel Alloys during Hot Plastic Deformation," Met. Res. Lab. Univ. of Florida, January, 1962.

10. C. Smeal, unpublished observation. 
11. A. Presland and R. Hutchinson, "The Effect of Substructure in the Nucleation of Grain Boundary Cavities in Magnesium, " J. Inst. Metals (1963-64) 22 264-269.

12. J. Suiter and W. Wood, "Deformation of Magnesium at Various Rates and Temperatures," J. Inst. Metals (1952-53) 81 181-184.

13. R. E. Reed-Hill, unpublished observation.

14. D. Hardwick and W. Tegart, 'IStructural Changes during the Deformation of Copper, Aluminum and Nickel at High Temperatures and High Strain Rates," J. Inst. Metals (1961-62) 90 17-20.

15. D. Hardwick and W. Tegart, "Le Déformation des Métaux et Alliages par Torsion à Haute Température," Rev. Met. Mem. Sci. (1961) 58 $869-880$.

16. H. Ormerod and W. Tegart, "Substructure Formation in Alumi num, Copper and $\mathrm{Nickel}$ during Deformation at High Temperatures and High Strain Rates," J. Inst. Metals (1963-64) 92 297-299.

17. P. B lain and C. Rossard, 'Mechani sche Warmformänderungsfestigkeit von Stählen und der Verlauf der Gefügeentwicklung unten Einfluss der Warmverformung," Freiberger Forschungshefte (1962) 69 5-17.

18. C. Rossard and P. Blain, "Evolution de la Structure de l'Acier sous l'Effet de la Déformation Plastique à Chaud," Rev. Met. Mem. Sci. (1959) 56 285-300.

19. D. Hardwick, W. Tegart, C. Rossard and P. Blain, "Observations sur la Déformation de l'Aluminum et du Cuivre par Torsion aux Températures Élevées," Comptes Rendus (1961) 252 2881-2883.

20. P. Swann and J. Nutting, "The Influence of Stacking-Fault Energy on the Modes of Deformation of Polycrystalline Copper Alloys," $\mathrm{J}$. Inst. Metals (1961-62) 20 133-138.

21. H. Hanemann and $F$. Lücke, "Rekristallisation nach Warmverformung," Stahl und Eisen (1925) 45 1117-1122.

22. H. Hanemann, "Darstellung der Rekristallisationserscheinungen auf Grund der Korngrössenanderung bei Warmverformung," Z. für Metallkunde (1925) 17 316-319.

23. W. Tafel, H. Hanemann and A. Schneider, "Die Rekristallisation beim Warmwalzen," Stahl und Eisen (1929) 49 7-12.

24. H. Kornfeld, "Rekristallisation bei Warmverformung," Archiv für das Eisenhuttenwesen (1936) 10 161-163. 
25. H. Kornfeld and G. Hartleif, "Rekristallisation nach Warmverformung bei besonderer Berücksichtigung von Verformungen im Gebeit des $\alpha$-Eisen," Archiv für das Eisenhuttenwesen (1944) 17 221-226.

26. A. English and W. Backofen, "Recrystallization in Hot-Worked Silicon-I ron," Trans. AIME (1964) 230 396-407.

27. C. Rossard and P. Blain, "Influence de la Déformation et de la Vitesse de Oéformation sur la Recrystallisation de l'Acier Ferritique à $25 \% \mathrm{Cr}$ après Oéformation Plastique à Chaud," Rev. Met. Mem. Sci. (1960) 57 173-178.

28. R. Reed-Hill, C. Smeal and L. Lee, "The Examination of Fcc Metals with Polarized Light," Trans. AlME (1964) 230 1019-1024.

29. J. Hilliard and J. Cahn, "An Evaluation of Procedures in Quantitative Metallography for Volume-Fraction Analysis," Trans. AlME (1961) 221 244-252.

30. C. Smith and L. Guttman, "Measurement of Internal Boundaries in Three-0imensional Structures by Random Sectioning," Trans. AlME (1953) $19781-87$.

31. R. Vandermeer and P. Gordon, "Edge-Nucleated, Growth Controlled Recrystallization in Alumi num," Trans AIME (1959) 215 577-589.

32. M. Cook and T. Richards, "Observations on the Rate and Mechanism of Recrystallization in Copper," J. Inst. Metals (1946-47) 73 $1-31$.

33. A. Howie and P. Swann, "Oirect Measurements of Stacking-Fault Energies from Observations of Dislocation Nodes," Phil. Mag. (1961) 6. $1215-1226$.

34. P. Thornton and P. Hirsch, "The Effect of Stacking-Fault Energy on Low Temperature Creep in Pure Metals," Phil. Mag. (1958) 3 $738-761$.

35. A. Rosen, M. Burton and G. Smith, "Recrystallization of High-Purity I ron," Trans. AIME (1964) 230 205-215.

36. T. Tiedema, W. May and W. Burgers, "Inclusions in Alumi num Crystals," Acta Cryst. (1949) 2 151-154.

37. R. DeHoff, "The Estimation of Particle Size Oistributions from Simple Counting Measurements Made on Random Plane Sections," Trans. AIME (1965) 233 25-29.

38. E. Underwood, to be published. 
39. R. Karnop and G. Sachs, "Zur Kinetik der Rekristallisation," Z. für Physik (1930) 60 464-480.

40. C. Smith, "Grain Shapes and Other Metallurgical Applications of Topology," in Metal Interfaces, ASM, Cleveland, Ohio (1952) $65-113$.

41. J. Bailey, "Electron Microscope Observations on Recovery and Recrystallization Processes in Cold-Worked Metals," in Electron Microscopy and Strength of Crystals, ed. G. Thomas and J. Washburn, Interscience Publishers, New York, N. Y. (1963) 535-574.

42. W. Bollmann, "Electron-Microscope Observations on the Recrystallization of Nickel," J. Inst. Metals (1958-59) 87 439-443.

43. W. Rachinger, "Relative Grain Translations in the Plastic Flow of Alumi num," J. Inst. Metals (1952-53) 81 33-41.

44. H. Busboom, J. Lytton and 0. Sherby, "Influence of Grain Boundaries on High Temperature Strength of Polycrystalline Solids," DMS Report 63-7, Stanford Univ., May 15, 1963.

45. W. Yim and N. Grant, "The Effect of Prior Strain and Polygonization on the Creep-Rupture Properties of Nickel," Trans. AIME (1963) 227 868-876.

46. D. Warrington, "Dis location Substructure in Polycrystalline Copper," Proc. Europ. Regional Conf. On Electron Microscopy 1960, De Nederlandse Vereniging Voor Electronenmicroscopic, Delft (1961) 354-357.

47. W. Rachinger, 'The Effect of Grain-Size on the Structural Changes Produced in Alumi num by Slow Deformation," J. Inst. Metals $(1951-52) 80$ 415-418.

48. H. Change and N. Grant, 'Observations of Creep of the Grain Boundary in High Purity Aluminum," J. Metals (1952) 4 619-625.

49. R. Namdar, "Observation du Movement des Dislocations au Cours du Fluage," Rev. Met. Mem. Sci. (1963) 60 859-878.

50. C. Wyon and C. Crussard, "Modifications de Structure de I'Alumi num du Cours du Fluage," Rev. Met. Mem, Sci. (1951) 48 121-130.

51. P. Forsyth, "Some Metallographic Observations on the Fatigure of Metals," J. Inst. Metals (1951-52) 80 181-186.

52. P. Forsyth, "Some Further Observations on the Fatigure Process in Pure Alumi num," J. Inst. Metals (1953-54) 82 449-455. 
53. J. Cahn, "The Kinetics of Grain Boundary Nucleated Reactions," Acta Met. (1956) 4 449-459.

54. W. Anderson and R. Mehl, "Recrystallization of Aluminum in Terms of the Rate of Nucleation and the Rate of Growth," Trans. AlME (1945) 161 140-172.

55. W. Upthegrove and M. Sinnott, "Grain Boundary Self-Diffusion in Nickel," Trans. ASM (1958) 50 1031-1046.

56. A. Shinyayev, "Nickel Self-Diffusion," Phys. of Metals and Metallog. (1963) 15 [1] 93-97.

57. K. Detert and G. Dressler, "Recrystallization in High-Purity Nickel," J. Metals (1965) 17102.

58. 0. Dimitrov, "Evolution Structurale, au Cours de Traitements Thermiques après Écrouissage de l'Aluminum a Haut Titre et de Zone Fondue," Rev. Met. Mem. Sci. (1960) 57 787-808. 


\section{BIOGRAPHICAL SKETCH}

Charles Robert Smeal was born September 27, 1932 in Altoona, Pennsylvania. He received his primary schooling in the Altoona Public Schools and graduated from the Altoona Senior High School in June, 1950. He attended The Pennsylvania State University and graduated in June, 1954 with the degree Bachelor of Science in Metallurgy. For the remainder of 1954 he was a Metallurgist for the Stackpole Carbon Company. In January, 1955 he entered the United States Army. After separation from the army in October, 1956 he began graduate work at The Pennsylvania State University and received the degree of Master of Science in Metallurgy in August of 1958. For the next twelve months he was a Research Engineer for the National Aeronautics and Space Administration at the Lewis Laboratory in Cleveland, Ohio. In September, 1959 he began studies for the doctorate at The Pennsylvania State University and in 0ctober, 1960 transferred to The University of Florida.

Charles Robert Smeal is married to the former Eleanor Marie Cutri, a graduate of Duke University and of The University of Florida. He is the father of one child. He is a member of the American Society for Metals and the American Institute of Mining and Metallurgical Engineers. 
This dissertation was prepared under the direction of the chairman of the candidate's supervisory committee and has been approved by all members of that committee. It was submitted to the Dean of the College of Engineering and to the Graduate Council, and was approved as partial fulfillment of the requirements for the degree of Doctor of Phi losophy.

April 24, 1965

$\frac{\text { homes oleate }}{\text { Dean, college of Engineering }}$

Supervisory Committee:

D. N. Chi

Chair ran
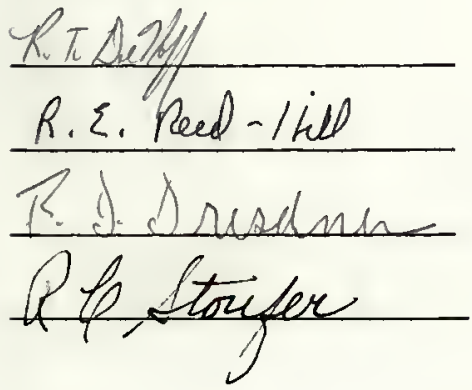


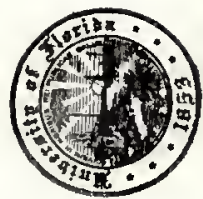

UNIVERSITY OF FLORIOA

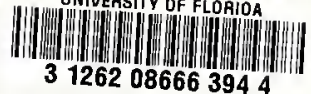

